Portland State University

PDXScholar

Summer 5-29-2013

\title{
Climate Change Impacts on Precipitation Extremes over the Columbia River Basin Based on Downscaled CMIP5 Climate Scenarios
}

Ghulam Hussain Dars

Portland State University

Follow this and additional works at: https://pdxscholar.library.pdx.edu/open_access_etds

Part of the Environmental Sciences Commons, and the Fresh Water Studies Commons Let us know how access to this document benefits you.

Recommended Citation

Dars, Ghulam Hussain, "Climate Change Impacts on Precipitation Extremes over the Columbia River Basin Based on Downscaled CMIP5 Climate Scenarios" (2013). Dissertations and Theses. Paper 979.

https://doi.org/10.15760/etd.979

This Thesis is brought to you for free and open access. It has been accepted for inclusion in Dissertations and Theses by an authorized administrator of PDXScholar. Please contact us if we can make this document more accessible: pdxscholar@pdx.edu. 
Climate Change Impacts on Precipitation Extremes over the Columbia River Basin Based on Downscaled CMIP5 Climate Scenarios

by

Ghulam Hussain Dars

A thesis submitted in partial fulfillment of the requirements for the degree of

Master of Science

in

Civil and Environmental Engineering

Thesis Committee:

Hamid Moradkhani, Chair

Scott Wells

Chris Berger

Portland State University

2013 


\begin{abstract}
Hydro-climate extreme analysis helps understanding the process of spatio-
\end{abstract} temporal variation of extreme events due to climate change, and it is an important aspect in designing hydrological structures, forecasting floods and an effective decision making in the field of water resources design and management. The study evaluates extreme precipitation events over the Columbia River Basin (CRB), the fourth largest basin in the U.S., by simulating four CMIP5 global climate models (GCMs) for the historical period (1970-1999) and future period (2041-2070) under RCP85 GHG scenario.

We estimated the intensity of extreme and average precipitation for both winter (DJF) and summer (JJA) seasons by using the GEV distribution and multi-model ensemble average over the domain of the Columbia River Basin. The four CMIP5 models performed very well at simulating precipitation extremes in the winter season. The CMIP5 climate models showed heterogeneous spatial pattern of summer extreme precipitation over the CRB for the future period. It was noticed that multi-model ensemble mean outperformed compared to the individual performance of climate models for both seasons.

We have found that the multi-model ensemble shows a consistent and significant increase in the extreme precipitation events in the west of the Cascades Range, Coastal Ranges of Oregon and Washington State, the Canadian portion of the basin and over the Rocky Mountains. However, the mean precipitation is projected to decrease in both winter and summer seasons in the future period. 
The Columbia River is dominated by the glacial snowmelt, so the increase in the intensity of extreme precipitation and decrease in mean precipitation in the future period, as simulated by four CMIP5 models, is expected to aggravate the earlier snowmelt and contribute to the flooding in the low lying areas especially in the west of the Cascades Range. In addition, the climate change shift could have serious implications on transboundary water issues in between the United States and Canada. Therefore, adaptation strategies should be devised to cope the possible adverse effects of the changing the future climate so that it could have minimal influence on hydrology, agriculture, aquatic species, hydro-power generation, human health and other water related infrastructure. 


\section{Acknowledgements}

I am very excited to express my deepest gratitude to all those who contributed in making this study possible, valuable and successful. First of all, I like to thank Almighty God for the wisdom, knowledge and perseverance he has been bestowed upon me during whole of my life.

Then, I would like to extend my appreciation for my Advisor Dr. Hamid Moradkhani for spending his enormous valuable time teaching, guiding, being patient and providing moral and technical support to perform this research. I like to thank the rest of my thesis committee members Dr. Scott Wells and Dr. Chris Berger, for their willingness to serve as members of the thesis committee on a very short notice. Their participation in editing and their valuable suggestions for improving my thesis was quite valuable.

Further, I take this opportunity to acknowledge the Institute of International Education (IIE) and United States Educational Foundation in Pakistan for offering me Fulbright Scholarship to study in the United States. My sincere thanks also go to all research group fellows especially M. Reza Najafi for his support especially in Matlab programming.

Last but not least, I like to thank my family especially my mother and wife for providing me their support, love and lot of prayers throughout my studies. I am very grateful to all of you for your contribution and support. 
Table of Contents

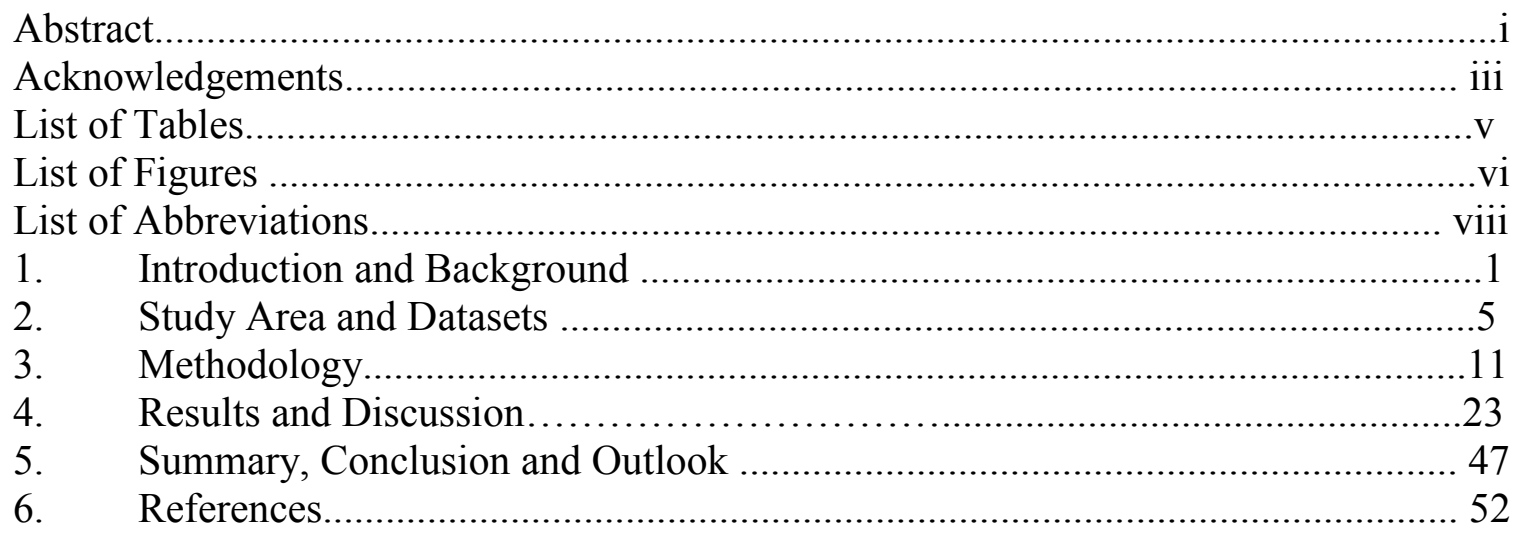


List of Tables

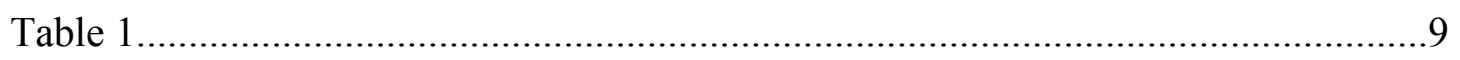

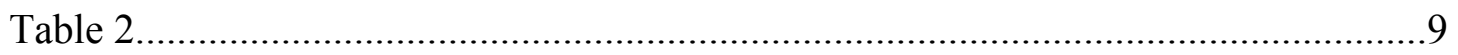

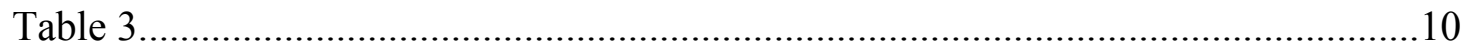




\section{List of Figures}

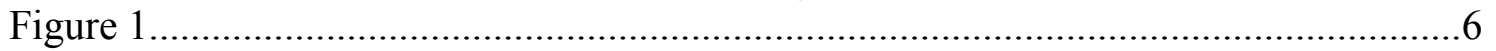

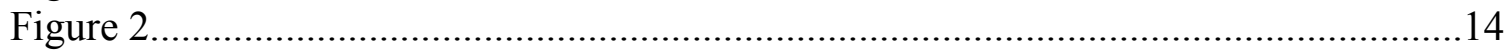

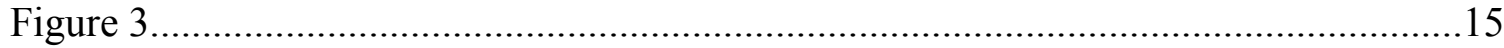

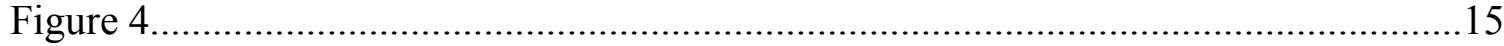

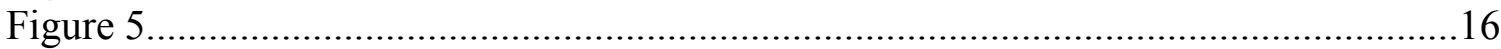

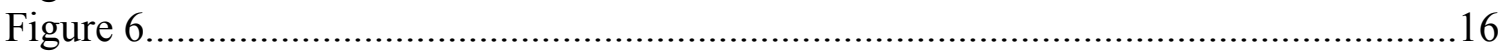

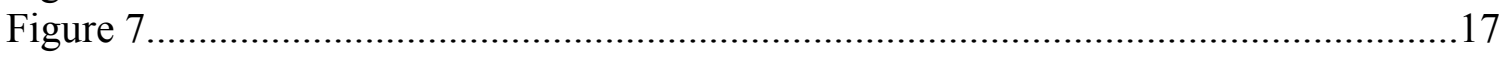

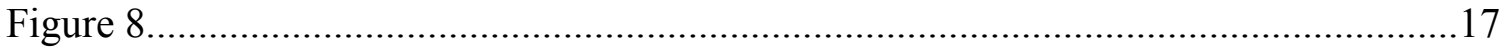

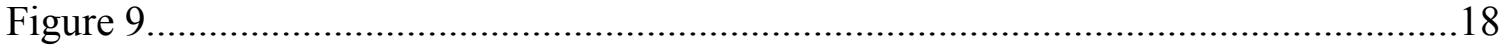

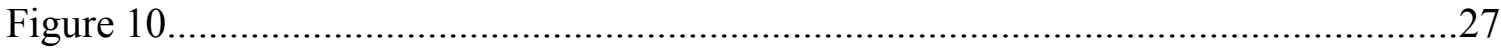

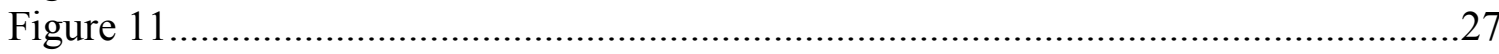

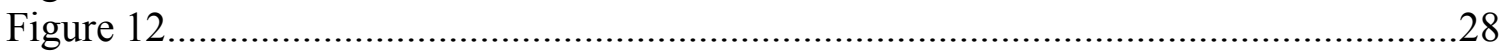

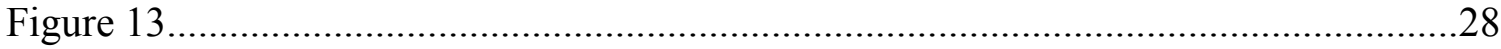

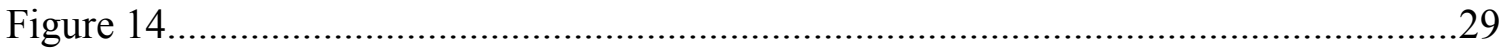

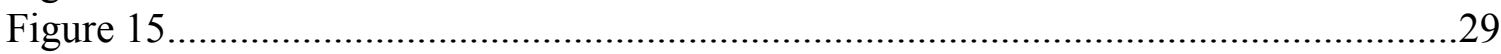

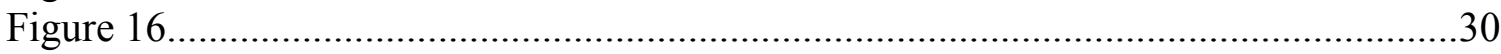

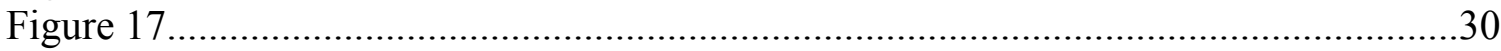

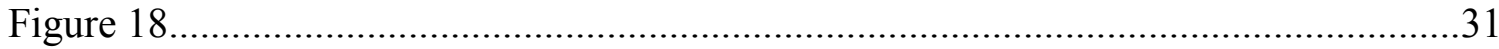

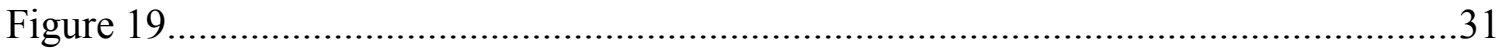

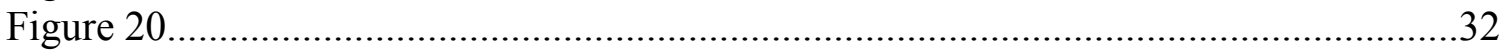

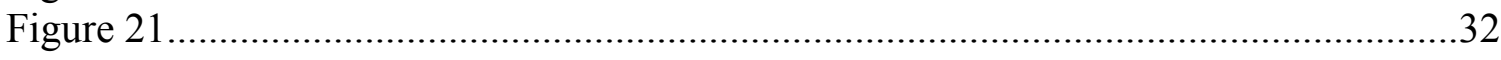

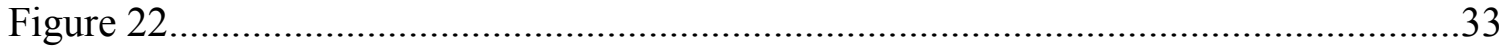

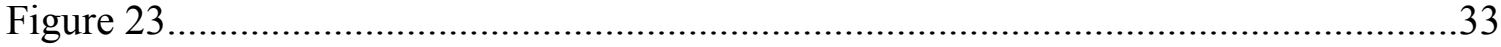

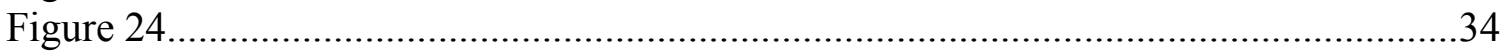

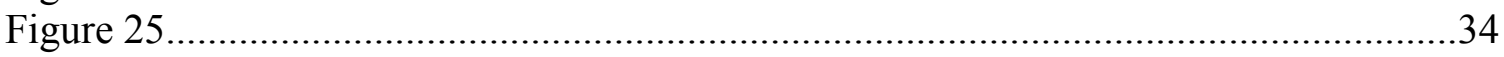

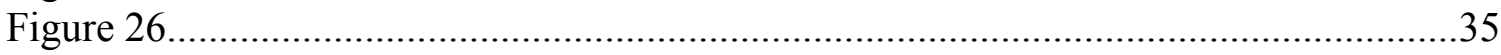

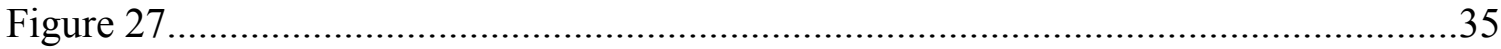

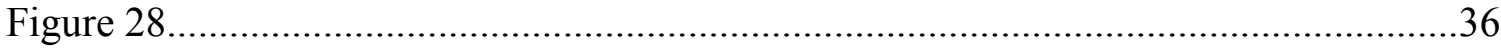

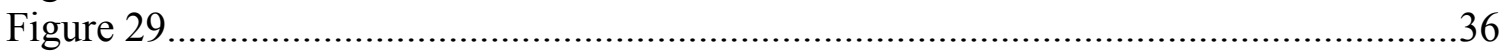

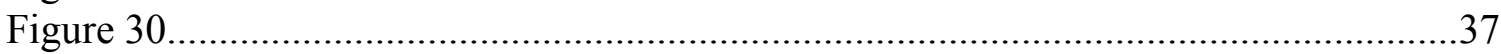

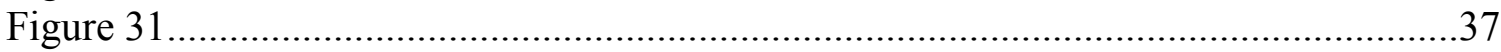

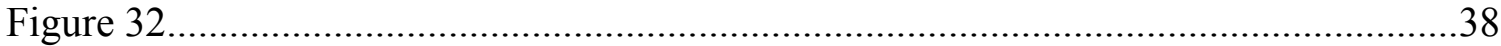

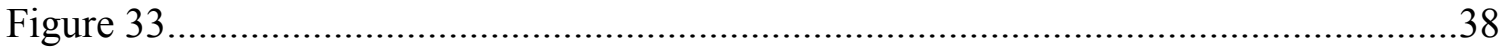

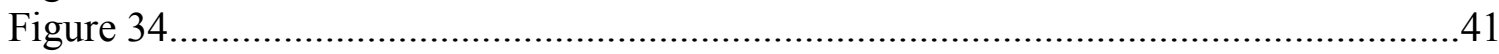

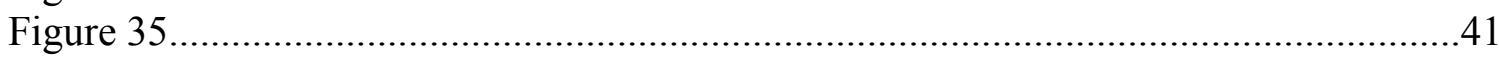

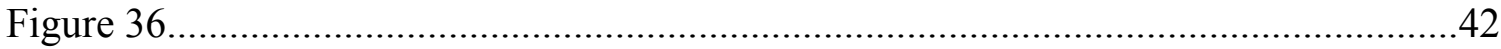

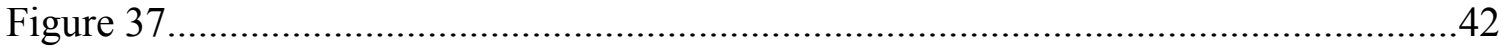

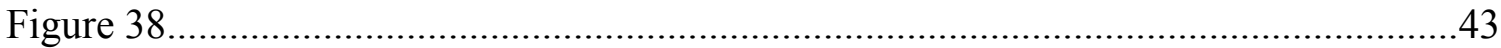

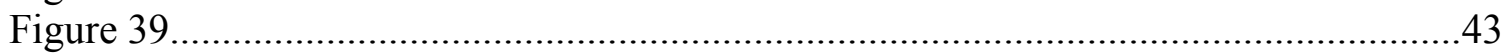

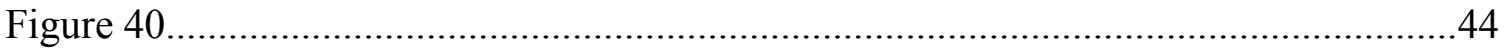

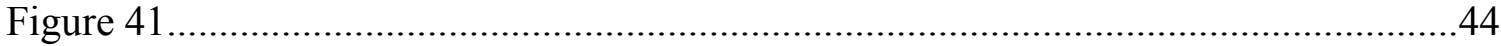

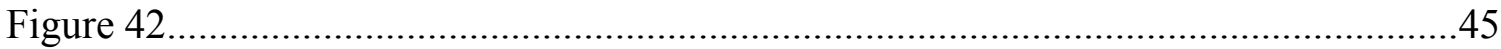

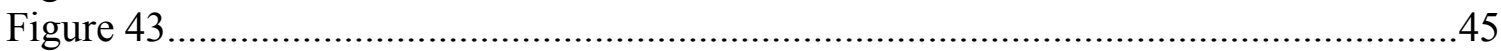




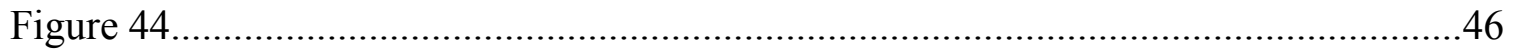

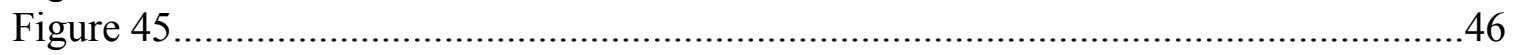


List of Abbreviations

Australian Community Climate and Earth-System Simulator version 1.0.... ACCESS 1.0 Bayesian Model Averaging BMA

Beijing Climate Center - Climate System Model, version 1.1.................... BCC-CSM 1.1

Canadian Center for Climate Modeling and Analysis CCCma

Canadian $2^{\text {nd }}$ generation Earth System Model. CanESM2

Carbon dioxide $\mathrm{CO}_{2}$

Climate Model Intercomparison Project Phase 5 CMIP5

Climate Model Intercomparison Project Phase 3 CMIP3

Columbia River Basin. $\mathrm{CRB}$

Commonwealth Scientific and Industrial Research Organization, Bureau of Meteorology CSIRO-BOM

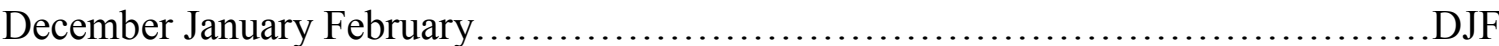

Multi-Model Ensemble MME

Community Climate System Model version 4.0. CCSM4

Cumulative Distribution Function CDF

Environmental Systems Research Institute ESRI

Generalized Extreme Value. GEV

Global Climate Model / Global Circulation Models GCM

Greenhouse Gas. GHG

Intergovernmental Panel on Climate Change Assessment Report. IPCC-AR

June July August ..JJA

Multi-Model Ensemble .MME

National Center for Atmospheric Research. NCAR

Probability Distribution Function. PDF

Program for Climate Model Diagnosis and Intercomparison. PCMDI

Quantile Mapping QM

Regional Circulation Models GCM

Representative Concentration Pathway. RCP

Special Report on Emissions Scenarios. SRES

United States. U.S.

Watts per square meter $\mathrm{W} / \mathrm{m}^{2}$ 


\section{Introduction and Background}

The climate change and variability could have serious impacts on water resources, ecological systems and human lives. The contribution of anthropogenic activities to the emission of greenhouse gases into the atmosphere is the main cause for the change of climate and extreme events. Solomon et al., (2007) concluded in the IPCC fourth assessment report that the global average surface temperature has increased significantly since 1950, and they pointed out that years 1998 and 2005 as the warmest years since 1850. It is further projected in the same report that the surface air temperature would rise from $2{ }^{\circ} \mathrm{C}$ to $3{ }^{\circ} \mathrm{C}$ in the U.S. by the end of $21^{\text {st }}$ century. This projection in the temperature is expected to intensify the hydrological cycles (Arnell, 1999; Del Genfo et al., 1991; Held and Soden, 2000; Huntington, 2006; Loaiciga et al., 1996). The intensification of water cycles is responsible for extreme events such as tropical storms, flash floods and droughts (Huntington, 2006). Extreme precipitation events are one of the major climate change concerns which can seriously influence the hydrology, agriculture, hydro-power generation and socio-economics.

It has been observed that numerous elements of the climate system are now changing including temperature, the frequency and distribution of precipitation, rise of sea levels, melting mountain glaciers, and these extreme events will become more frequent and intense in the future (Halmstad et al., 2012; Kharin and Zwiers, 2000; Kharin and Zwiers, 2005; Kharin et al., 2007; Solomon et al., 2007; Wilby and Wigley, 2002). In the case of the United States, the historical records demonstrate that the amount and frequency extreme precipitation events have been increased (Dominguez et al., 2012; 
Easterling et al., 2000; Groisman et al., 2001). For the future period, in the U.S., the mean precipitation is expected to decrease, whereas extreme precipitation is projected to increase (Dominguez et al., 2012; Emori and Brown, 2005).

Possible future changes in the climate change and extreme events can be predicted by global circulation models (GCMs). For this study, the GCM simulations daily data was collected from the Climate Model Intercomparison Project Phase 5 archive (CMIP5) (Taylor et al., 2012). The CMIP5 is newly developed data archive and contains a great number of model output to conduct the research and enhance the understanding of climate processes and their effects. These data will provide a basis of Intergovernmental Panel on Climate Change (IPCC) Fifth Assessment Report (AR5). A new type of greenhouse gas emission scenarios have been introduced in the CMIP5 ensemble data called representative concentration pathways, which are more comprehensive compared to Special Report on Emission Scenarios (SRES). In spite of various improvements in spatial resolution and other advances in climate models, considerable bias and uncertainties still exist in the climate models. These uncertainties may be available due model initialization, data observation errors, and/or inappropriate data assimilation procedures (Parrish et al., 2012). The GCMs have very coarse resolution and therefore, don't represent precipitation or any other variable at local or regional scales. Therefore, downscaling is conducted to remove bias and downscale the climate models to give reasonable estimates at local or regional scales (Fowler et al., 2007; Halmstad et al., 2012; Najafi et al., 2011b). 
This study evaluates extreme precipitation events over the Columbia River Basin (CRB), the fourth largest basin in the U.S., by multi-modeling ensemble of four GCMs for the historical period (1970-1999) and future period (2041-2070). Relying on one model can lead to several uncertainties because no model is believed to be superior to others. Therefore, multi-modeling ensemble averages can reduce the uncertainty to larger degree to produce more reliable hydrologic predictions. Multi-model ensemble methods have widely been used in the field of economics, meteorology and hydrology (Bates and Granger, 1969; Dickinson, 1973; Duan et al., 2007). The multi-model techniques usually involve obtaining weights based on the individual performance of the model. The earlier multi-model averaging methods such as equal weight, artificial neural network (ANN) technique by (Shamseldin et al., 1997) could not perform well because the weights obtained by these methods were not related to the performance of the model (Duan et al., 2007; Parrish et al., 2012). Then, Hoeting et al., (1999) developed an alternative approach called Bayesian Model Averaging (BMA) to overcome the issues faced by earlier methods of multi-model averaging. The BMA technique is an efficient method in determining within-model variance and the between-model variance, and the models showing their weights based on their performances. It has been successfully applied in various fields of statistics, groundwater modeling, hydrology, meteorology, medicine and management science (Duan et al., 2007; Fernandez et al., 2001; Hoeting et al., 1999; Najafi et al., 2011a; Viallefont et al., 2001; Wintle et al., 2003). This research would could help water related agencies in efficient design and operation of water related infrastructures in the Columbia River Basin for sustainable development. 
This thesis is organized as follow: introduction and background is described in chapter 1; study area and datasets are explained in chapter 2; methodology of downscaling, extreme value analysis by GEV distribution and multi-model extreme analysis is described in chapter 3; results of the extreme analysis and multi-model average is explained in chapter 4; and finally conclusion is provided in chapter 5 . 


\section{Study Area and Datasets}

\subsection{Study Area}

The Columbia River Basin (CRB) is one of the largest transboundary river basins in the world. The Columbia River originates from the Columbia Lake in the Canada and is the largest river in the Pacific Northwest and the fourth largest river in the US (map is displayed in figure 1). The CRB spreads into one Canadian province of British Columbia and seven western states of Washington, Oregon, Idaho, Montana, Wyoming, Nevada and Utah, and its length and drainage area are 1243 miles and 258,000 square miles respectively (Davidson and Paisley, 2009). The CRB receives a significant amount of precipitation because of its prime location and finally drains it into the Pacific Ocean. It irrigates about 1.4 million hectares (3.5 million acres) and generates about 16,500 MW of hydropower annually (Payne et al., 2004). Having construction of large dams in the CRB, it has now become highly developed river basin system. The construction of dams in the CRB helped reducing flood and increase hydropower generation (Cohen et al., 2000). In the Columbia River Basin, major part of the precipitation falls in the winter season, and that contributes to the peak runoff in the late spring and early summer (Wood et al., 2004).

Numerous studies have found an increase in the temperature and precipitation in the western United States in the historic period especially from 1950 to 2005, and both temperature and extreme precipitation are expected to increase in the future (Cayan et al., 2001; Dominguez et al., 2012; Easterling et al., 2000; Groisman et al., 2001; Halmstad et al., 2012; Najafi et al., 2011a; Solomon et al., 2007). The Canadian portion of the basin and west of the Cascade Mountains usually get sufficient amount precipitation and the 
precipitation from the Canadian portion contribute greatly to the hydropower generation (Cohen et al., 2000).

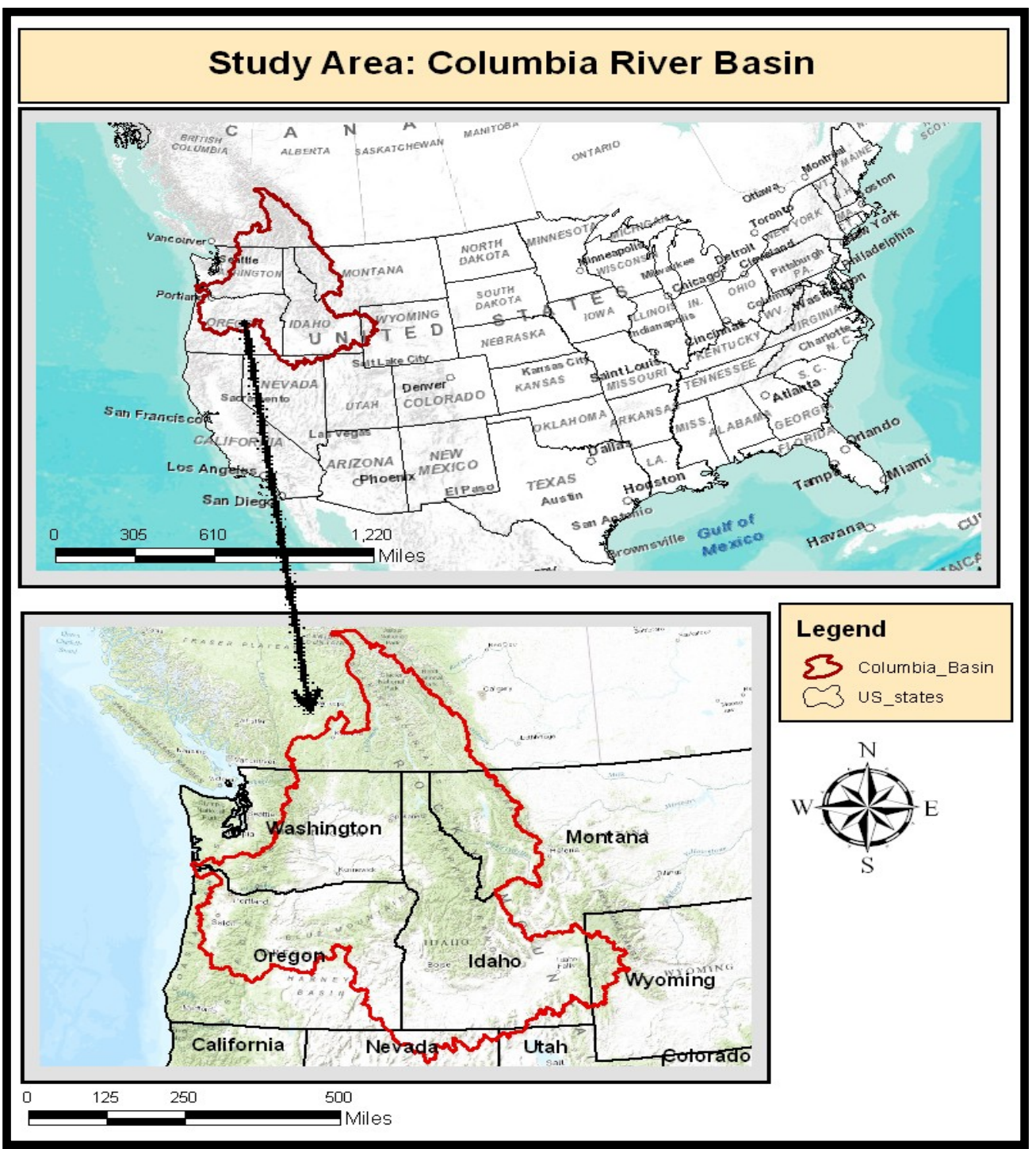

Figure 1: Study Area: Columbia River Basin. 


\subsection{Climate Models Data:}

This research collects four GCM simulations data (detail is given in table 1) from the Climate Model Intercomparison Project Phase 5 archive (CMIP5). The CMIP5 has provided a great number of model output to advance our understanding of climate processes and their effects (Taylor et al., 2012). These data will provide a basis of Intergovernmental Panel on Climate Change (IPCC) Fifth Assessment Report (AR5). According to (Taylor et al., 2012), CMIP5 simulations were carried out by more than 20 modeling groups, which combined have more than 50 models. CMIP5 simulations include two types of climate change modeling experiments known as decadal prediction experiments (10-30 years) and long-term integrations (century time scales) (Hibbard et al., 2007; Meehl et al., 2009; Meehl and Hibbard, 2007). The long-term experiments build on the design of CMIP3, whereas the near-term decadal prediction experiments are a new addition to the CMIP5. Taylor et al., (2012) describe that CMIP5 models run on higher spatial resolution and being comprehensive, they involve plenty of variables, which are given in parentheses: atmosphere (60), ocean (77), land surface and carbon cycle (58), ocean biogeochemistry (74), sea ice (38), land ice and snow (14), and clouds (100). All CMIP5 model output data have been provided on PCMDI (Program for Climate Model Diagnosis and Intercomparison) archive.

Several scenarios have been adopted in the past, including IS92 scenarios (Leggett et al., 1992) and Special Report on Emissions Scenarios (SRES) (Nakicenovic et al., 2000). The CMIP5 projections provide new types of scenarios called representative concentration pathways (RCPs) compared to the earlier CMIP3 having the SRES 
scenarios (difference between CMIP5 and CMIP3 is given in the table 3). A proper selection procedure was adopted behind the name of RCP (Moss et al., 2008; Van Vuuren et al., 2011), and the main purpose behind its selection was its use. RCPs refer to pathways as their main objective is to provide time-dependent projections of greenhouse gases (GHG) concentrations (Taylor et al., 2012).

Anthropogenic activities are major contributors for the climate change and are forced by many factors; and all of these contribute to radiative forcing of the climate system. The radiative forcing factors are very comprehensive and incorporate the collection of greenhouse gases (GHGs), aerosols, chemically active gases, and land use or land cover (Moss et al., 2008). The four RCPs are provided in the CMIP5 called RCP $8.5,6.0,4.5$ and $3.0 \mathrm{~W} / \mathrm{m}^{2}$, and these labels show a rough estimate of the radiative forcing at the end of the 21 st century. RCP8.5 scenario describes that the radiative forcing reaches at approximately $8.5 \mathrm{~W} / \mathrm{m}^{2}$ by the end of $21^{\text {st }}$ century and it continues to rise for some amount of time. RCP6.0 and RCP4.5 scenarios depict that the radiative forcing will stabilize at approximately $6 \mathrm{~W} / \mathrm{m}^{2}$ and $4.5 \mathrm{~W} / \mathrm{m}^{2}$ after $21^{\text {st }}$ century. RCP3 tells that the radiative forcing would rise to approximately $3 \mathrm{~W} / \mathrm{m}^{2}$ before the end of $21^{\text {st }}$ century and then declines. The details of the RCPs are given in the table 2 .

In the CMIP5, historical simulations data is available from 1850 through 2005, whereas the future simulations data is available from 2006 through 2300. In this study, four GCM simulations have been used to analyze precipitation extremes for the historical period (1970-1999) and future period (2041-2070). We evaluated the historical period of recent 30 years (1970-1999) depending upon the availability of data and the future period 
(2041-2070) because this time period is neither too far nor too close. For the future period, the RCP85 scenario has been used because it somehow relates to the A2 SRES scenario in terms of the Carbon dioxide equivalent.

Table 1: CMIP5 Models and their resolutions

\begin{tabular}{|c|c|c|c|c|}
\hline $\begin{array}{l}\text { S. } \\
\text { No. }\end{array}$ & Modeling Center & Model/GCM Name & $\begin{array}{l}\text { Resolution } \\
\text { (Lon X } \\
\text { Lat) }\end{array}$ & $\begin{array}{l}\text { Referen } \\
\text { ce }\end{array}$ \\
\hline 1 & $\begin{array}{l}\text { CSIRO-BOM } \\
\text { (Commonwealth } \\
\text { Scientific and } \\
\text { Industrial Research } \\
\text { Organization, } \\
\text { Australia), and Bureau } \\
\text { of Meteorology }\end{array}$ & $\begin{array}{l}\text { ACCESS } 1.0 \\
\text { (Australian Community } \\
\text { Climate and Earth-System } \\
\text { Simulator) }\end{array}$ & $\begin{array}{ll}1.875 & \mathrm{X} \\
1.25 & \end{array}$ & $\begin{array}{l}\mathrm{Bi}, \\
2012)\end{array}$ \\
\hline 2 & $\begin{array}{l}\text { BCC (Beijing Climate } \\
\text { Center) }\end{array}$ & $\begin{array}{l}\text { BCC-CSM } 1.1 \text { (Beijing } \\
\text { Climate Center - Climate } \\
\text { System Model) } \\
\end{array}$ & $2.8 \times 2.8$ & $\begin{array}{l}\text { (Xin X., } \\
\text { 2012) }\end{array}$ \\
\hline 3 & $\begin{array}{l}\text { NCAR } \\
\text { (National Center for } \\
\text { Atmospheric Research) }\end{array}$ & $\begin{array}{l}\text { CCSM4 } \\
\text { (Community } \\
\text { System Model) }\end{array}$ & $\begin{array}{ll}0.94 & \mathrm{X} \\
1.25 & \end{array}$ & $\begin{array}{l}\text { (Chylek, } \\
\text { 2011) }\end{array}$ \\
\hline 4 & $\begin{array}{l}\text { CCCma (Canadian } \\
\text { Center for Climate } \\
\text { Modeling \& Analysis) }\end{array}$ & $\begin{array}{l}\text { CanESM2 } \text { (Canadian } 2^{\text {nd }} \\
\text { generation Earth System } \\
\text { Model) }\end{array}$ & $2.8 \times 2.8$ & $\begin{array}{l}\text { (Gent, } \\
\text { 2011) }\end{array}$ \\
\hline
\end{tabular}

Table 2: Names of RCPs and their descriptions (Moss et al., 2008; Van Vuuren et al., 2011)

\begin{tabular}{|l|c|l|l|}
\hline S. No. & RCPs & \multicolumn{1}{|c|}{ Description } & Publication \\
\hline 1 & RCP 8.5 & $\begin{array}{l}>8.5 \mathrm{~W} / \mathrm{m}^{2} \text { in } 2100\left(>\sim 1370 \mathrm{ppm} \mathrm{CO}_{2}\right. \\
\text { eq) }\end{array}$ & (Riahi et al., 2007) \\
\hline 2 & RCP 6.0 & $\begin{array}{l}\text { Rise to } \sim 6 \mathrm{~W} / \mathrm{m}^{2}(\sim 850 \mathrm{ppm} \mathrm{CO} \text { eq) at } \\
\text { stabilization after } 2100\end{array}$ & (Fujino et al., 2006) \\
\hline 3 & RCP 4.5 & $\begin{array}{l}\text { Rise to } 4.5 \mathrm{~W} / \mathrm{m}^{2}(\sim 650 \mathrm{ppm} \mathrm{CO} \text { eq) at } \\
\text { stabilization after } 2100\end{array}$ & (Clarke et al., 2007) \\
\hline 4 & RCP 3 & $\begin{array}{l}\text { Peak at } \sim 3 \mathrm{~W} / \mathrm{m}^{2}\left(\sim 490 \mathrm{ppm} \mathrm{CO}_{2} \text { eq) }\right. \\
\text { before } 2100 \text { and then decline (the } \\
\text { selected pathway declines to } 2.6 \mathrm{~W} / \mathrm{m}^{2} \\
\text { by 2100). }\end{array}$ & $\begin{array}{l}\text { (van Vuuren et al., } \\
\text { 2007) }\end{array}$ \\
\hline
\end{tabular}


Table 3: Differences between the CMIP5and CMIP3 (Solomon et al., 2007; Taylor et al., 2012)

\begin{tabular}{|l|l|l|}
\hline Specification & CMIP5 & CMIP3 \\
\hline No. of models & More than 50 & 25 \\
\hline GHG emission Scenario & RCP (More comprehensive) & SRES \\
\hline Output parameters & 404 & 118 \\
\hline $\begin{array}{l}\text { Latitude resolution coarser } \\
\text { than } 1^{\circ}\end{array}$ & 2 models & About half of models \\
\hline $\begin{array}{l}\text { Latitude resolution finer } \\
\text { than } 1.3^{\circ}\end{array}$ & 5 models & 1 model \\
\hline Spatial Resolution & $\begin{array}{l}0.5^{\circ}-4.0^{\circ} \text { for atmospheric } \\
\text { components \& } \\
0.2^{\circ}-2.0^{\circ} \text { for ocean } \\
\text { components }\end{array}$ & $\begin{array}{l}1.1^{\circ}-5.0^{\circ} \text { for atmospheric } \\
\text { components \& } \\
0.2^{\circ}-5.0^{\circ} \\
\text { components for }\end{array}$ \\
\hline Time period & $\begin{array}{l}850-2300 \text { years } \\
850-2000 \text { years, } \\
2000-2100 \text { years, } \\
2100-2300 \text { years, }\end{array}$ \\
\hline $\begin{array}{l}\text { Output time steps } \\
\text { frequency }\end{array}$ & $\begin{array}{l}\text { 3hr, 6hr, daily, monthly, } \\
\text { annual mean data is } \\
\text { available }\end{array}$ & $\begin{array}{l}3 \mathrm{hr} \text { daily, monthly, } \\
\text { annual mean and extreme } \\
\text { data is available }\end{array}$ \\
\hline Notes & Basis for IPCC AR5 & \begin{tabular}{l} 
Basis for IPCC AR4 \\
\hline
\end{tabular} \\
\hline
\end{tabular}

\subsection{Observed Data sets:}

The observed daily meteorological gridded dataset for the Columbia River Basin, taken from University of Washington, (Maurer et al., 2002), has been used in this study. The dataset is gridded at $1 / 8$ th degree, and provides information about four climate variables namely precipitation, maximum and minimum temperature and wind speed for the period of 1949 through 2010. 


\section{Methodology}

Hydro-climate extremes are very critical in considering the possible adverse impacts of climate change and variability. It affects the total runoff volume, infrastructures, aquatic species, forests, hydropower generation, and more importantly human lives. Therefore, it is imperative for water resources engineers and planners to consider hydro-climate extreme analysis in long as wells as short term planning of water resources. The study analyzes multi-model precipitation extremes over the Columbia River Basin for the historical period (1970-1999) and future period (2041-2070) by using the CMIP5 simulations data. The simulations of daily data from four global climate model (GCM) have been used. The GCMs were then visualized in the ESRI ArcMap 10.1 to analyze the number of grids (see figure 2), and the ArcMap was used to analyze the downscaled GCM simulations data. The methodology includes selecting the GCMs, bias correction and downscaling to required degree depending upon the resolution of the observed data, and multi-model ensemble extreme analysis.

\subsection{Downscaling}

Global climate models (GCMs) are the primary tools of assessing the potential impacts of climate Change (Solomon et al., 2007). Using GCMs to predict or forecast the impact of climate change on precipitation extremes is quite a challenge because of the resolution of the GCMs. They have very coarse resolution $(125-300 \mathrm{~km})$ which makes them unable to predict the climate change and variability effects on regional or local 
scales accurately. Despite some improvements in spatial resolution and other advances in climate models, considerable bias still exists in most climate models. Therefore, downscaling is needed to relate the information between coarse and regional or local scales (Fowler et al., 2007). Downscaling is a term used to refer the process of relocating the coarse resolution climate model data to the fine spatial scale data to allow local analyses of climate effects. There are two fundamental approaches for downscaling climate models called dynamical and statistical downscaling. In dynamical downscaling, regional climate models (RCMs) are nested with GCMs to generate high resolution outputs. Statistical downscaling methods are based on some robust statistical relationships between the coarse-resolution climate model and fine-resolution local climate variables. Statistical downscaling methods have been widely adopted due to being comparatively cheap, computationally efficient and easily applicable across multiple GCMs (Fowler et al., 2007; Jung et al., 2011; Madadgar and Moradkhani, 2011; Moradkhani et al., 2010; Moradkhani and Meier, 2010; Moradkhani and Sorooshian, 2008; Najafi et al., 2011b; Samadi et al., 2013; Wilby and Wigley, 2002). Fowler et al., (2007) describes three types of the statistical downscaling called regression models, weather typing schemes and weather generators. In regression models, the transfer functions are developed to downscale the climate model data. We have implemented Quantile Mapping statistical downscaling method which is described below: 


\subsubsection{Quantile Mapping}

This study adopts the quantile based mapping approach (Quintana Segue et al., 2010; Salathe et al., 2007; Wood et al., 2004) to downscale the climate simulation. The quantile mapping approach uses daily time step precipitation values obtained from GCM simulation for the historical period of 1970-1999 and future period of 2041-2070. The selection of the future period (2041-2070) is a useful time horizon as it is neither too far nor too close, so it would help all water related stakeholder plan and design the water resources for the CRB for sustainable water management. The RCP 85 scenario has been adopted for the future period which is estimated to be stabilized at $8.5 \mathrm{~W} / \mathrm{m} 2$ at the end of $21^{\text {st }}$ century. The observed data was derived from (Maurer et al., 2002) for the period of 30 years (1970-1999).

As described in (Quintana Segue et al., 2010), the CMIP5 GCM simulated data and observed data for the period of 30 years (1970-1999) are categorized in cumulative distribution functions (CDFs). For each grid cell, the transfer factors (correction factors) are then developed between simulated and observed data based on the CDFs at the daily time step for the entire period of 30 years based on the resolution of the observed data. This basically functions as mapping the GCM simulations distribution over the observed data distribution at each grid cell to remove the bias. The future simulated data is then bias corrected by applying the transfer factors for each grid cell at the same resolution of the observed data. We are using a typical 30 year period to fit the distributions for both the historical (1970-1999) and future (2041-2070). This method of downscaling uses multiplicative perturbations for precipitation and additive perturbations for temperature. 
The Quantile Mapping downscaling method is based on a hypothesis that transfer or correction factors calculated from historical and observed quantiles remain constant in the future which is absolutely not justifiable because we don't know about the future changes in the climate. The figures showing bias corrected and downscaled GCMs are provided below.

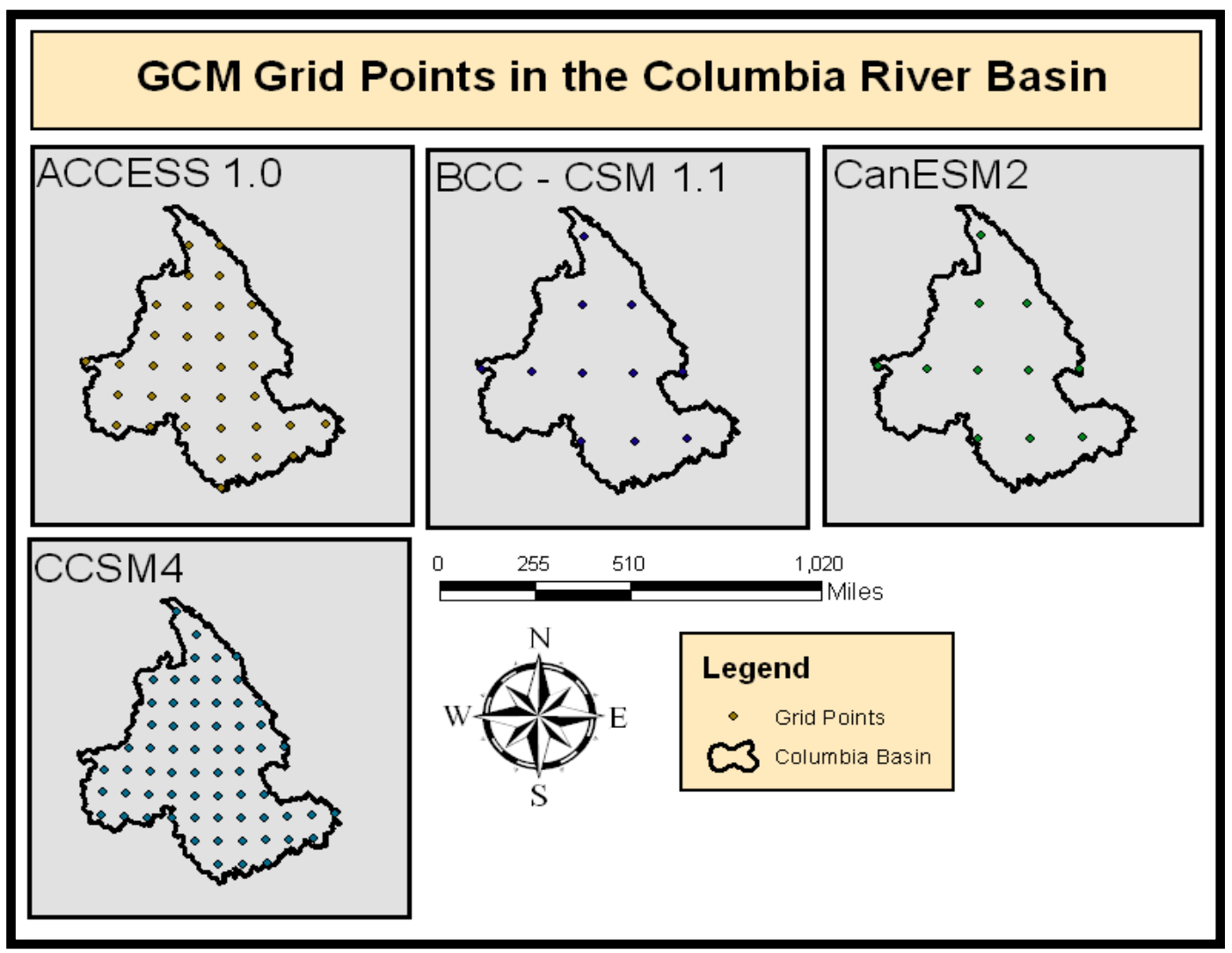

Figure 2: GCMs Grid Points for four CMIP5 models over the Columbia River Basin 


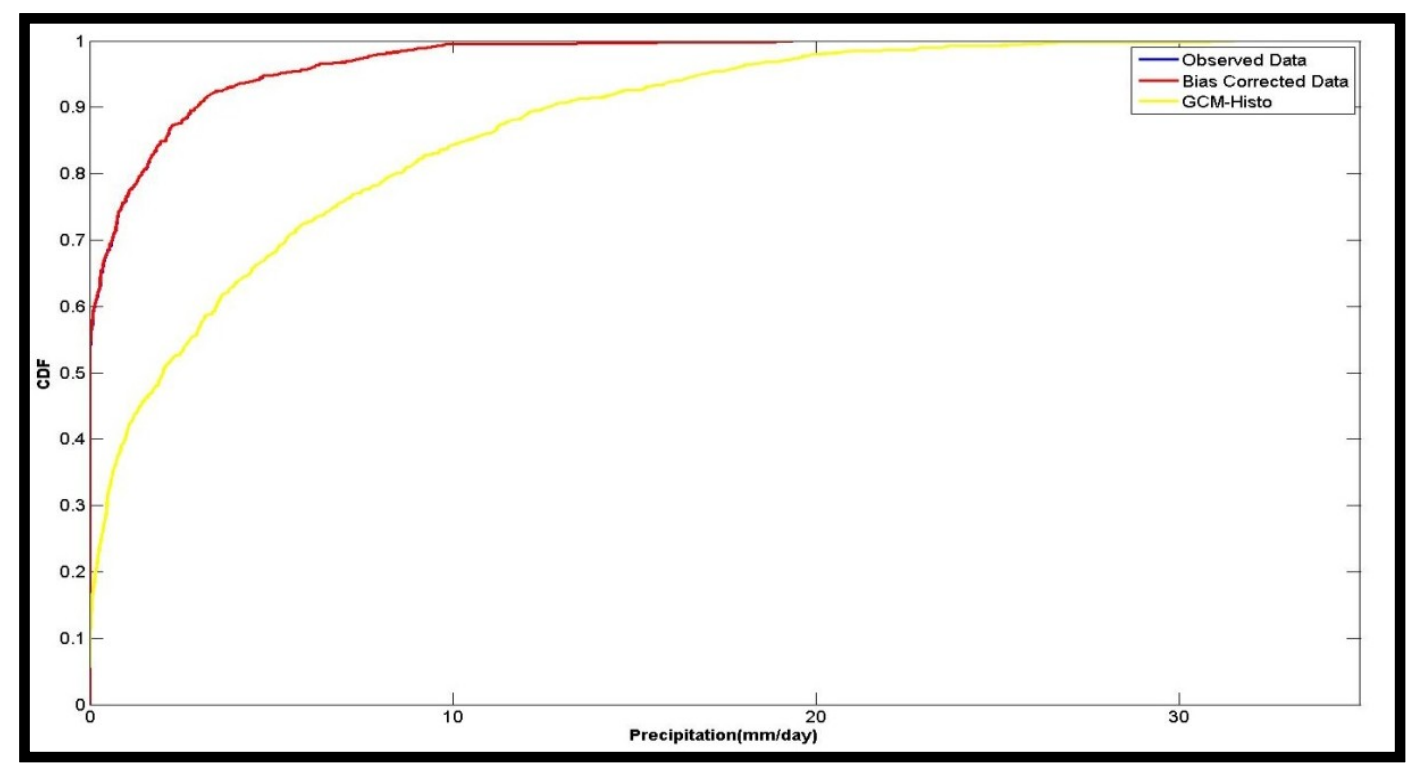

Figure 3: Example of one gird showing Observed, historical and bias corrected data over the Columbia River Basin

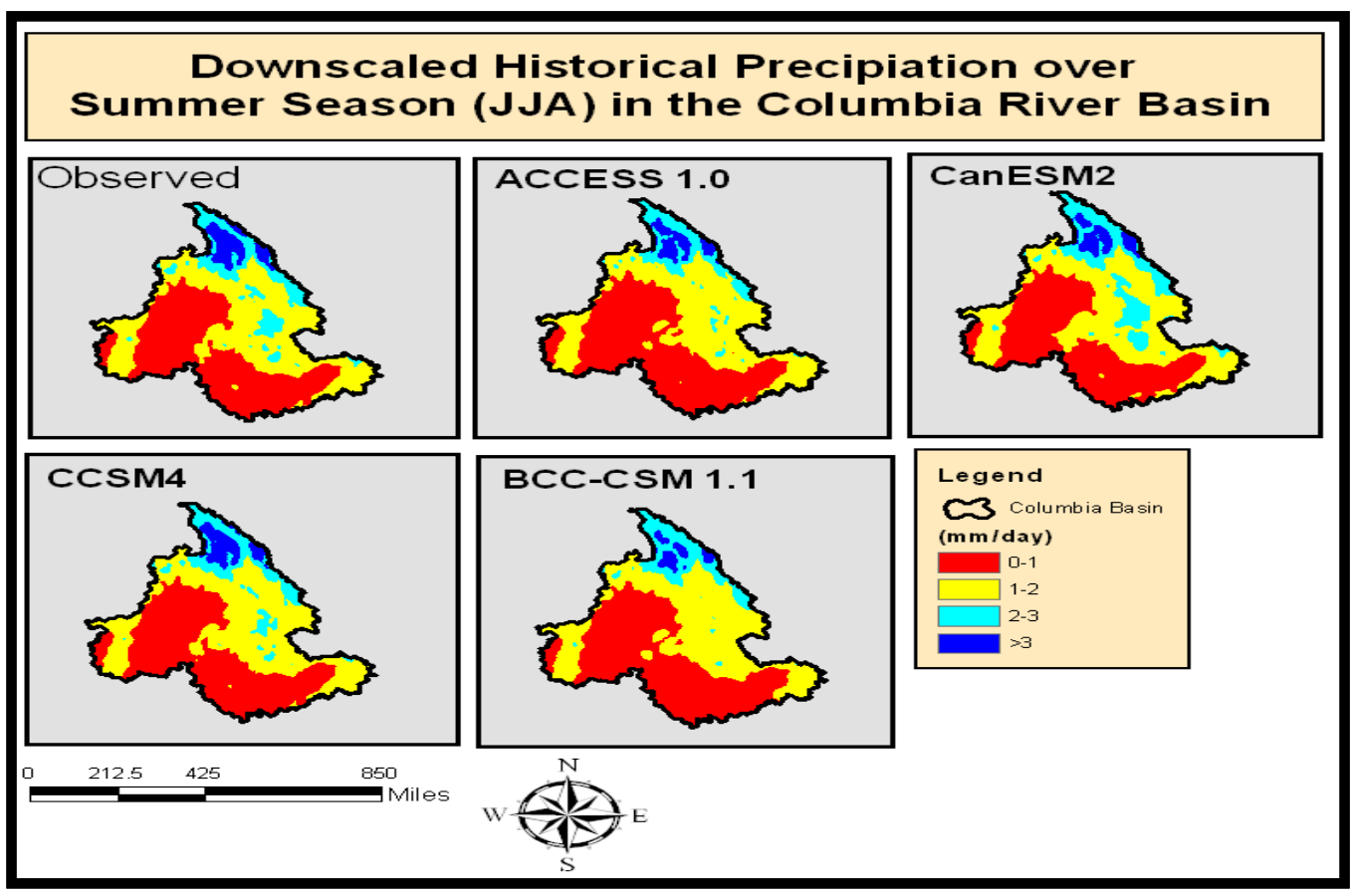

Figure 4: Downscaled Historical Precipitation for 30 years (1970-1999) in the summer season over the CRB 


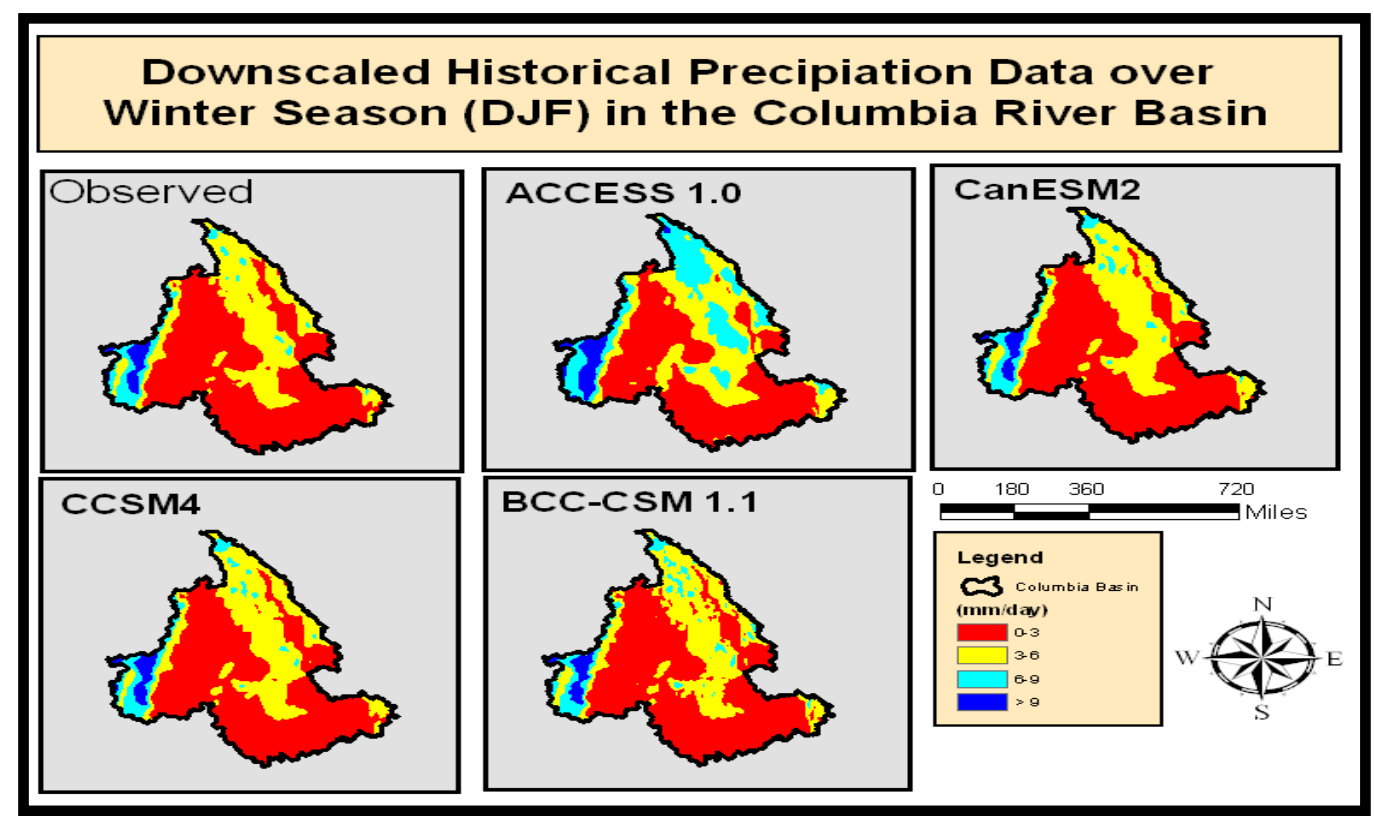

Figure 5: Downscaled Historical Precipitation for 30 years (1970-1999) in the winter season over the CRB

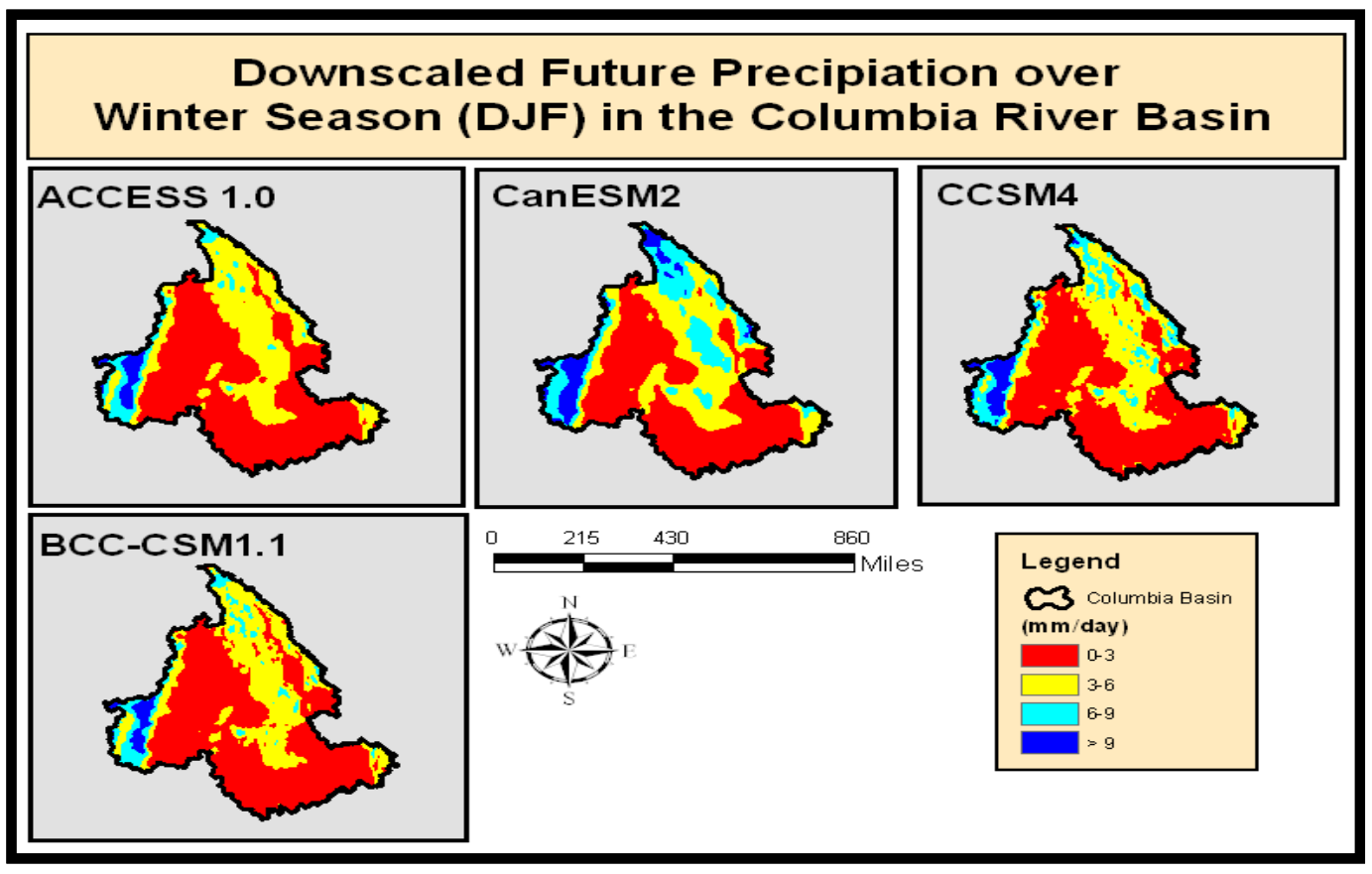

Figure 6: Downscaled Future Precipitation for 30 years (2041-2070) in the winter season over the CRB 


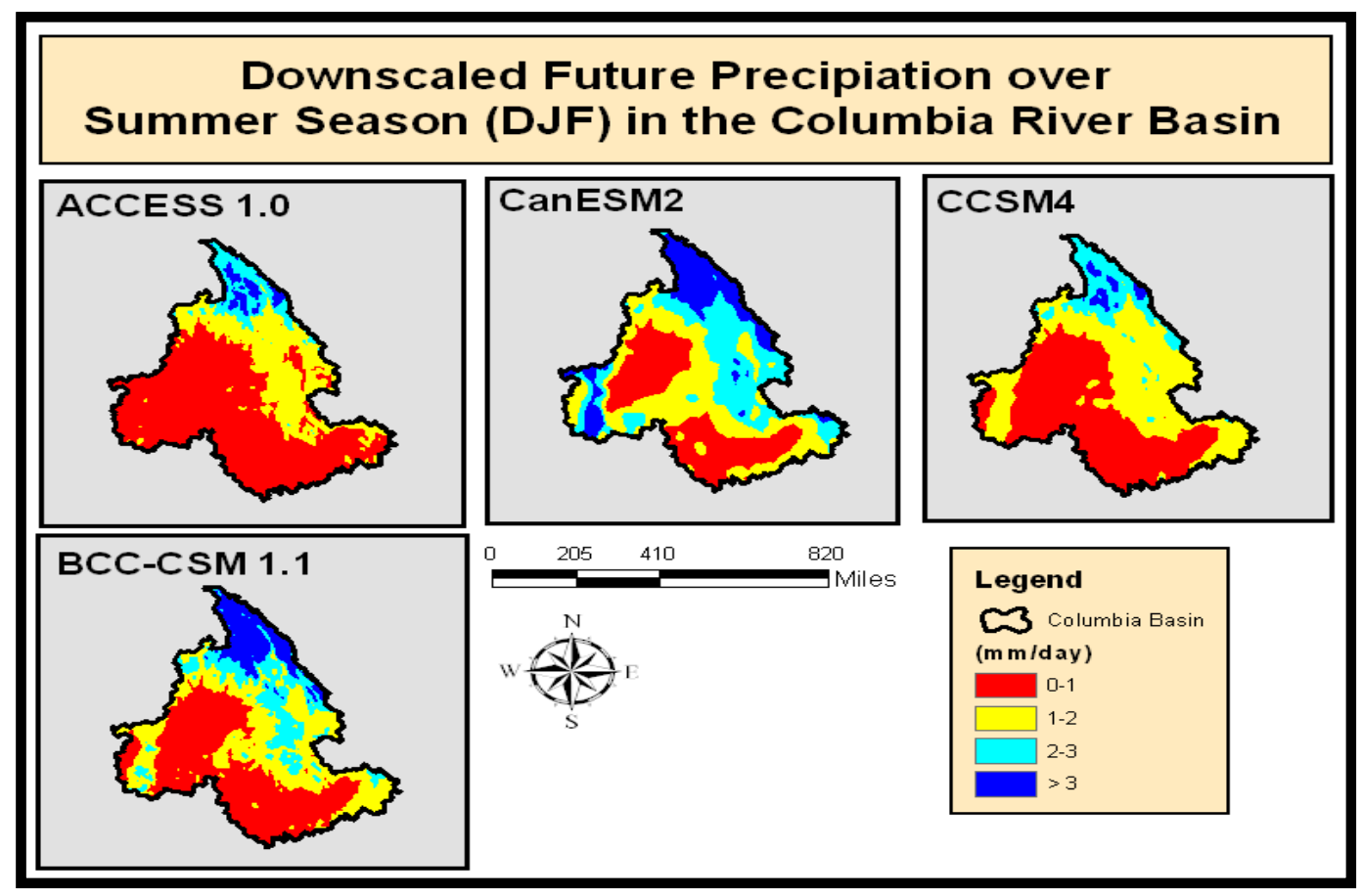

Figure 7: Downscaled Future Precipitation for 30 years (2041-2070) in the summer season over the CRB

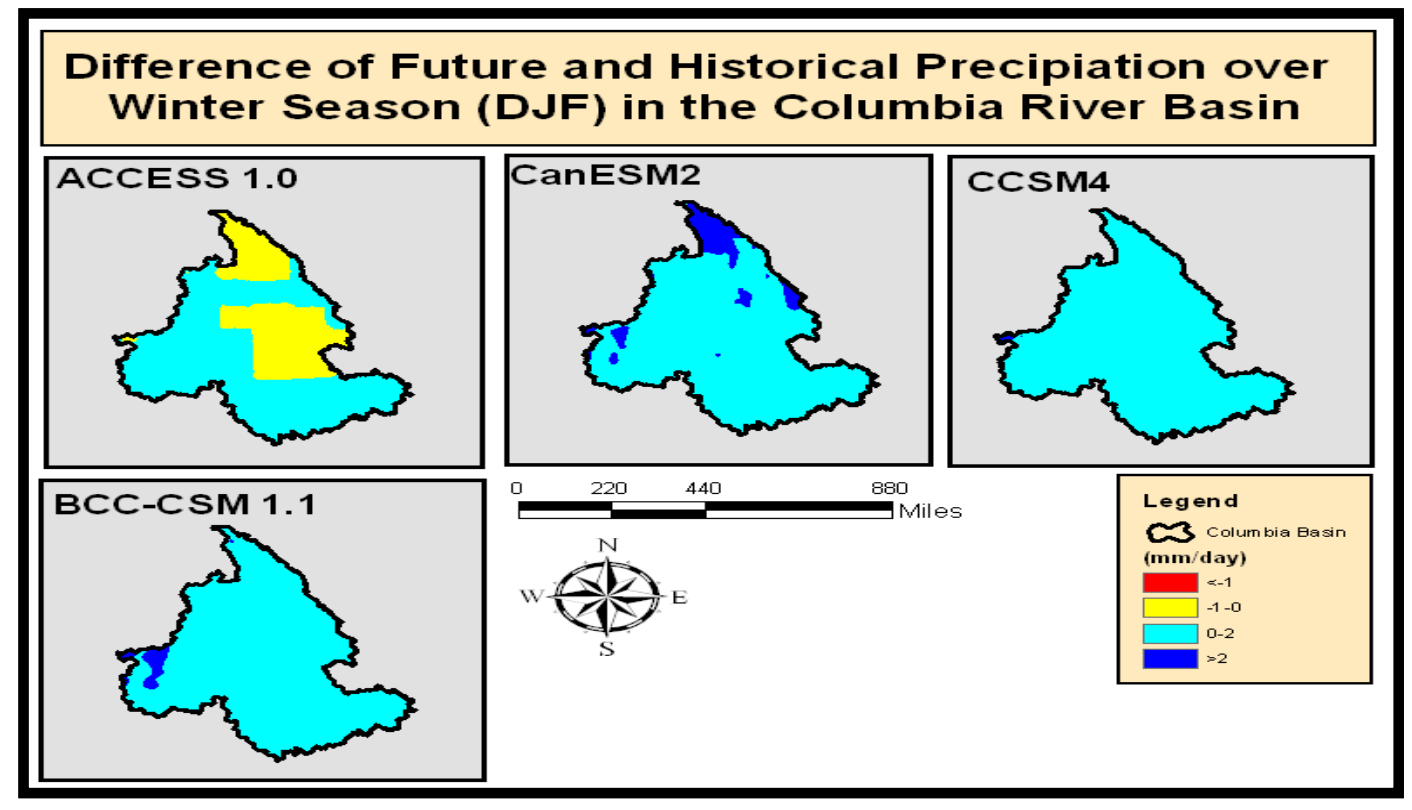

Figure 8: Difference of Precipitation (Future-Historical) in the winter season over the CRB 


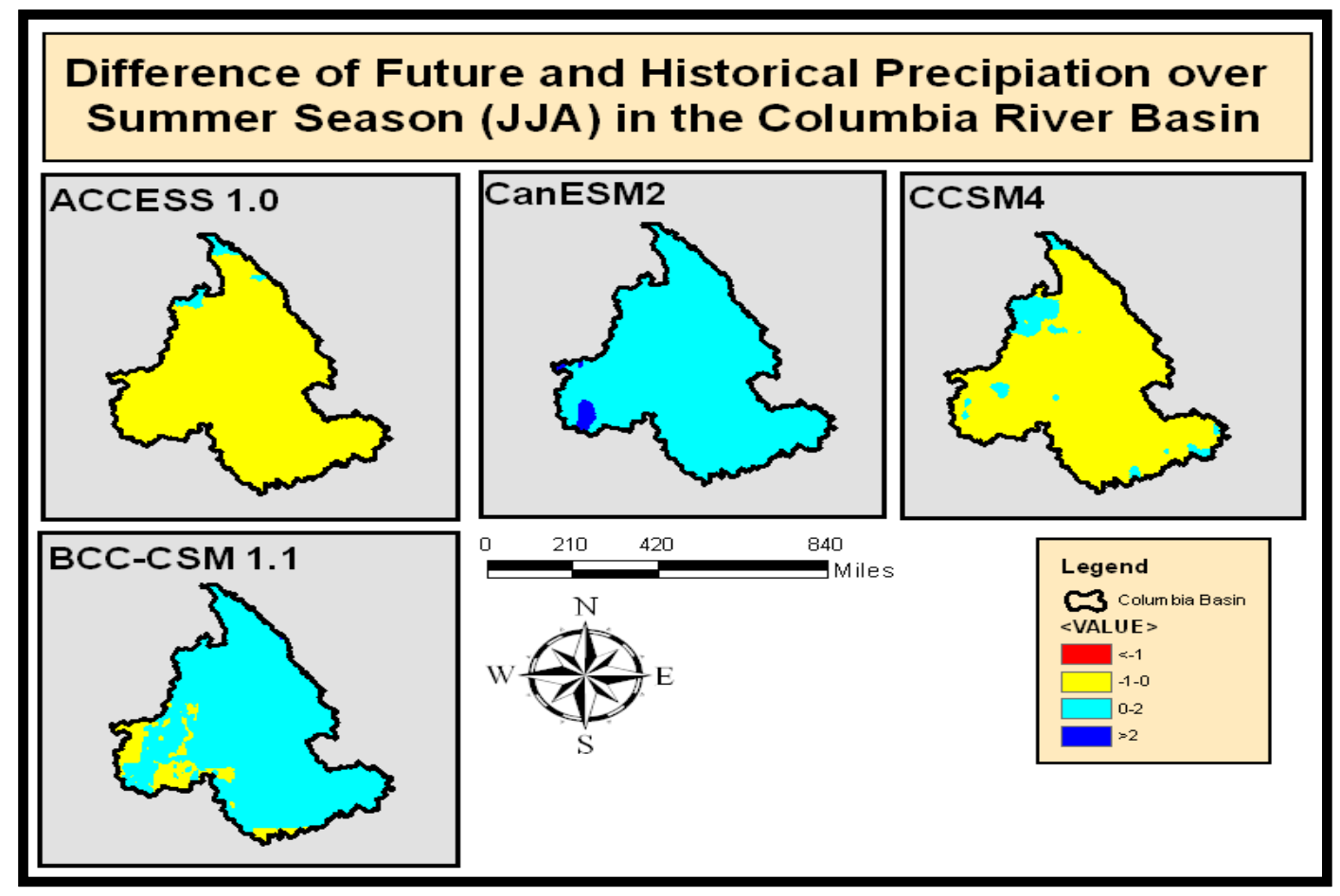

Figure 9: Difference of Precipitation (Future-Historical) in the summer season over the CRB

\subsection{Extreme Value Analysis:}

Extreme value analysis plays an important role in detecting climate change effects. Changes in the process of spatio-temporal variation of precipitation extremes will have a serious impact our socio-economics, aquatic species, hydrological infrastructures and human lives. Therefore, the evaluation of future changes in extreme events has now become essential part of water resources planning studies. It helps evaluate the hydrological data to understand the historical records of climate change and variability, and predict the future probabilities of extreme events. The GEV distribution is one of the most frequently used distributions in determining climate change effects (El Adlouni et 
al., 2007; Katz et al., 2002; Stedinger, 1993). The research shows that the GEV distribution is capable of simulating nearly accurate historical extreme events and predicting future extreme events (Halmstad et al., 2012; Tryhorn and DeGaetano, 2011). Many renowned researchers used GEV distribution to study extreme rainfall and temperature in the U.K. (Cooley, 2009; Ekstrom et al., 2005; Fowler et al., 2005). Kharin and Zwiers (2000), Kharin and Zwiers (2005), Kharin et al., (2005) and Zwiers and Kharin (1998) also studied precipitation, temperature and wind speed extremes by using GEV distribution.

In this study, generalized extreme value (GEV) distribution (Fisher and Tippett, 1928; Gnedenko, 1943; Gumbel, 1958; Jenkinson, 1955) comprising three extreme value distributions, has been used to analyze extreme precipitation in terms of return values. These three distributions are named Gumbel, Frechet, Weibull distributions. The cumulative distribution function (CDF) of the GEV distribution is as follows:

$$
\begin{aligned}
& F(x, \mu, \delta, \varepsilon)=\exp \left[-\left(1+\varepsilon \frac{x-\mu}{\delta}\right)^{-\frac{1}{\varepsilon}}\right] \text { when } \varepsilon \neq 0 \\
& F(x, \mu, \delta, \varepsilon)=\exp [-\exp (-(x-\mu) / \delta))] \text { when } \varepsilon=0
\end{aligned}
$$

where $\mu$ is the location parameter, $\varepsilon$ is the shape parameter and $\sigma$ is the scale parameter. According to (Katz et al., 2002; Kotz and Nadarajah, 2000), shape parameter can be used to describe the tail behavior of the distribution. If $\varepsilon=0$, then GEV is called type-I or Gumbel distribution, and this distribution has unbounded and exponentially decreasing thin tail. If $\varepsilon>0$, then GEV distribution is called type-II or Frechet distribution and this 
distribution has a heavy tail. If $\varepsilon<0$, then GEV is termed type-III or Weibull distribution and has a short tailed distribution.

Kharin et al., (2007) define a return value as "a threshold that is exceeded by an annual extreme in any given year with the probability $\mathrm{p}=1 / \mathrm{T}$ ". Return values are the quantiles obtained from GEV distribution at every grid of the data. According to some studies, the GEV distribution works best on sufficiently large annual maximum data of at least more than 25 years (Coles, 2001; El Adlouni et al., 2007; Halmstad et al., 2012). This study uses the historical data from 1970 through 1999 (30 years) and future data from 2041 through 2070 (30 years). After fitting the GEV distribution to the annual maximum values in the Matlab, the T-year return levels are obtained by the inverse of the cumulative distribution function. Mathematically, this quantile function can be represented by:

$$
\begin{gathered}
F^{-1}(1-p, \mu, \delta, \varepsilon)=\mu+\left(\frac{\sigma}{\varepsilon}\right)\left[\{-\log (1-p)\}^{-\varepsilon}-1\right] \quad \text { when } \varepsilon \neq 0 \\
F^{-1}(1-p, \mu, \delta, \varepsilon)=\mu+\sigma[-\log \{-\log (1-p)\}] \quad \text { when } \varepsilon=0
\end{gathered}
$$

where $\mu$ is the location parameter, $\varepsilon$ is the shape parameter and $\delta$ is the scale parameter and $1-p$ is non-exceedance probability. The results of return levels for 2 years, 5 years, 10 years and 25 years are described in results section. 


\subsection{Multi-model Ensemble:}

In hydrologic modeling, it is generally relied on a single model, whereas relying on one model can lead to unreliable and uncertain hydrologic forecasts due to statistical bias and structural error inherent in any single model (Ajami et al., 2007; Hsu et al., 2009; Najafi and Moradkhani, 2013a; Najafi et al., 2011a; Raftery et al., 2005).

The BMA predictions are weighted averages of the individual models, and the sum of all weights is equal to 1 because they are probabilistic likelihoods of a model. The weights (likelihood measures) of each model are based on their predictions. The research shows that the BMA provides a more realistic and reliable probabilistic prediction involving both between-model variance and in-model variance (Ajami et al., 2007; Duan et al., 2007; Najafi et al., 2011a; Raftery and Zheng, 2003). Recently, the BMA has been popular, and applied in various fields of statistics, groundwater modeling, hydrology, meteorology, medicine and management science (Duan et al., 2007; Fernandez et al., 2001; Hoeting et al., 1999; Najafi and Moradkhani, 2013b; Najafi et al., 2011a; Viallefont et al., 2001; Wintle et al., 2003).

Consider a variable $y$ is to be forecasted, and then the probability distribution function (PDF) of the variable $y$ can be expressed as, according to the law of total probability:

$$
p(y \mid O)=\sum_{i=1}^{I} p\left(y \mid m_{i} . O\right) \cdot p\left(m_{i} \mid O\right)
$$

where $p\left(y \mid m_{i} . O\right)$ is the posterior distribution of $y$ based on model prediction $\left(m_{i}\right)$ at each grid $(i)$, and the observation data $(O), p\left(m_{i} \mid O\right)$ is the posterior probability of 
model prediction $\left(m_{i}\right)$. This ensemble methodology replicates the procedure of Expectation-Maximization (EM) algorithm described by (Duan et al., 2007). Before the BMA is implemented, the simulated data of each model first needs to be downscaled. After bias correction and downscaling, the BMA is carried out. In this procedure, the conditional probability distribution $p\left(y \mid m_{i}, O\right)$ should be considered to be Gaussian, and if it is not Gaussian distribution, then Box-Cox transformation is used to transform both modeled and observed data close to the Gaussian distribution before the BMA is implemented. The BMA is a very efficient method describing within-model variance and the between-model variance. Based on the weights and variance values obtained from BMA, it is easily decidable that which model is performing the best. More detail about this method can be found in (Duan et al., 2007).

An enhancement to BMA was made recently by Parrish et al., (2012) where they combined the strength of sequential data assimilation (e.g., Moradkhani et al., 2005a\&b; Moradkhani 2008; DeChant and Moradkhani 2012) with BMA to make the weights change in time. This will improve the effectiveness of BMA and multi-modeling with increased reliability of multi-model performance. 


\section{Results and Discussion}

\subsection{Changes in the Future Climatology}

\subsubsection{Future Changes in Winter Extreme Precipitation (DJF)}

In this section, we evaluate the future changes in winter extreme precipitation events over the Columbia River Basin by the t-years return levels. The t-years return levels have estimated by using generalized extreme value (GEV) distribution from four CMIP5 climate models (their names and other details are given in the table 1). The simulated changes for the future period of 30 years (2041-2070) are analyzed relative to the baseline period of 30 years (1970 to 1999). In this study, 2-years, 5 years, 10-years and 25-years return levels are calculated for both historic and future periods in the unit of $\mathrm{mm} /$ day. The figures 10 through 13 display 2 -years, 5 -years, 10 -years and 25 -years return levels for the winter season, and the figures 14 through 17 display differences for the winter return levels (future - historical) against 2-years, 5-years, 10-years and 25-years return periods respectively. In the figures 10 through 13 , the top row having only one figure shape represents return levels for the observed dataset, whereas the middle row represents return levels for the historical period and bottom row represents return levels for the future period for the four CMIP5 climate models.

We have found a consistent and significant increase in the intensity of winter extreme precipitation (DJF) in the future period of 30 years over the Columbia River Basin. All four CMIP5 climate models analyzed in this study show an increase in the winter extreme precipitation with the increase of return periods. The maximum range of the winter return level values for the future period is somewhat different from each other 
but they all models agree on the increase in the winter extreme precipitation. The maximum range of the return levels is more than $84 \mathrm{~mm} /$ day for 2-years return period, more than $108 \mathrm{~mm} /$ day for 5 -years return period, more than $123 \mathrm{~mm} /$ day for 10 -years return period and more than $156 \mathrm{~mm} /$ day for 25 -years return period. For all return periods, the intensity of the increase in winter extreme precipitation is found in the Canadian portion of the basin, west of the Cascade Mountain Range, Coastal range of Oregon and Washington State, two counties of Montana State named Flathead and Lincoln and some parts of Rocky Mountains in the Idaho State. Here, it is notable that the CanESM2 model is consistently over-predicting while ACCESS 1.0 model is underpredicting the winter extreme precipitation compared to other models, whereas the two other models CCSM4 and BCC-CSM 1.1 show the almost same result.

\subsubsection{Future Changes in Summer Extreme Precipitation (JJA)}

In this section, we evaluate the future changes in summer extreme precipitation events in the Columbia River Basin by the t-years return levels. The figures 18 through 21 display 2-years, 5-years, 10-years and 25-years return levels for the summer season, and the figures 22 through 25 display difference of summer return levels (future historical) against 2-years, 5-years, 10 -years and 25-years return periods respectively. In the figures 18 through 21 , the top row having only one figure shape represents return levels for the observed dataset, whereas the middle row represents return levels for the historical period and bottom row represents return levels for the future period of the four climate models. 
It in notable that the four CMIP5 climate models studied in this research show heterogeneous spatial pattern of the future changes in the extreme precipitation for the summer season. The figure 22 demonstrates the differences of future and historical 2-year return levels to describe the spatial pattern in the extreme precipitation changes. In this figure, the CCSM4 model shows an increase over the Rocky Mountains in the Idaho State; otherwise it shows a decline in the summer extreme precipitation over the other domain of CRB. The ACCESS1.0 model shows an increase over the Canadian portion of the basin and Rocky Mountains Ranges, whereas it shows a decline in the summer extreme precipitation over the other domain of CRB. The CanESM2 and BCC-CSM1.1 models show some similar spatial pattern showing an increase in the extreme precipitation in the summer season over the whole domain of basin. The CanESM2 model shows some major increase of precipitation in some parts of southwest of the CRB.

Figure 23 explains the differences of future and historical 5-year return levels it shows that the CCSM4 model shows the shrinkage in summer extreme precipitation in the Canadian portion and some southwest parts of Idaho State and some parts over the Rocky Mountains Range, whereas it shows a slight increase in the other domain of the basin. The ACCESS1.0 model shows some reduction in the whole Oregon and Washington States, west of the Idaho State; however it indicates a slight increase in the other domain of the basin; it also shows huge increase of extreme precipitation in the Canadian portion of the basin. The CanESM2 and BCC-CSM1.1 models show some similar spatial pattern showing the increase in almost whole domain of the CRB. 
The figure 24 displays the differences of future and historical 10-year return levels. This figure describes that that all four models project an increase in the summer extreme precipitation all over the domain of the basin except the ACCESS1.0 model, which shows a slight decrease over the Rocky Mountains in the Montana State and Idaho State. The figure 25 describes the differences of future and historical 25 -year return levels and it shows that all four models project an increase in the summer extreme precipitation all over the domain of the basin except the ACCESS1.0 model, which shows a slight decrease over the Rocky Mountains in the Montana State and Idaho State.

\subsubsection{Future Changes in the Mean Precipitation}

In this part, the future changes in the mean precipitation for both winter and summer seasons are estimated over the Columbia River Basin for the future period of 30 years (2041-2070). The figures 26 through 33 describe mean precipitation for both winter and summer seasons. The figures demonstrate a $3.17 \%$ increase by the ACCESS 1.0 model, $15.3 \%$ increase by the CanESM2 model, $18.7 \%$ decrease by the BCC-CSM1.1 model and $7.8 \%$ decrease by the CCSM 4 model in the projected mean winter precipitation from 2041 to 2070 over the CRB. We also find $18.7 \%$ increase by the ACCESS1.0 model, 1.7\% increase by the BCC-CSM1.1 model, $14.3 \%$ decrease by the CanESM2 model and 30\% decrease by the CCSM4 model in the projected mean summer precipitation from 2041 to 2070 over the CRB. 


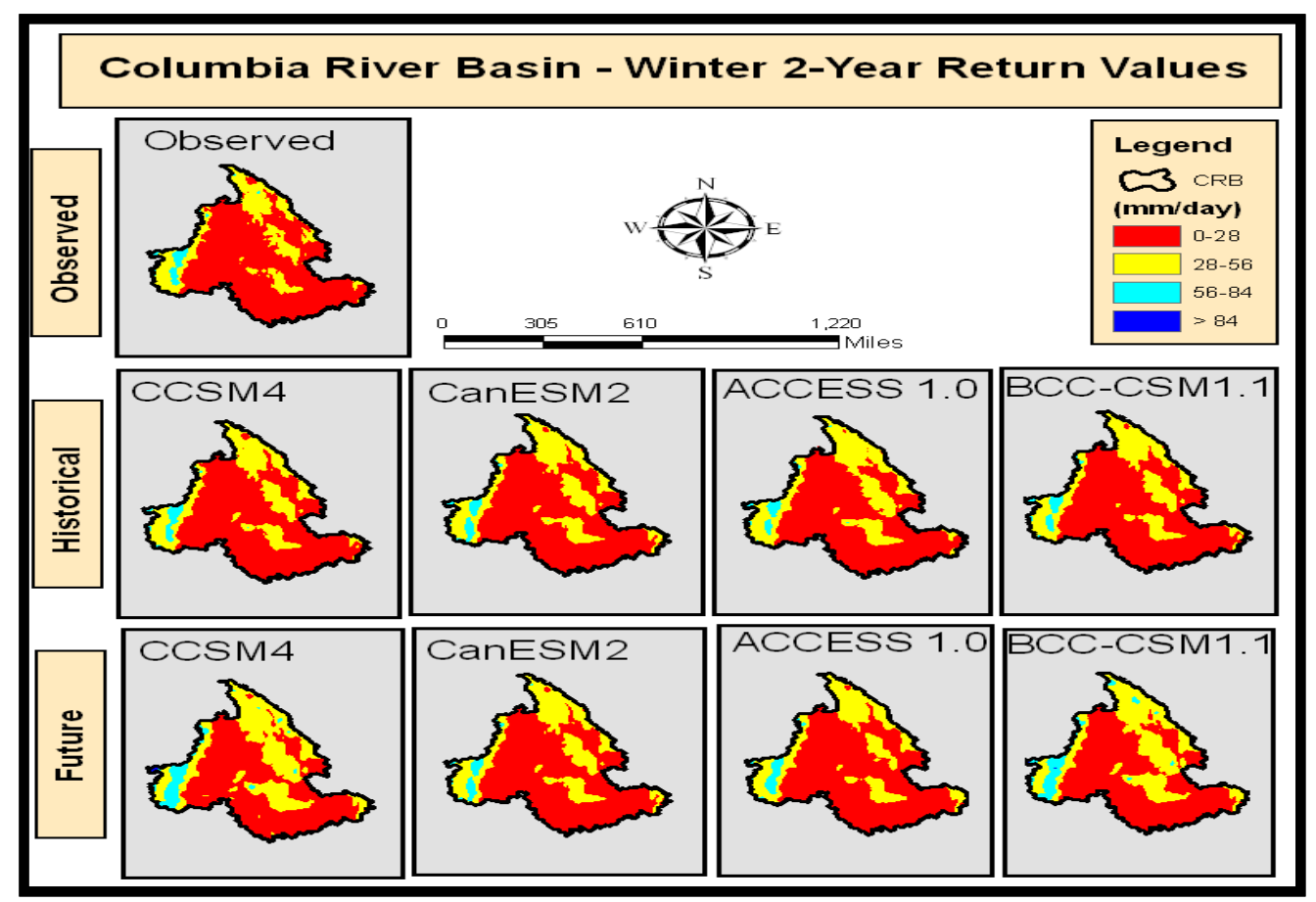

Figure 10: 2-years return levels (mm/day) in Winter Season (DJF) for the historical (1970-1999) and future period (2041-2070) over the CRB

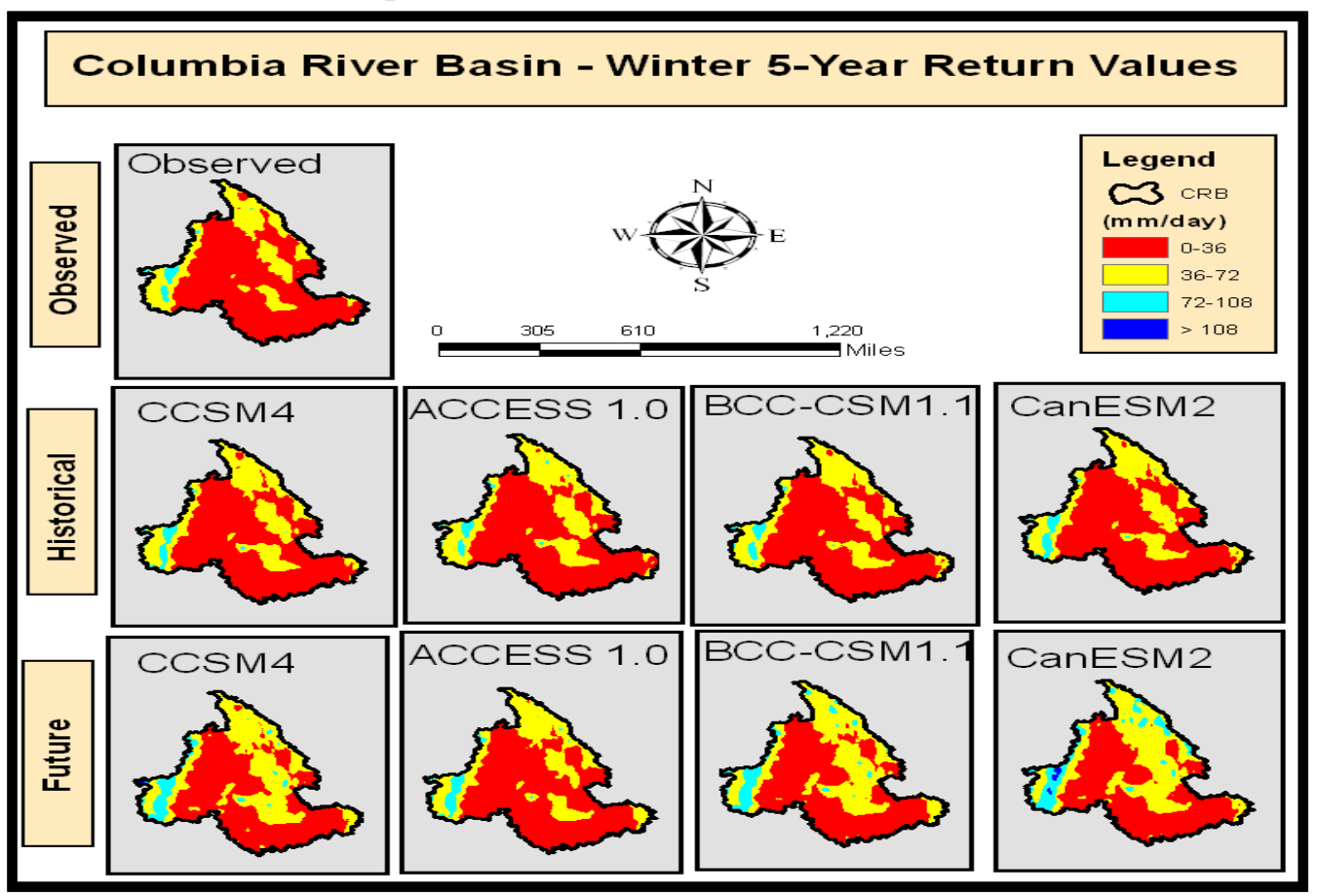

Figure 11: 5-years return levels (mm/day) in Winter Season (DJF) for the historical (1970-1999) and future period (2041-2070) over the CRB 


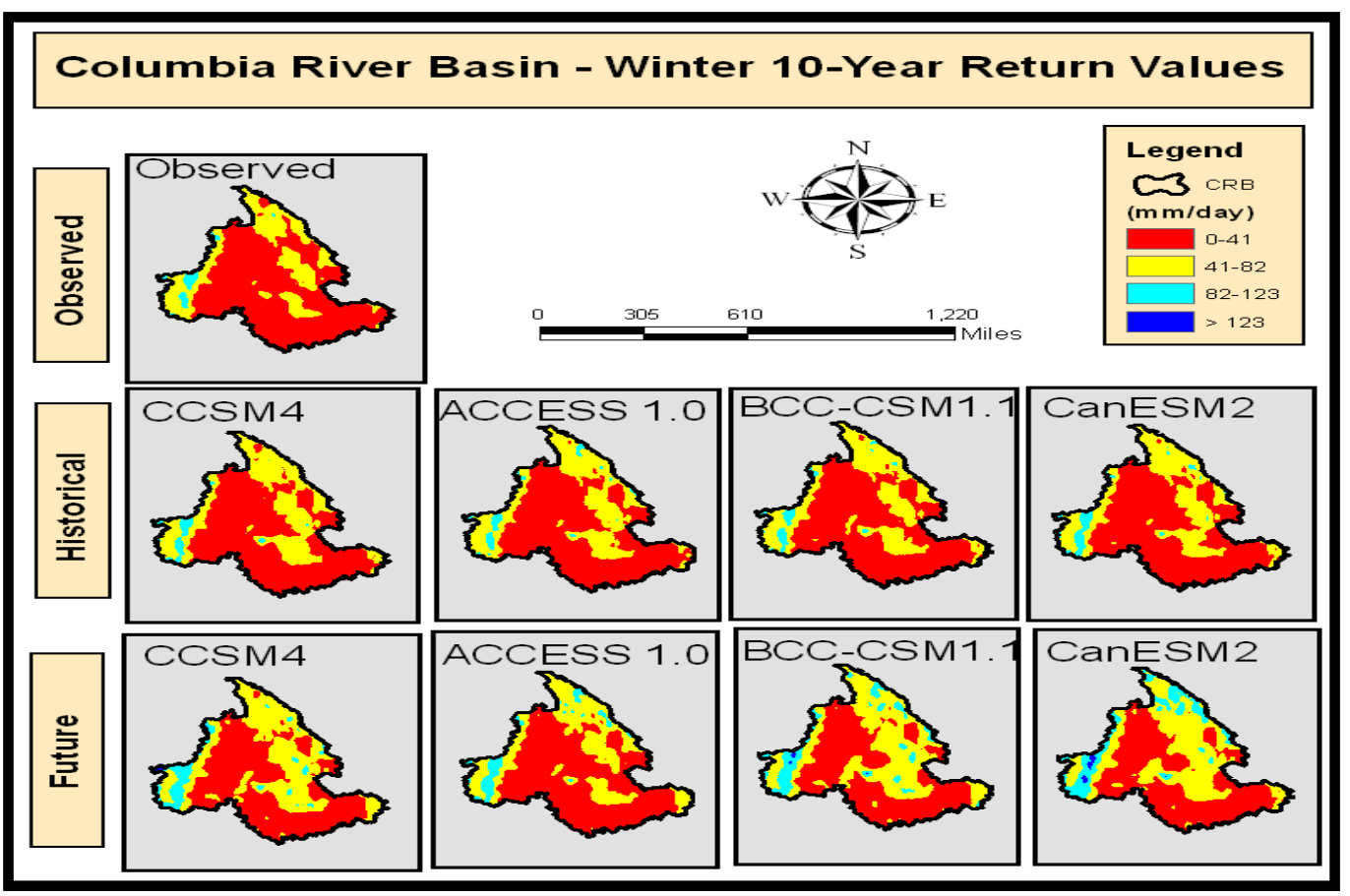

Figure 12: 10-years return levels (mm/day) in Winter Season (DJF) for the historical (1970-1999) and future period (2041-2070) over the CRB

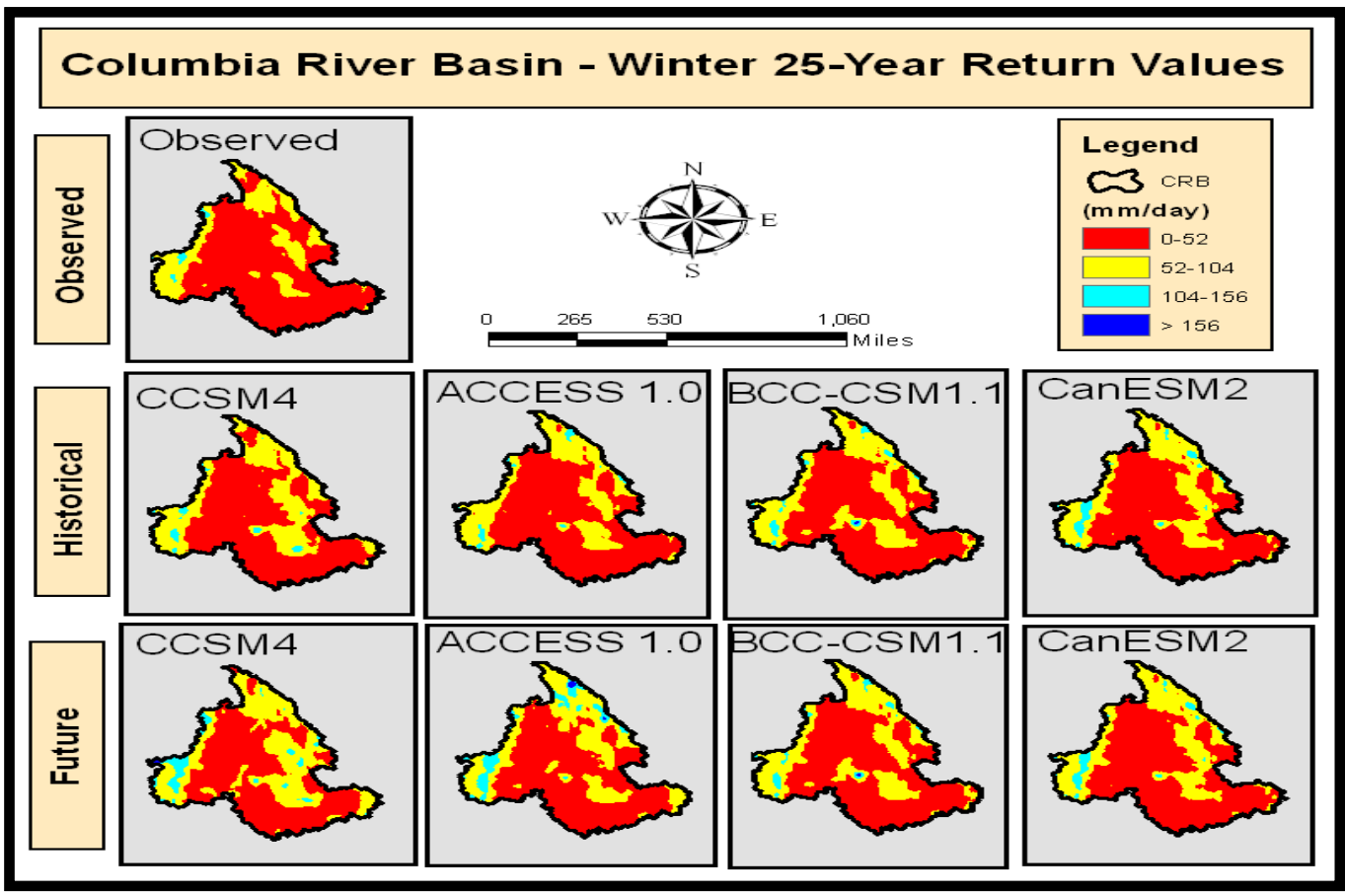

Figure 13: 25-years return levels (mm/day) in Winter Season (DJF) for the historical (1970-1999) and future period (2041-2070) over the CRB 


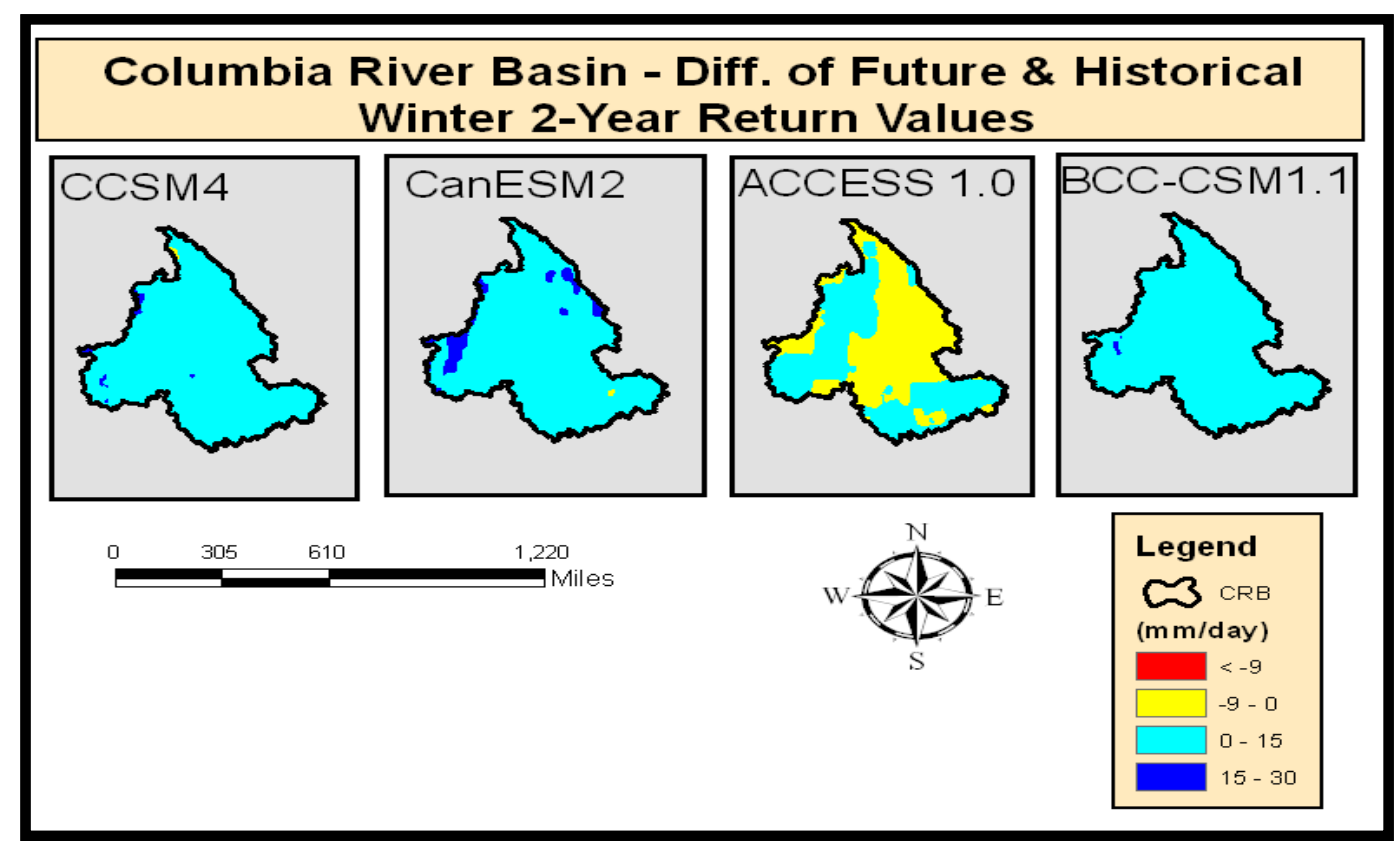

Figure 14: Difference of 2-years return levels (mm/day) (Future-Historical) in Winter Season (DJF) over the CRB

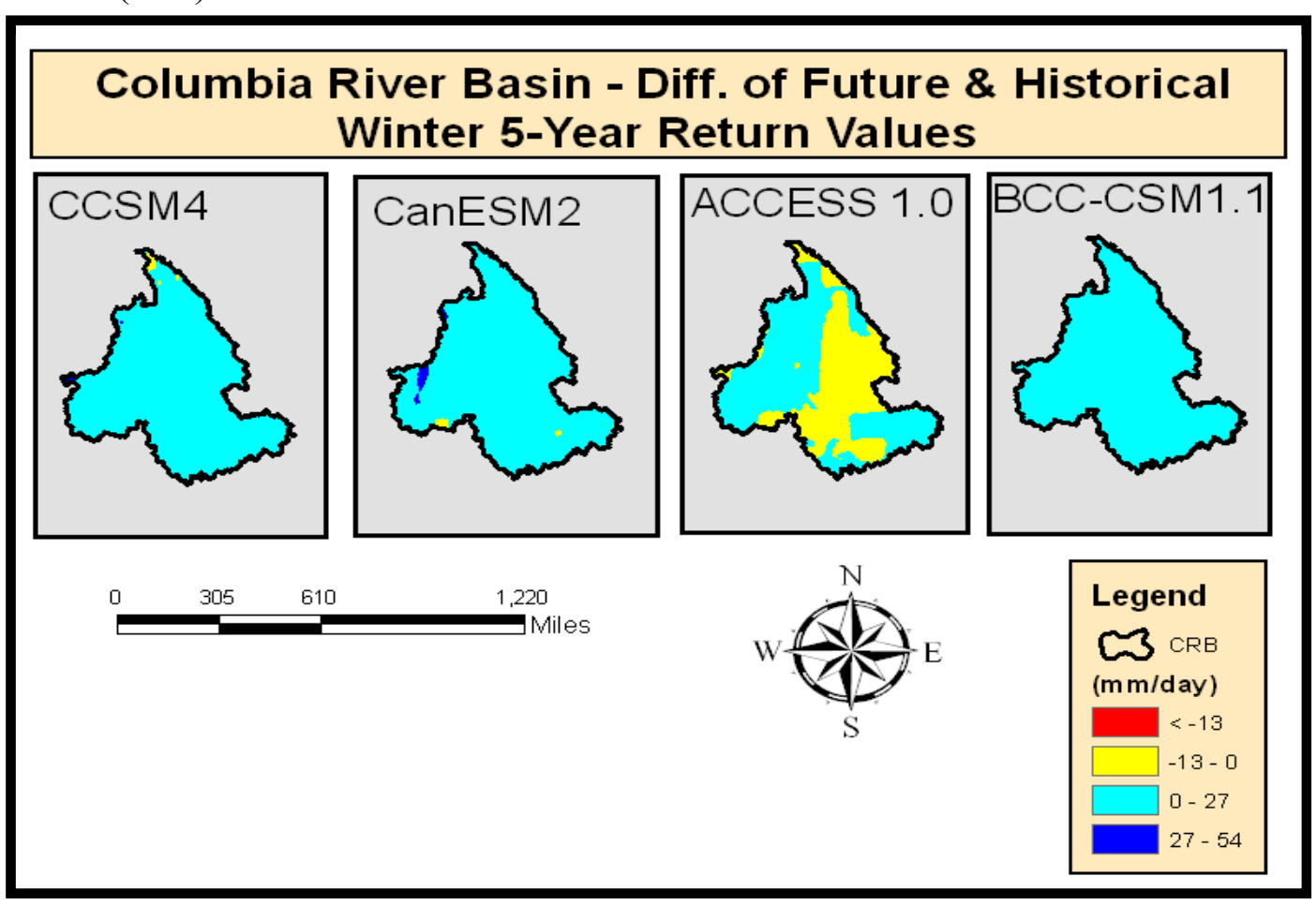

Figure 15: Difference of 5-years return levels (mm/day) (Future-Historical) in the Winter Season (DJF) over the CRB 


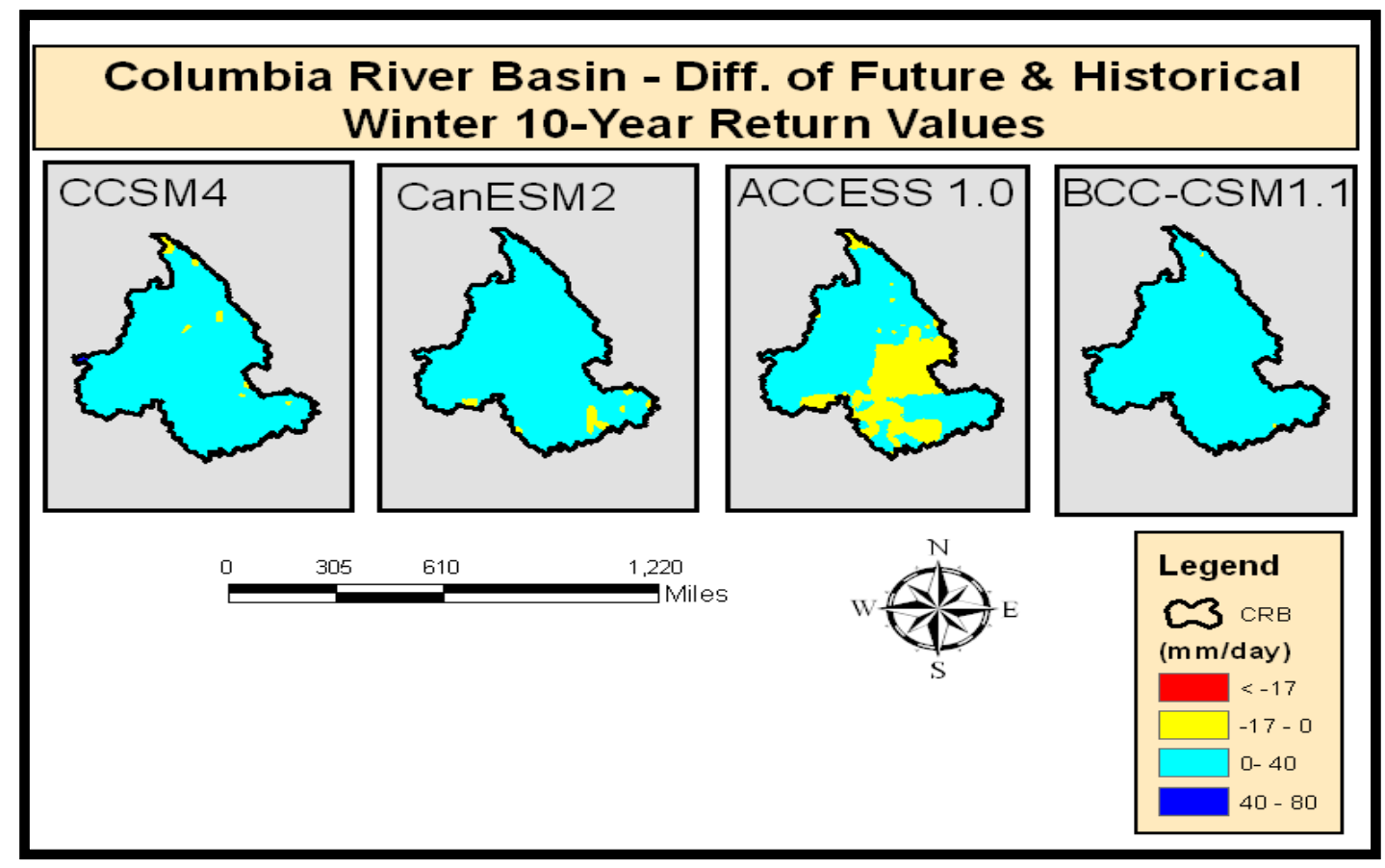

Figure 16: Difference of 10-years return levels (mm/day) (Future-Historical) in the Winter Season (DJF) over the CRB

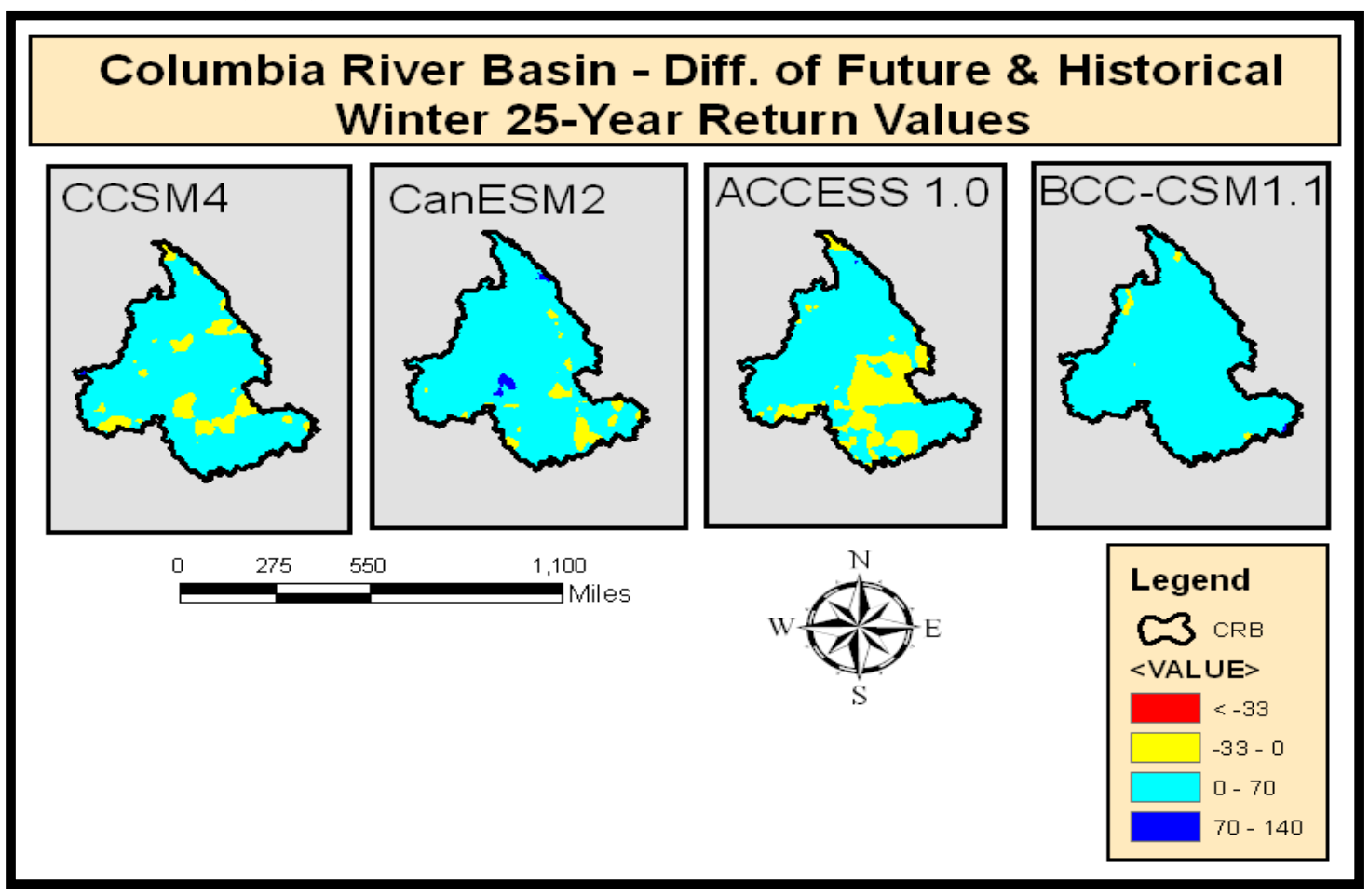

Figure 17: Difference of 25-years return levels (mm/day) (Future-Historical) in Winter Season (DJF) over the CRB 


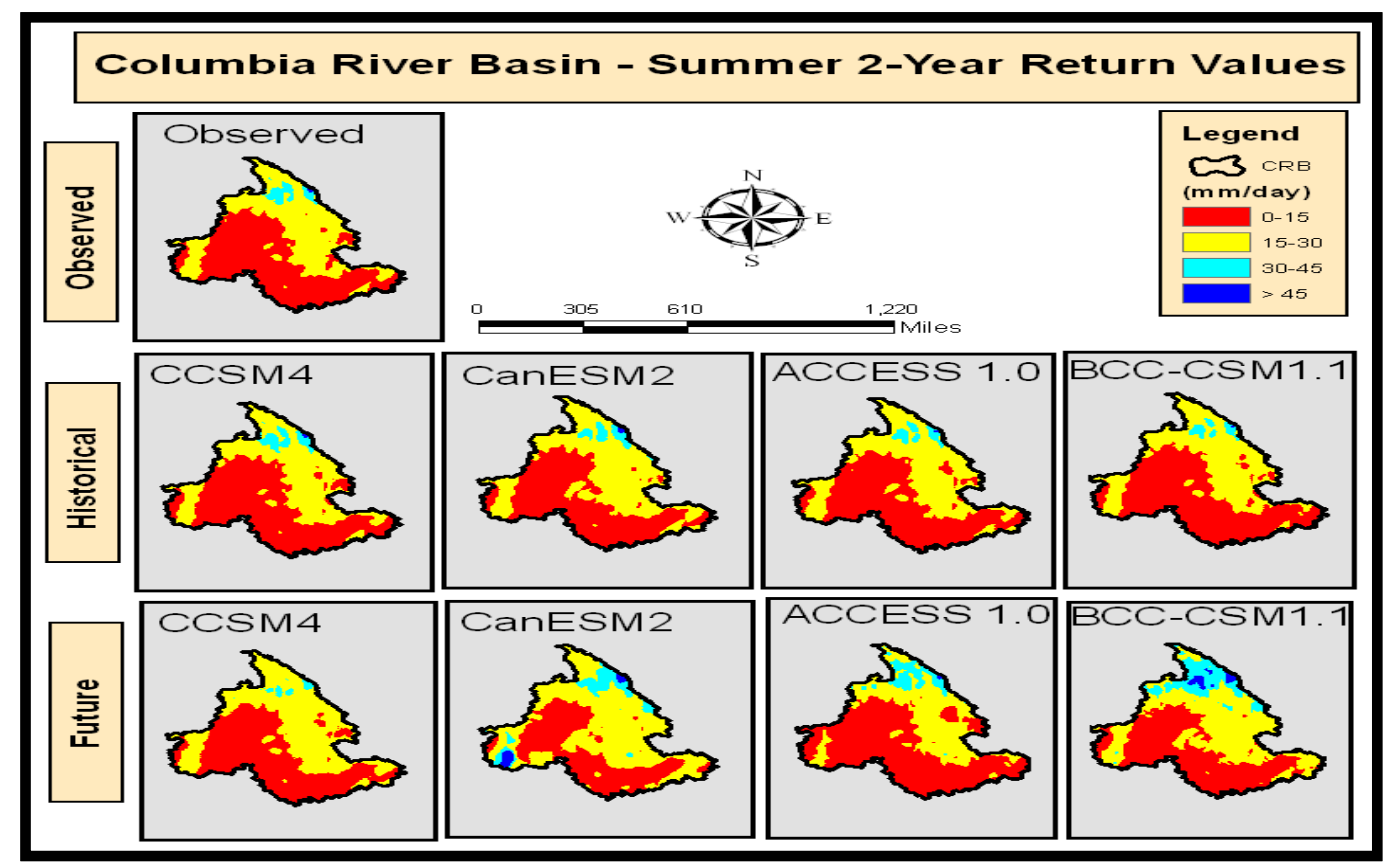

Figure 18: 2-years return levels (mm/day) in Summer Season (JJA) for the historical (1970-1999) and future period (2041-2070) over the CRB

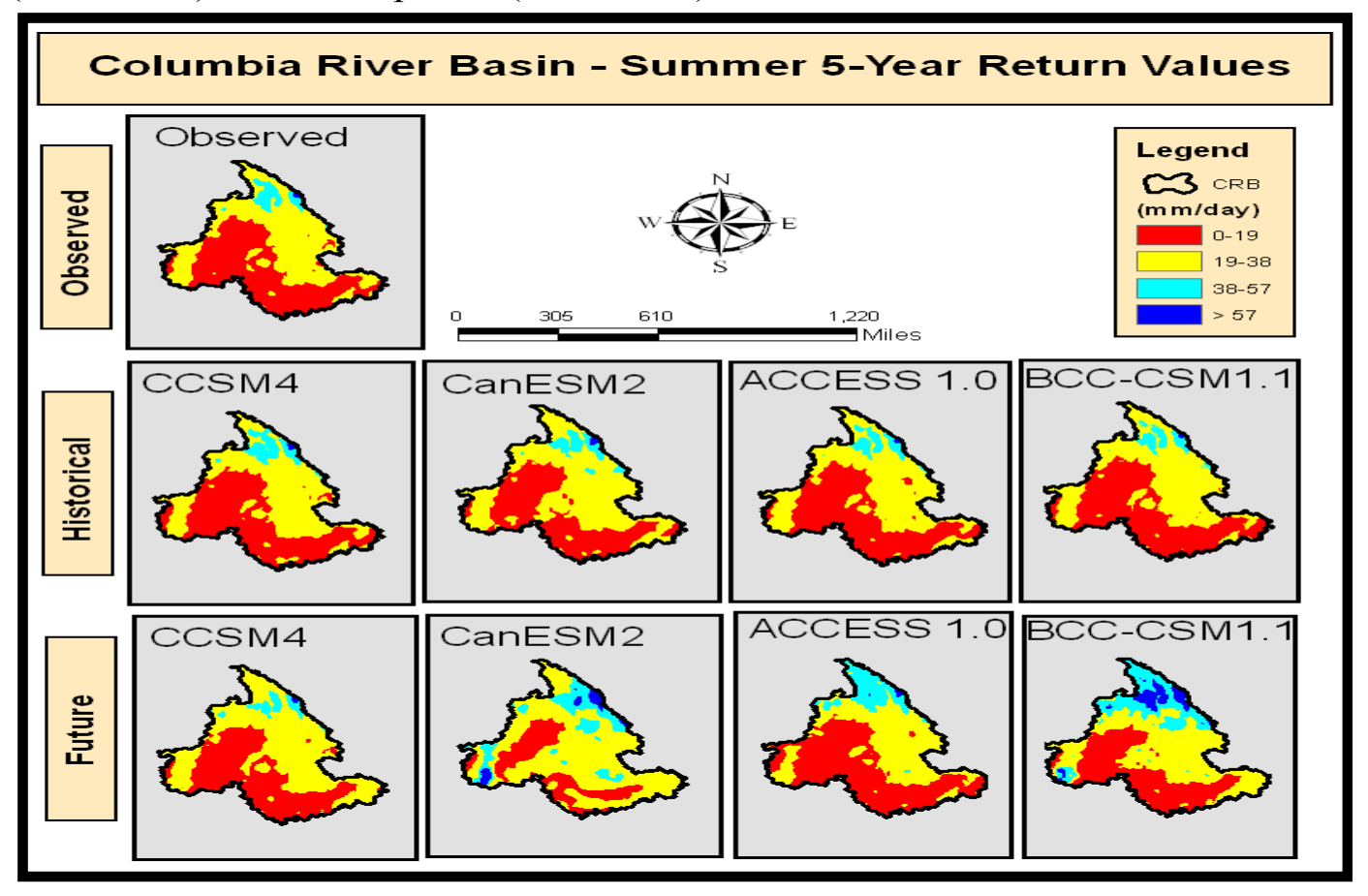

Figure 19: 5-years return levels (mm/day) in Summer Season (JJA) for the historical (1970-1999) and future period (2041-2070) over the CRB 


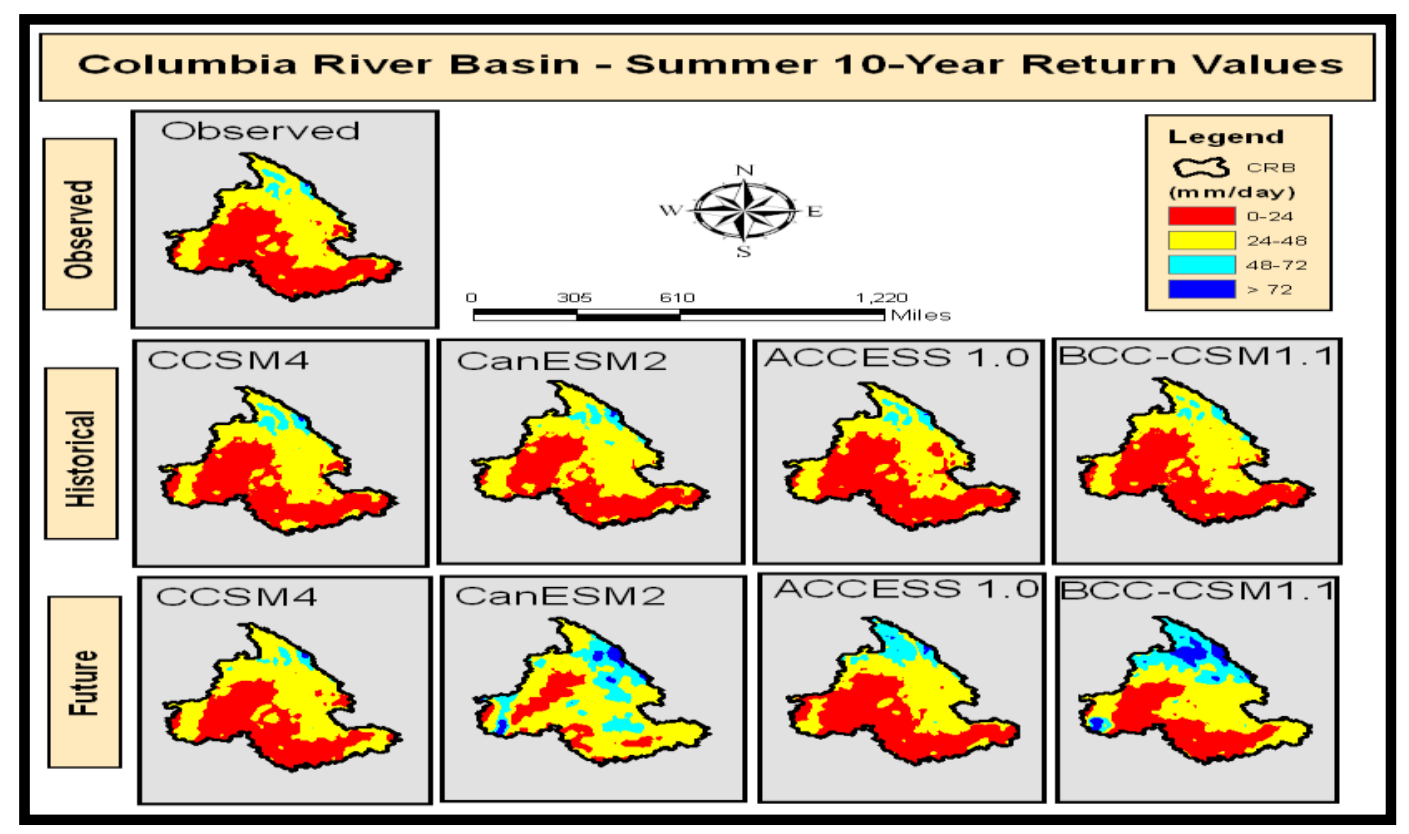

Figure 20: 10-years return levels (mm/day) in Summer Season (JJA) for the historical (1970-1999) and future period (2041-2070) over the CRB

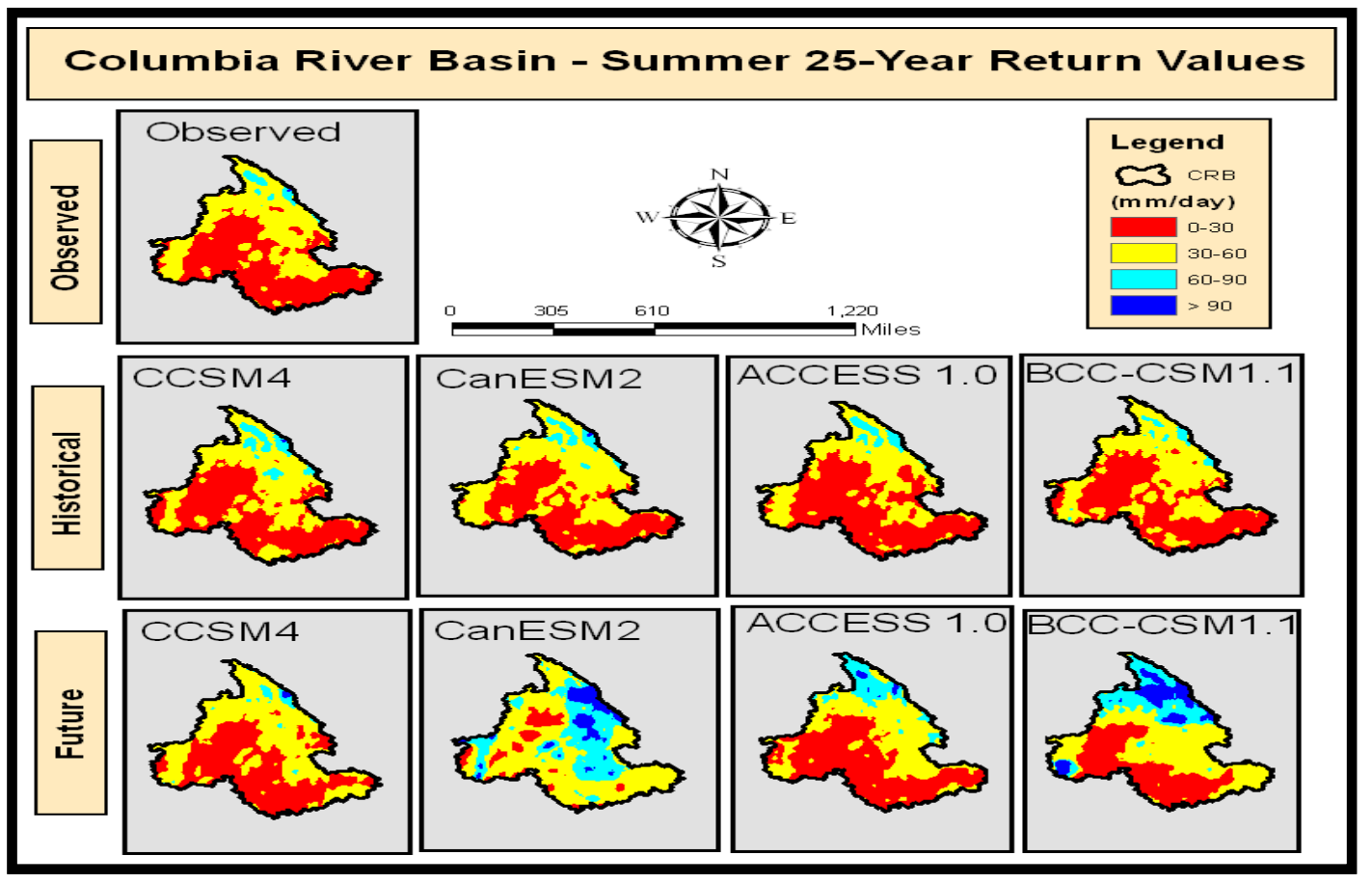

Figure 21: 25-years return levels (mm/day) in Summer Season (JJA) for the historical (1970-1999) and future period (2041-2070) over the CRB 


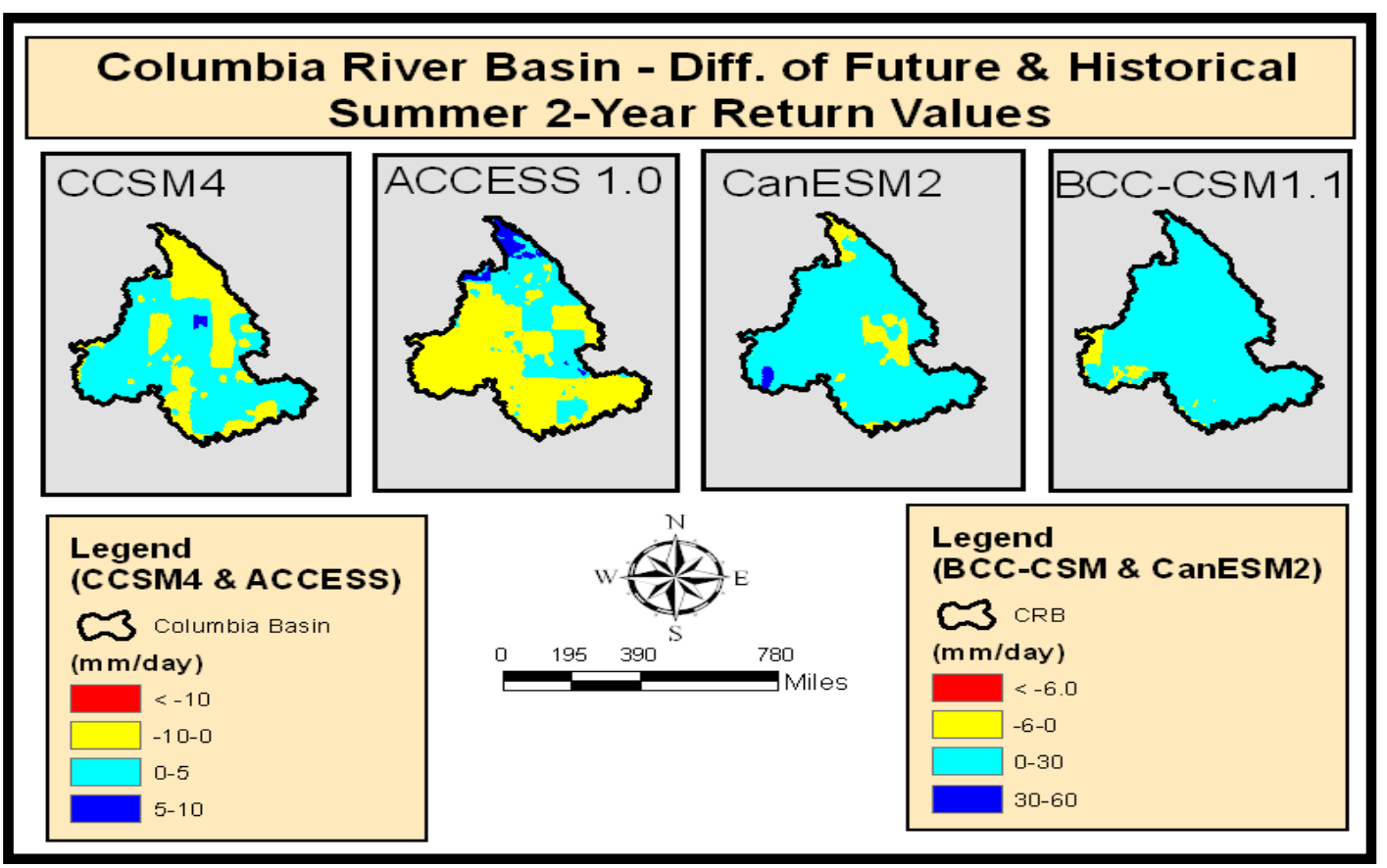

Figure 22: Difference of 2-years return levels (mm/day) for future period (2041-2070) and historical (1970-1999) in Summer Season (JJA) over the CRB

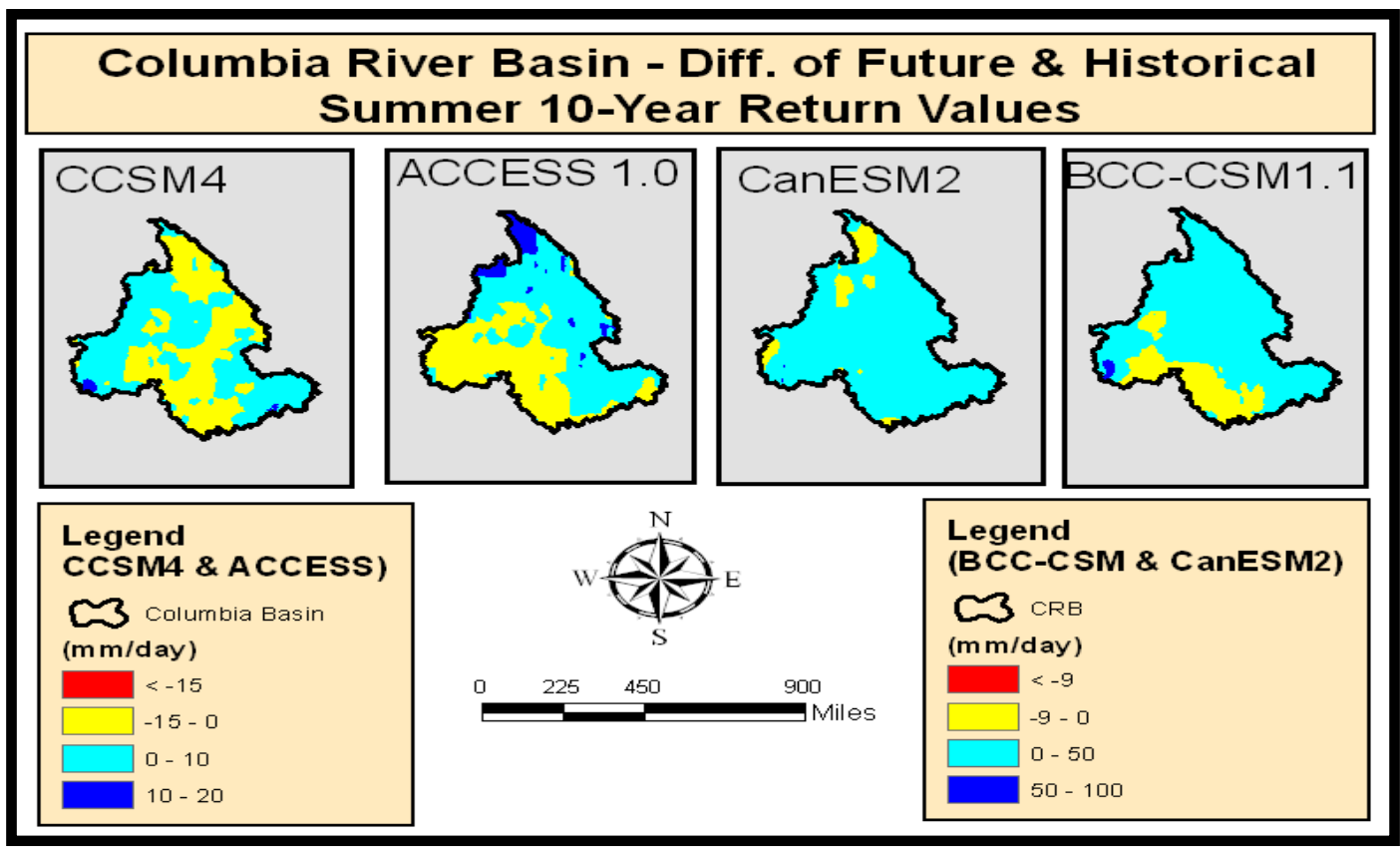

Figure 23: Difference of 5-years return levels (mm/day) for future period (2041-2070) and historical (1970-1999) in Summer Season (JJA) over the CRB 


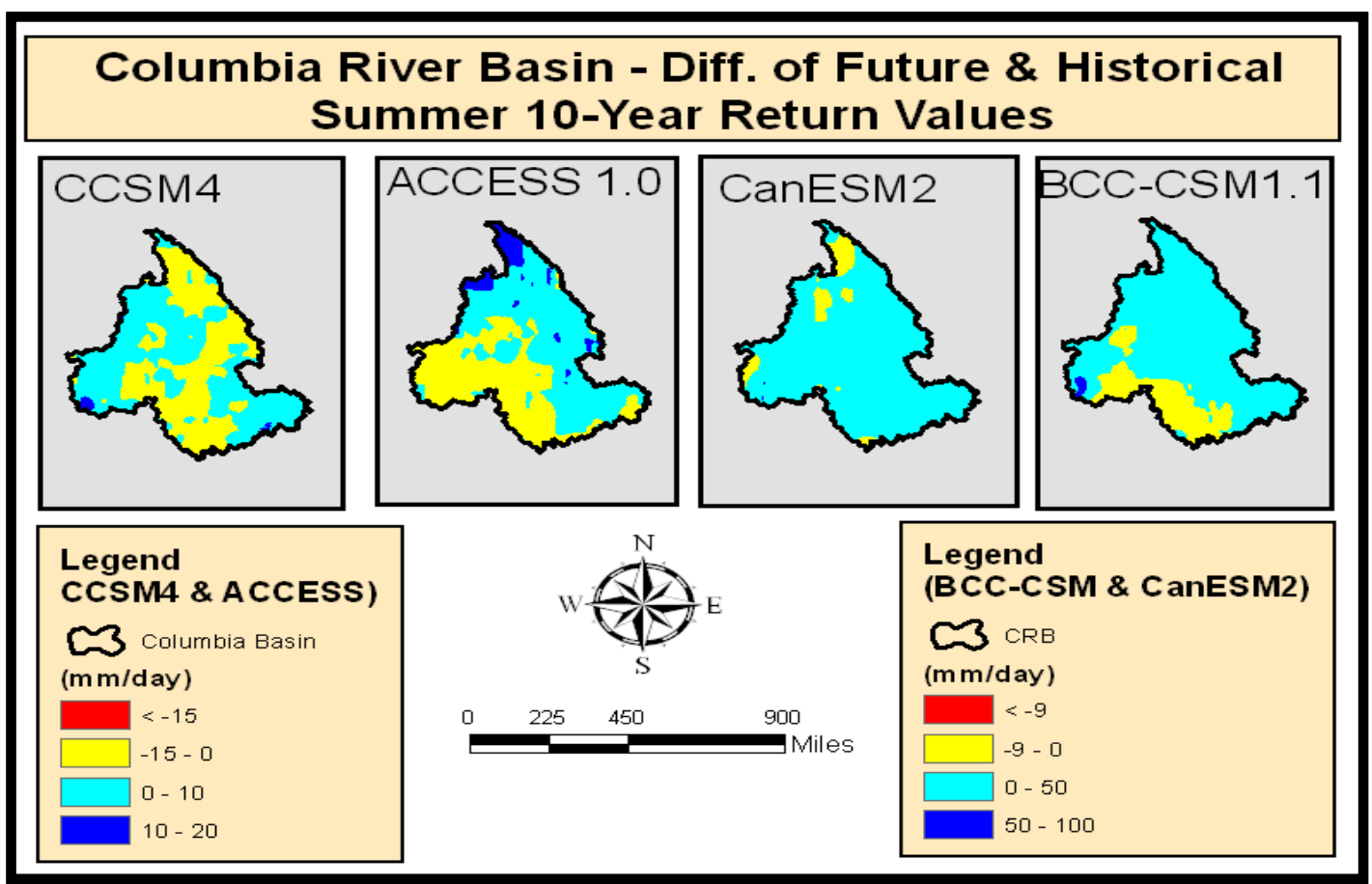

Figure 24: Difference of 10-years return levels (mm/day) for future period (2041-2070) and historical (1970-1999) in Summer Season (JJA) over the CRB

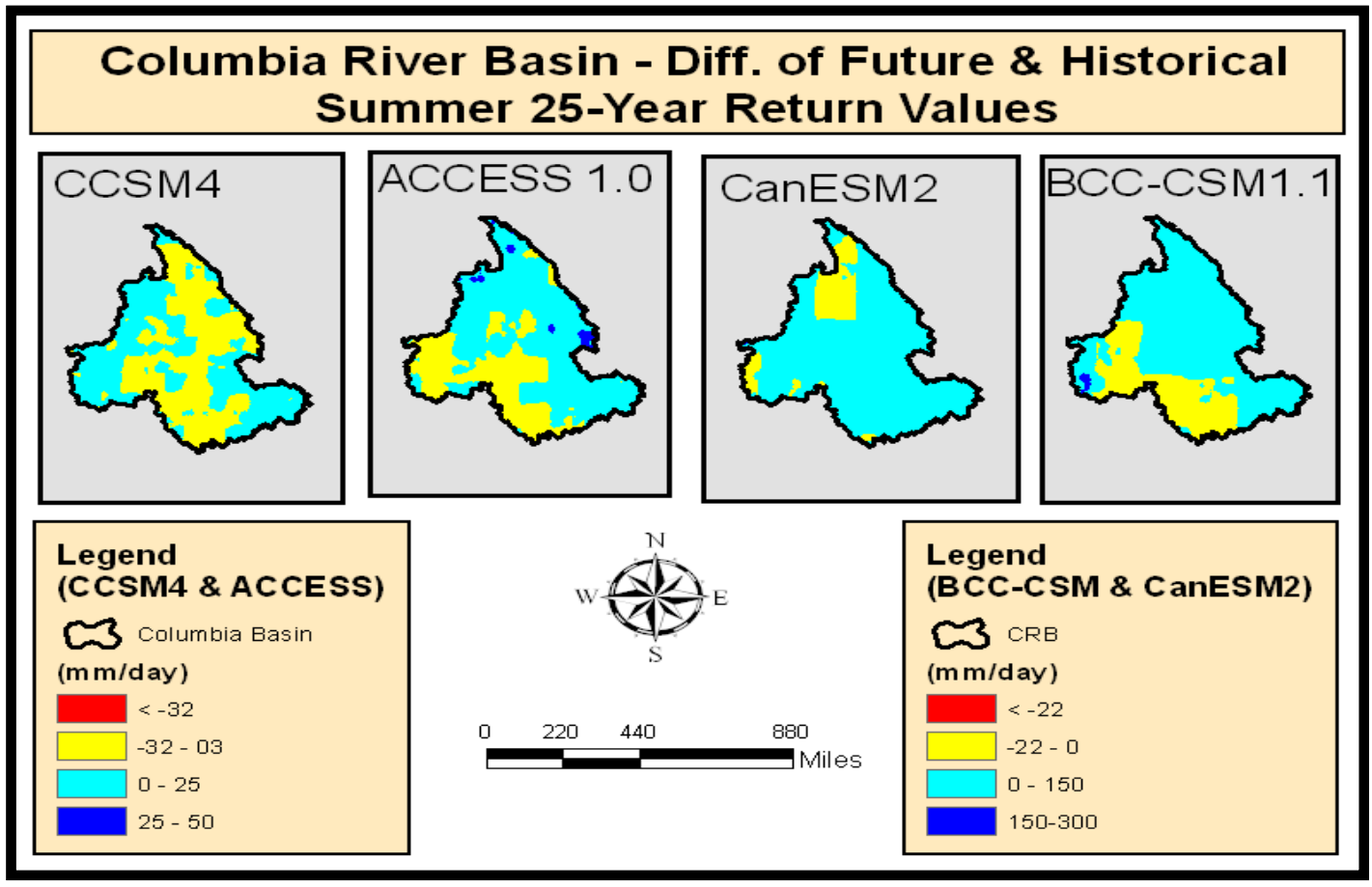

Figure 25: Difference of 25-years return levels (mm/day) for future period (2041-2070) and historical (1970-1999) in Summer Season (JJA) over the CRB 


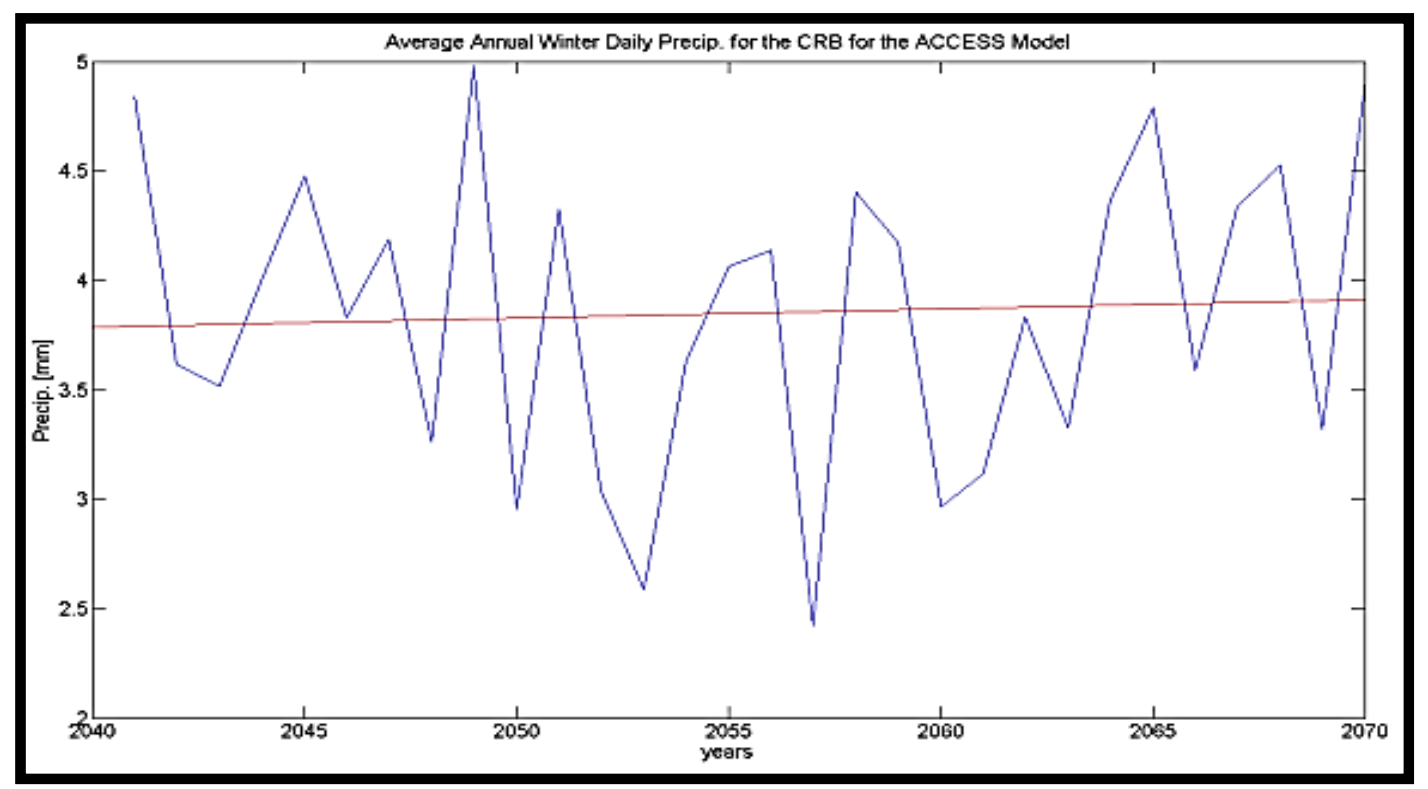

Figure 26: Annual Mean Winter (DJF) Precipitation (mm) calculated by ACCESS 1.0 model for the future period (2041-2070) over the CRB.

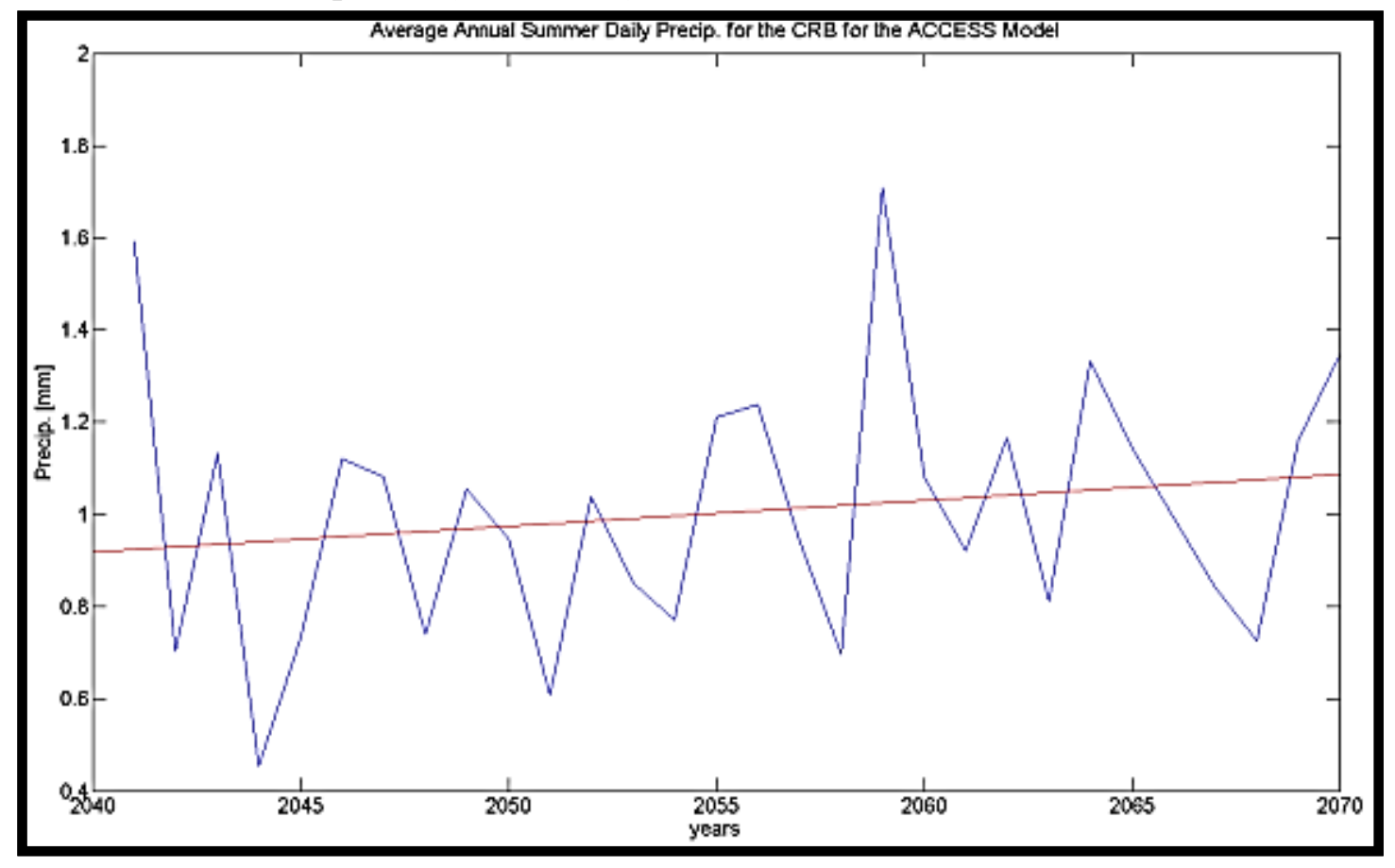

Figure 27: Annual Mean Summer (JJA) Precipitation (mm) calculated by ACCESS 1.0 model for the future period (2041-2070) over the CRB. 


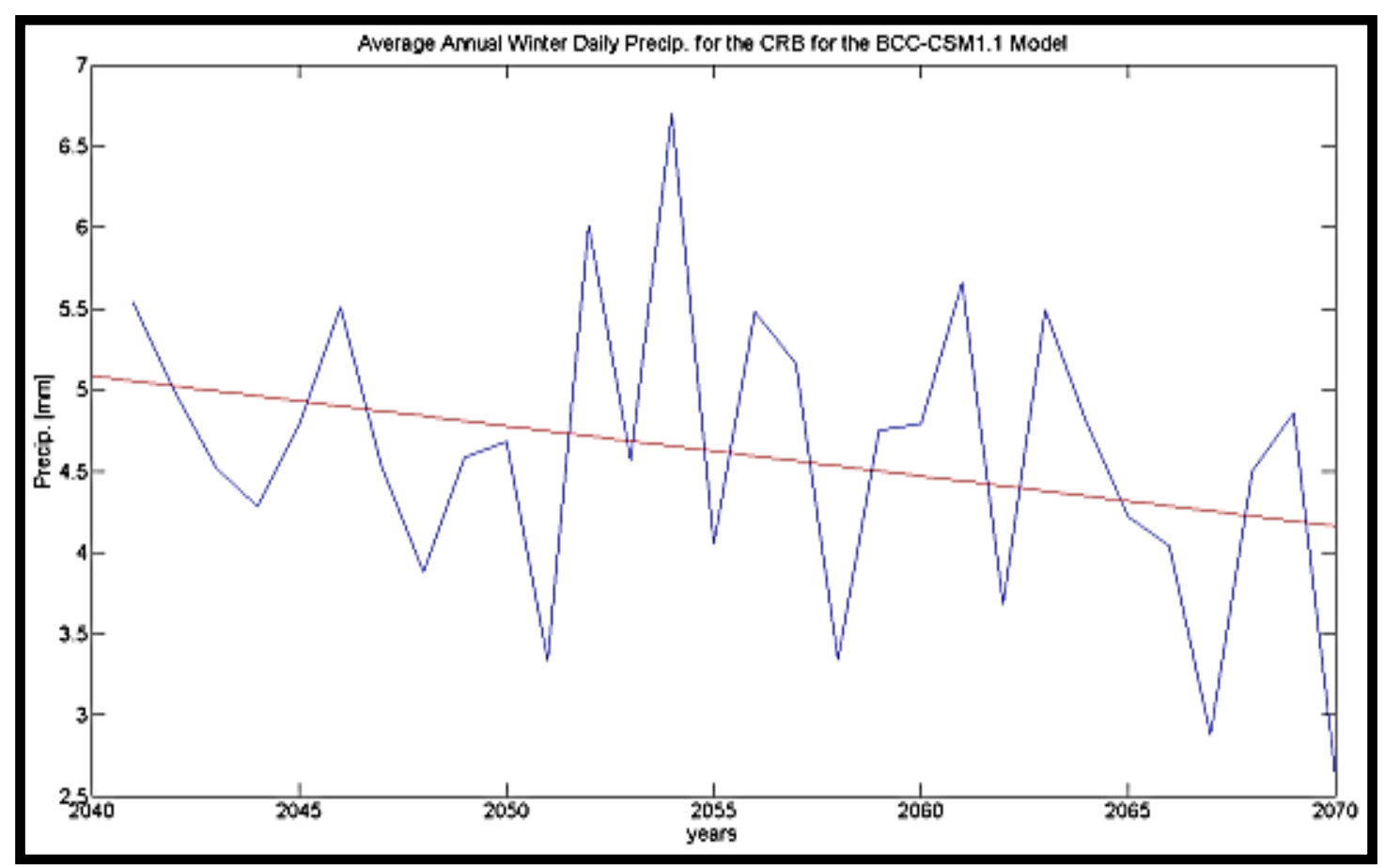

Figure 28: Annual Mean Winter (DJF) Precipitation (mm) calculated by BCC-CSM1.1 model for the future period (2041-2070) over the CRB.

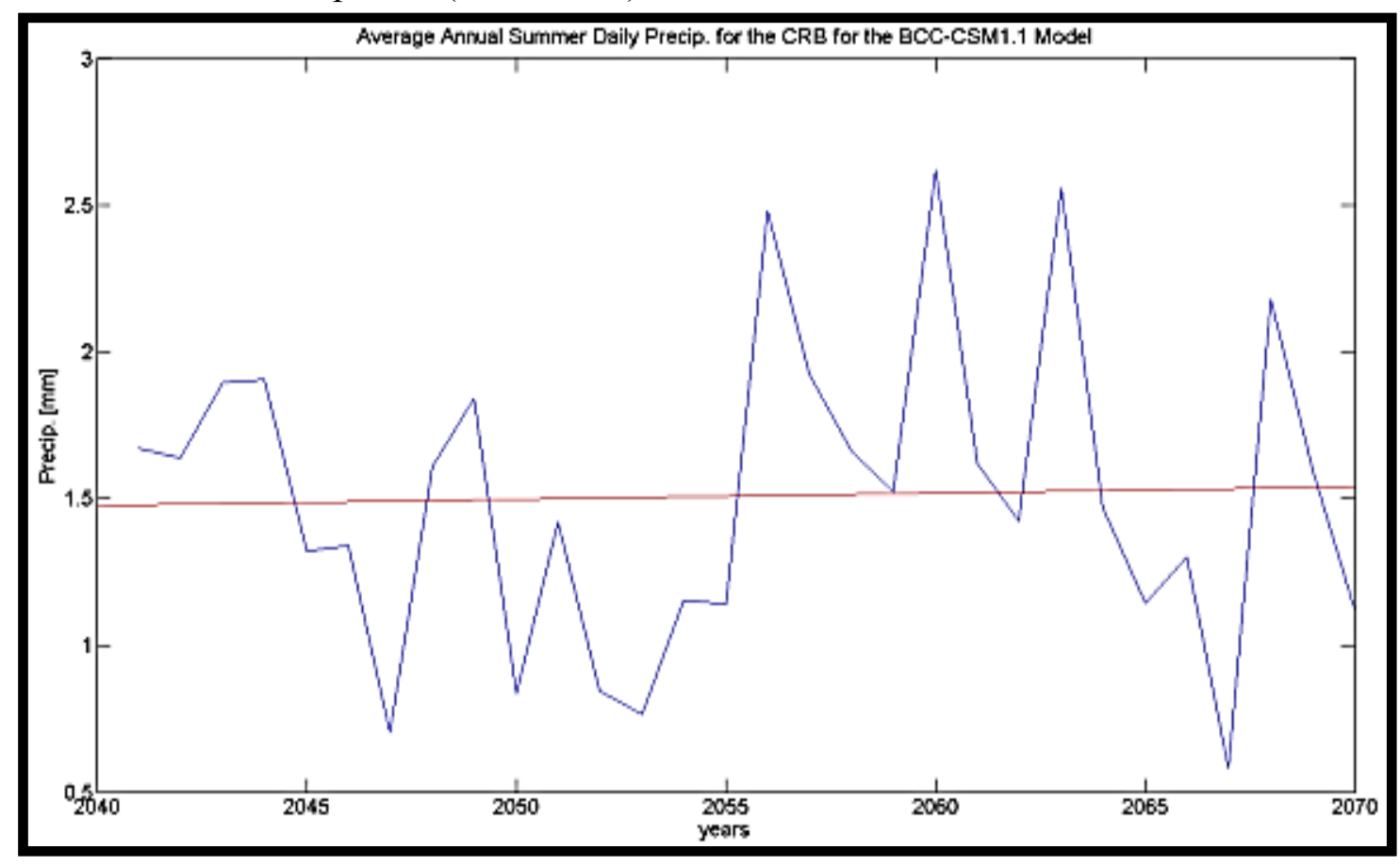

Figure 29: Annual Mean Summer (JJA) Precipitation (mm) calculated by BCC-CSM1.1 model for the future period (2041-2070) over the CRB. 


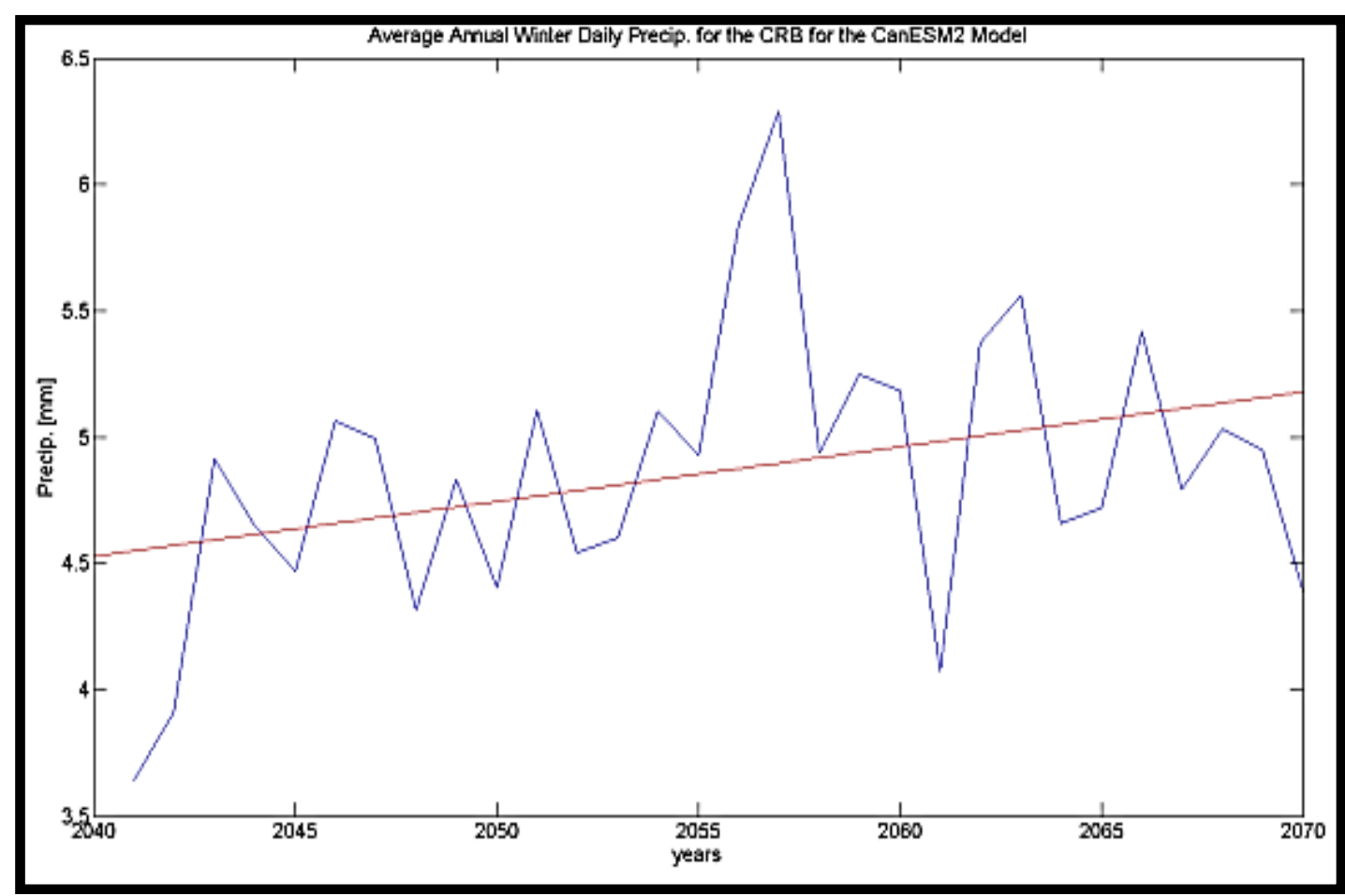

Figure 30: Annual Mean Winter (DJF) Precipitation (mm) calculated by CanESM2 model for the future period (2041-2070) over the CRB.

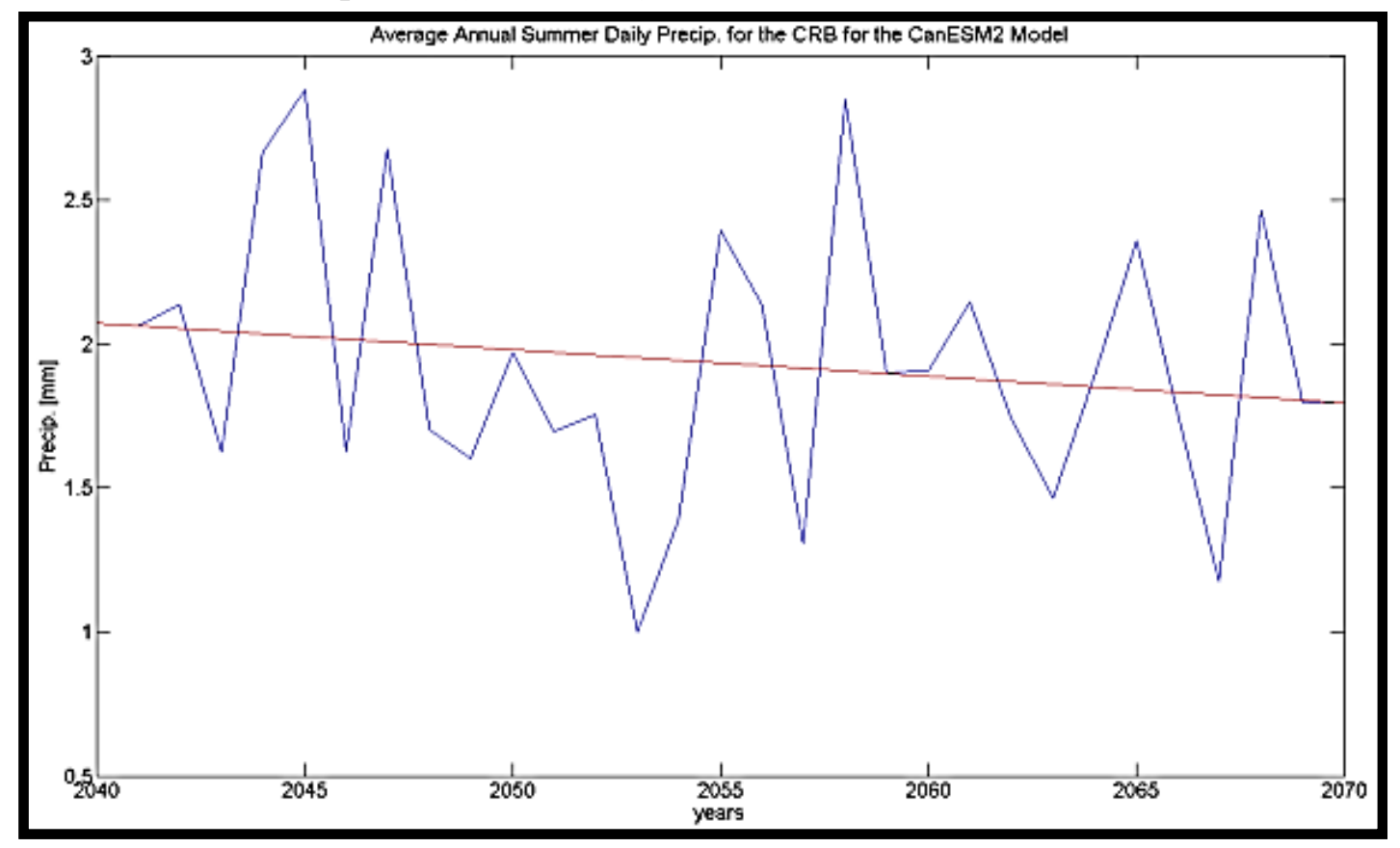

Figure 31: Annual Mean Summer (JJA) Precipitation (mm) calculated by CanESM2 model for the future period (2041-2070) over the CRB. 


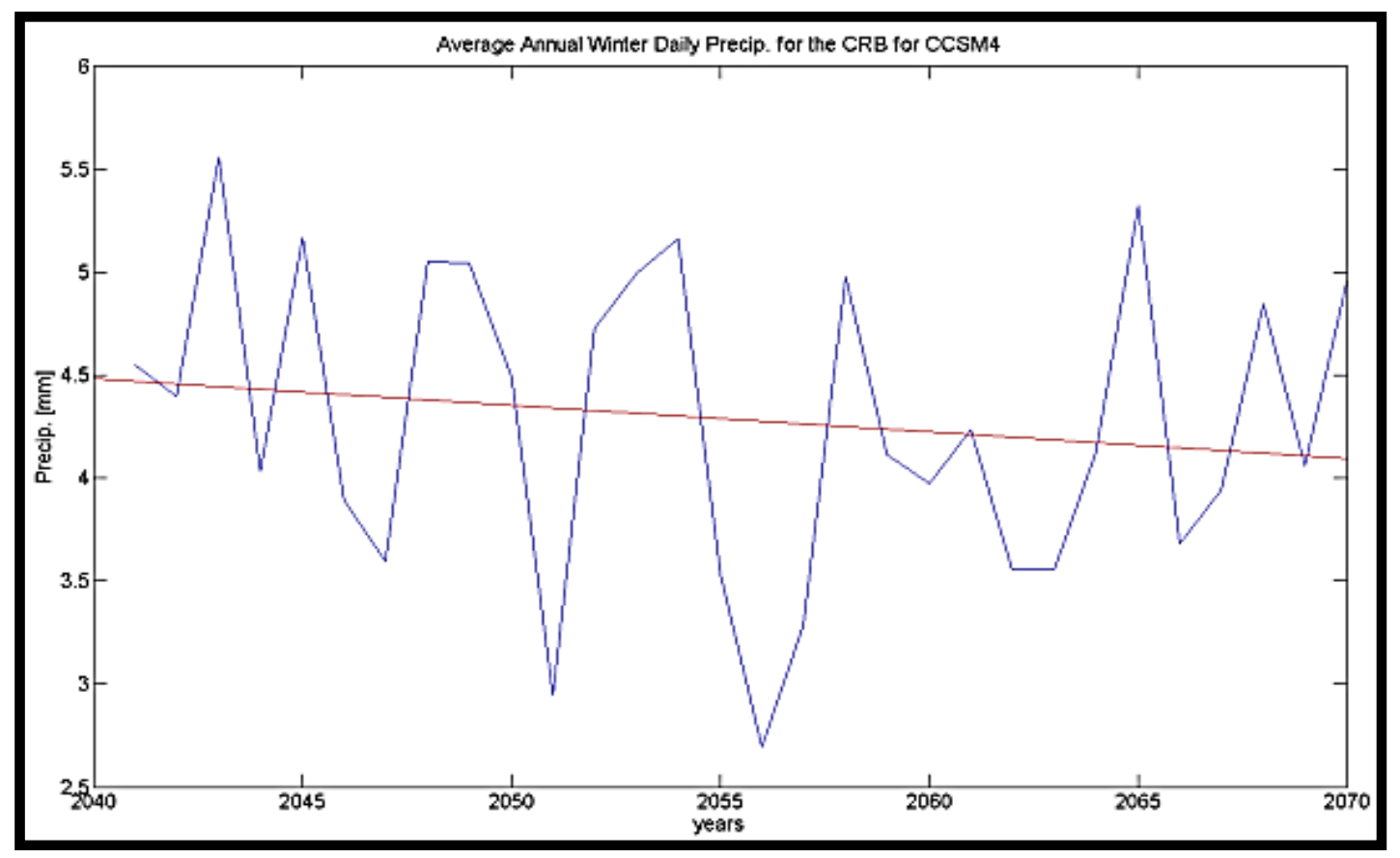

Figure 32: Annual Mean Winter (DJF) Precipitation (mm) calculated by CCSM4 model for the future period (2041-2070) over the CRB.

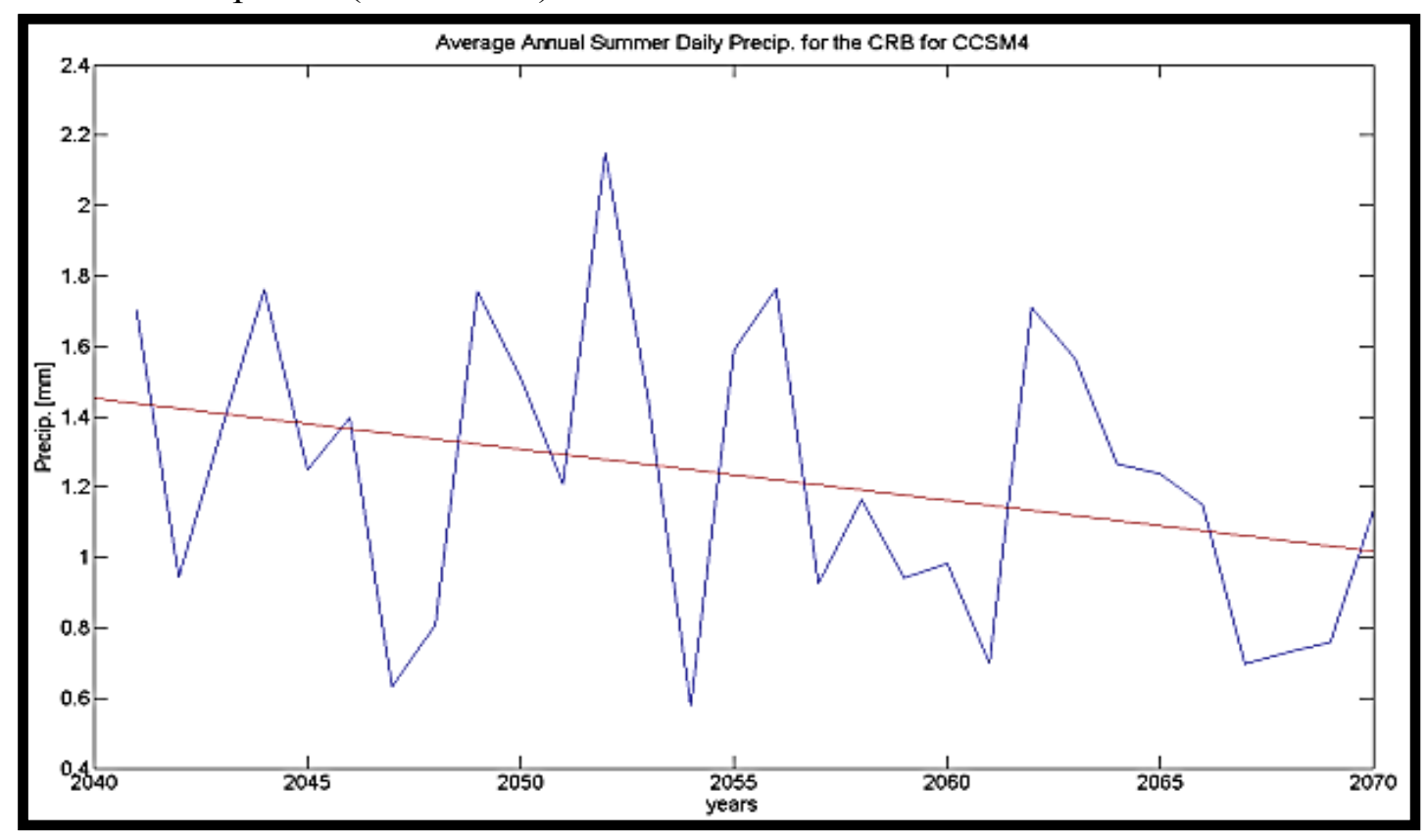

Figure 33: Annual Mean Summer (JJA) Precipitation (mm) calculated by CCSM4 model for the future period (2041-2070) over the CRB. 


\subsection{Changes in the Future Climate by Multi-Model Ensemble Data}

\subsubsection{Future changes in winter extreme precipitation (DJF)}

In this part, we estimated the intensity of winter extreme precipitation for the future period of 30 years (2041-2070) by using the multi-model ensemble average over the domain of the Columbia River Basin. The figures 34 through 37 represent the projected extreme winter precipitation for 2-year, 5-year, 10-year and 25-year return levels. The multi-model ensemble return levels are obtained by multiplying the BMA weights with the return levels obtained by GEV distribution described in the results and discussion section. After multiplying the weights, the return levels are combined together to get ensemble average values of the extreme precipitation. It can be observed from the results that the multi-model ensemble mean outperforms compared to the individual performance of climate models. The result of ensemble average return levels shows a consistent and significant increase in the extreme precipitation with the increase of the return periods. The increase in extreme precipitation is almost found in the whole domain of the CRB with maximum increase over the Canadian portion of the basin, west of the Cascade Mountain Range, Coastal range of Oregon and Washington States, scattered parts over Rocky Mountains.

\subsubsection{Future changes in Summer Extreme Precipitation (JJA)}

This section portrays the intensity of summer extreme precipitation for the future period of 30 years (2041-2070) by using the multi-model ensemble mean return levels over the domain of the Columbia River Basin. The figures 38 through 41 represent the 
projected extreme summer precipitation for the 2-year, 5-year, 10-year and 25-year return levels respectively. It can be observed from the results that the multi-model ensemble mean return levels outperforms compared to the individual performance of climate models obtained from GEV distribution. The ensemble average return levels show a significant increase in the extreme summer precipitation with the increase of the return periods. The increase in extreme precipitation is also found in the whole domain of the CRB with maximum increase over the Canadian portion of the basin, southwest of the Oregon State, Coastal range of Oregon and Washington States and scattered parts over Rocky Mountains.

\subsubsection{Future changes in the Mean Precipitation}

This section describes the future changes in the mean precipitation for both winter and summer seasons over the Columbia River Basin by using the multi-model ensemble average for the period of 30 years (2041-2070). The figures 42 through 43 represent the projected changes in the mean precipitation for both winter and summer seasons over the CRB. The MME average result shows that the mean precipitation is projected to decrease in the future from $4.46 \mathrm{~mm}$ in 2041 to $4.35 \mathrm{~mm}$ in $2070(-2.47 \%)$ in the winter season and from $1.49 \mathrm{~mm}$ in 2041 to $1.36 \mathrm{~mm}$ in $2070(-8.7 \%)$ in summer season. This result shows that the mean precipitation is projected to decrease more in summer season $(8.7 \%$ decrease). 


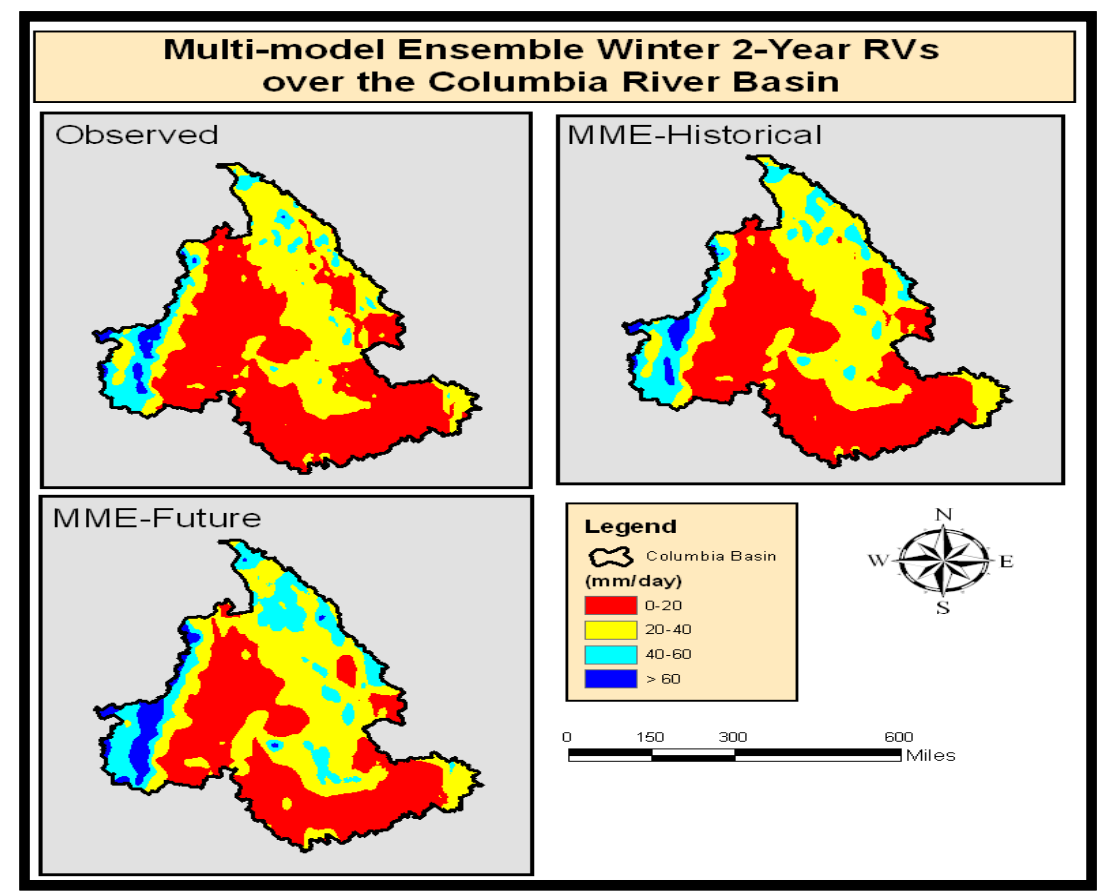

Figure 34: Multi-model ensemble winter (DJF) 2-year return levels (mm/day) for the historical (1970-1999) and future (2041-2070) periods over the CRB.

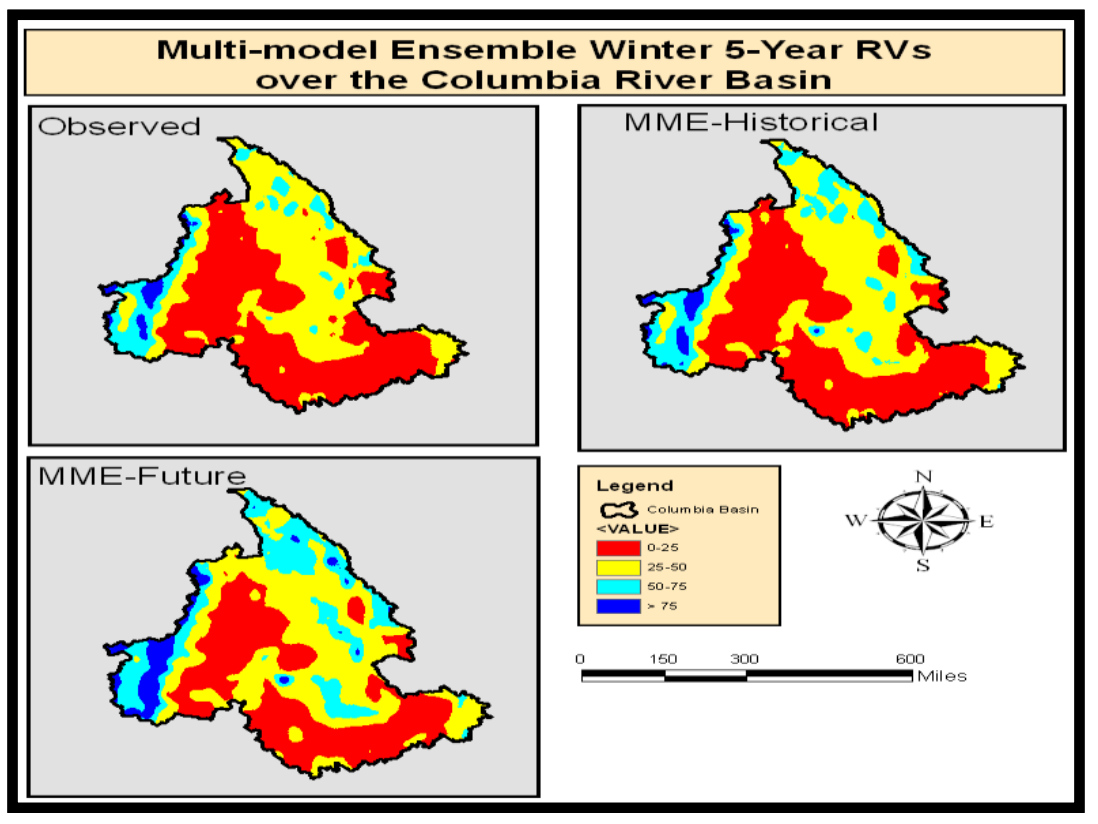

Figure 35: Multi-model ensemble winter (DJF) 5-year return levels (mm/day) for the historical (1970-1999) and future (2041-2070) periods over the CRB. 


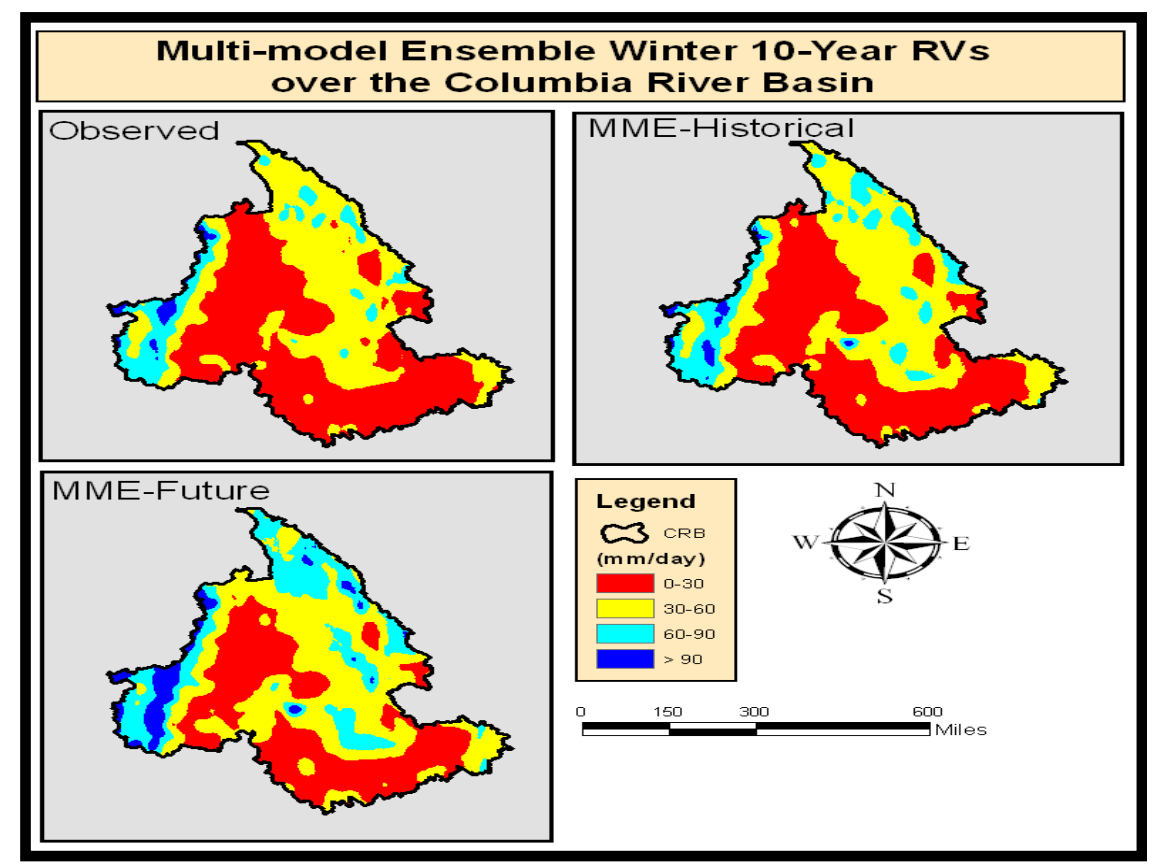

Figure 36: Multi-model ensemble winter (DJF) 10-year return levels (mm/day) for the historical (1970-1999) and future (2041-2070) periods over the CRB.

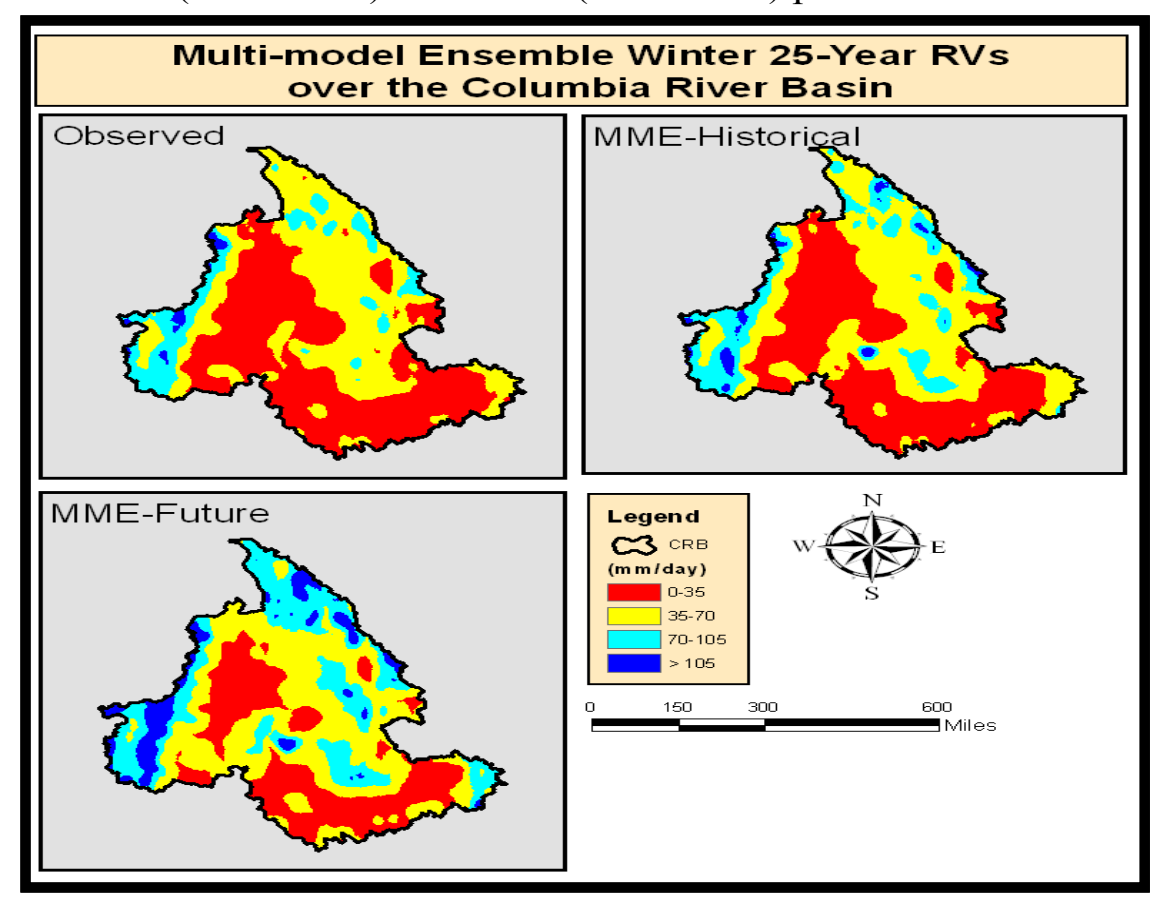

Figure 37: Multi-model ensemble winter (DJF) 25-year return levels (mm/day) for the historical (1970-1999) and future (2041-2070) periods over the CRB. 


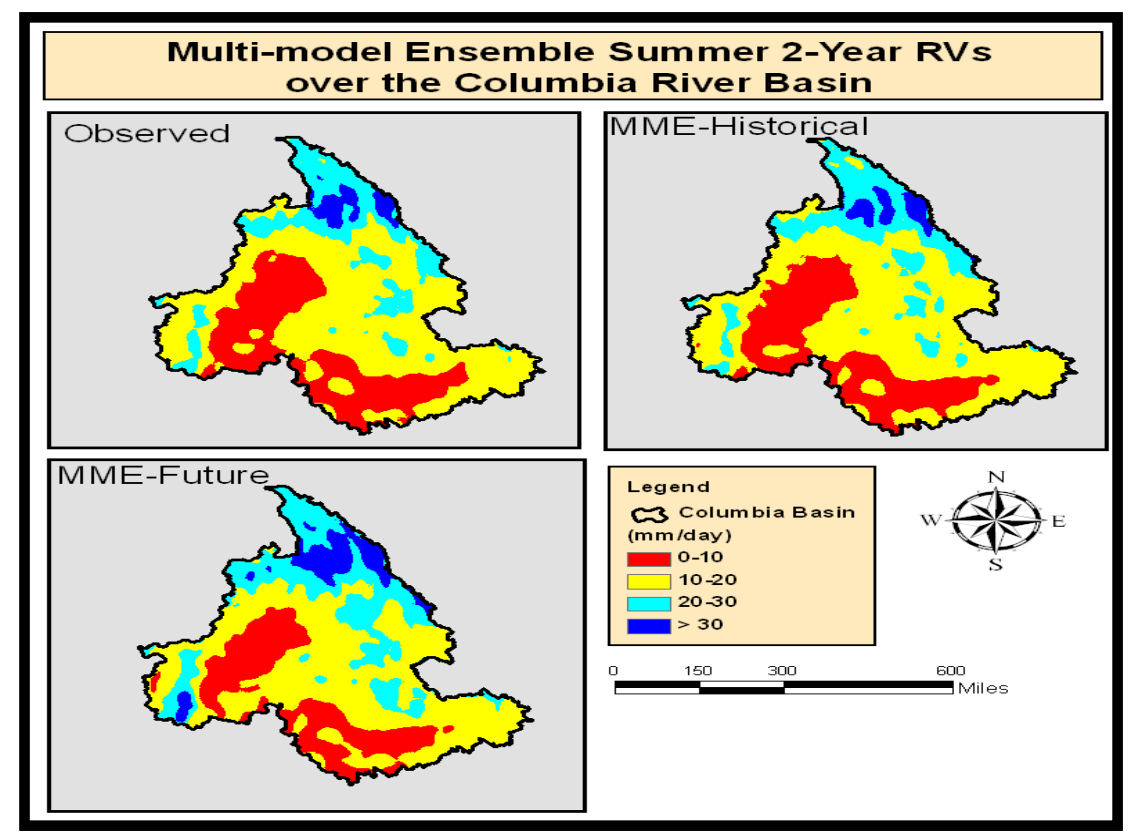

Figure 38: Multi-model ensemble average 2-year return levels (mm/day) in summer (JJA) for the historical (1970-1999) and future (2041-2070) periods over the CRB.

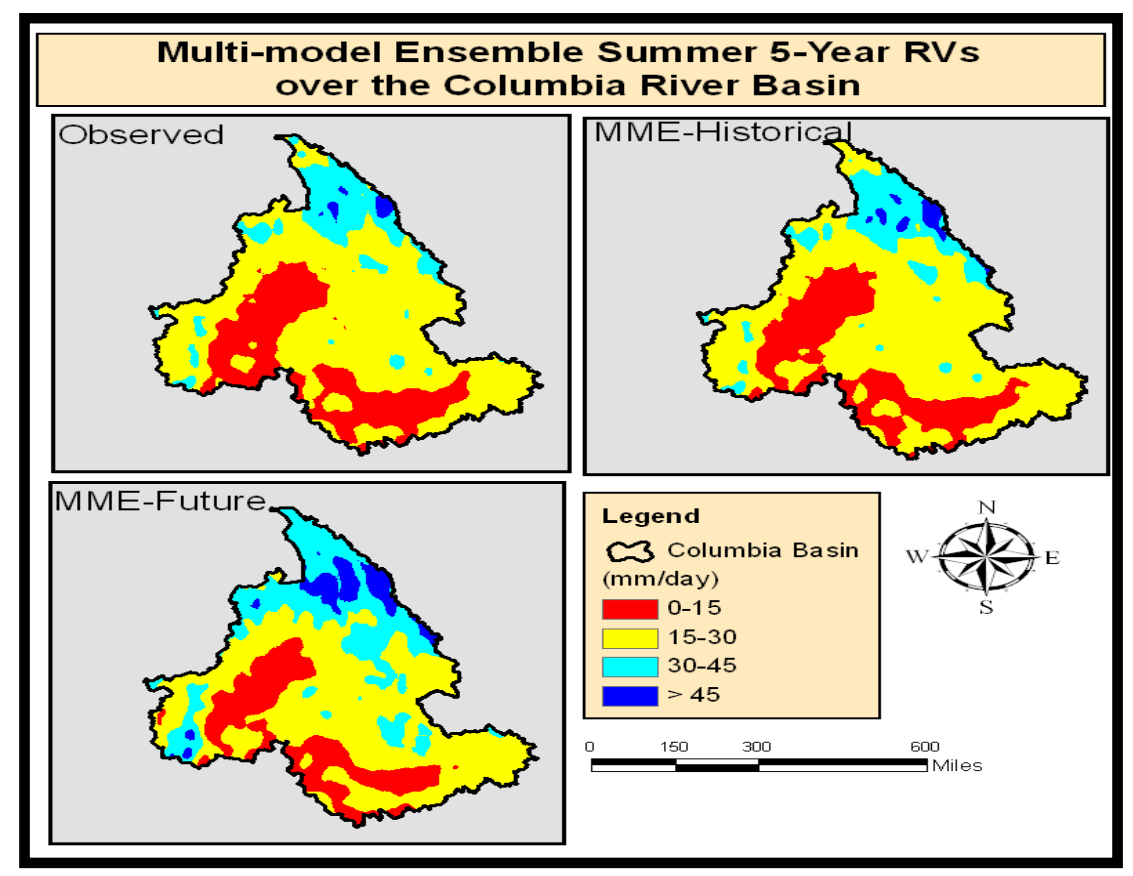

Figure 39: Multi-model ensemble average 5-year return levels (mm/day) in summer (JJA) for the historical (1970-1999) and future (2041-2070) periods over the CRB. 


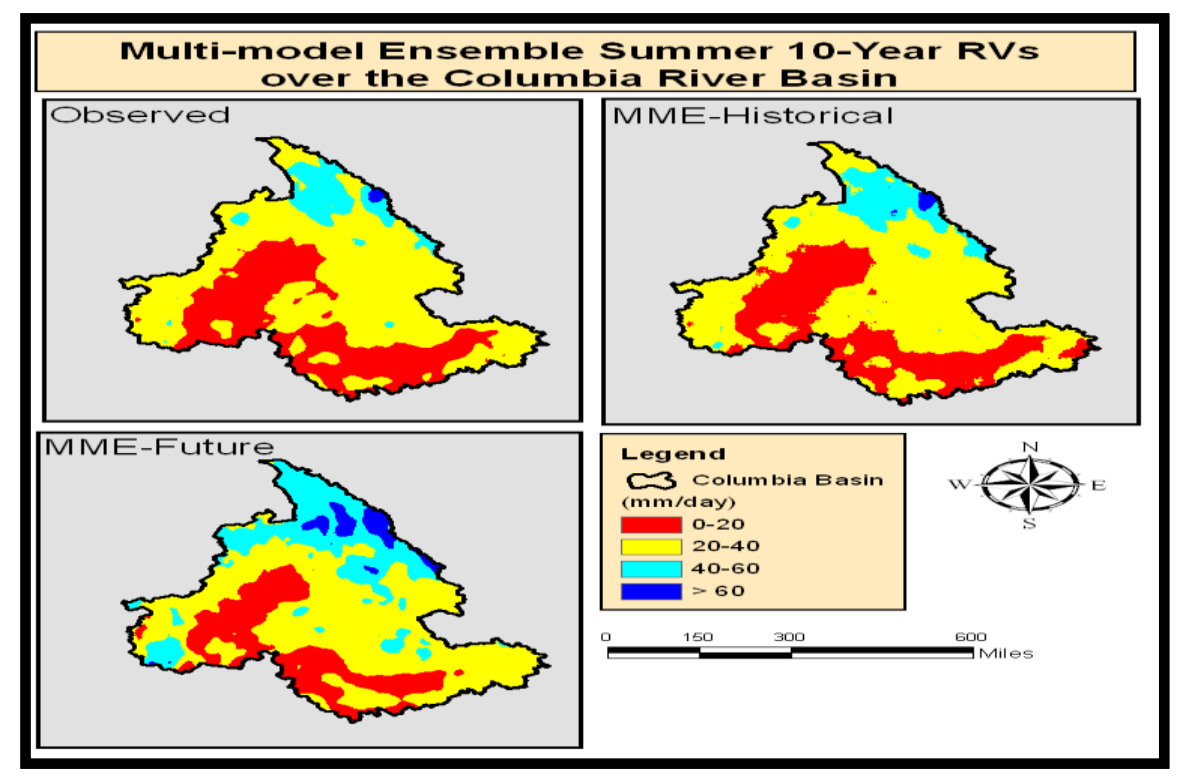

Figure 40: Multi-model ensemble average 10-year return levels (mm/day) in summer (JJA) for the historical (1970-1999) and future (2041-2070) periods over the CRB.

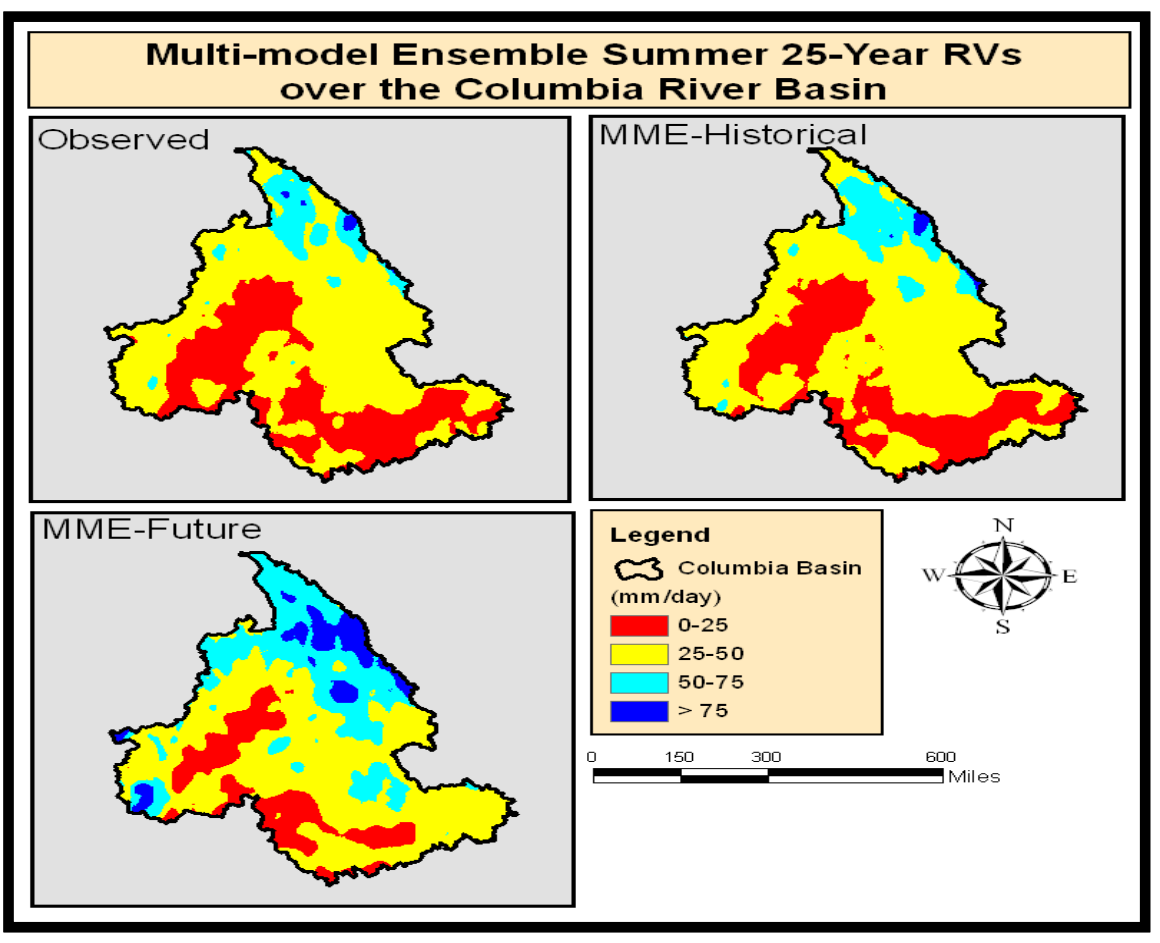

Figure 41: Multi-model ensemble average 25-year return levels (mm/day) in summer (JJA) for the historical (1970-1999) and future (2041-2070) periods over the CRB. 


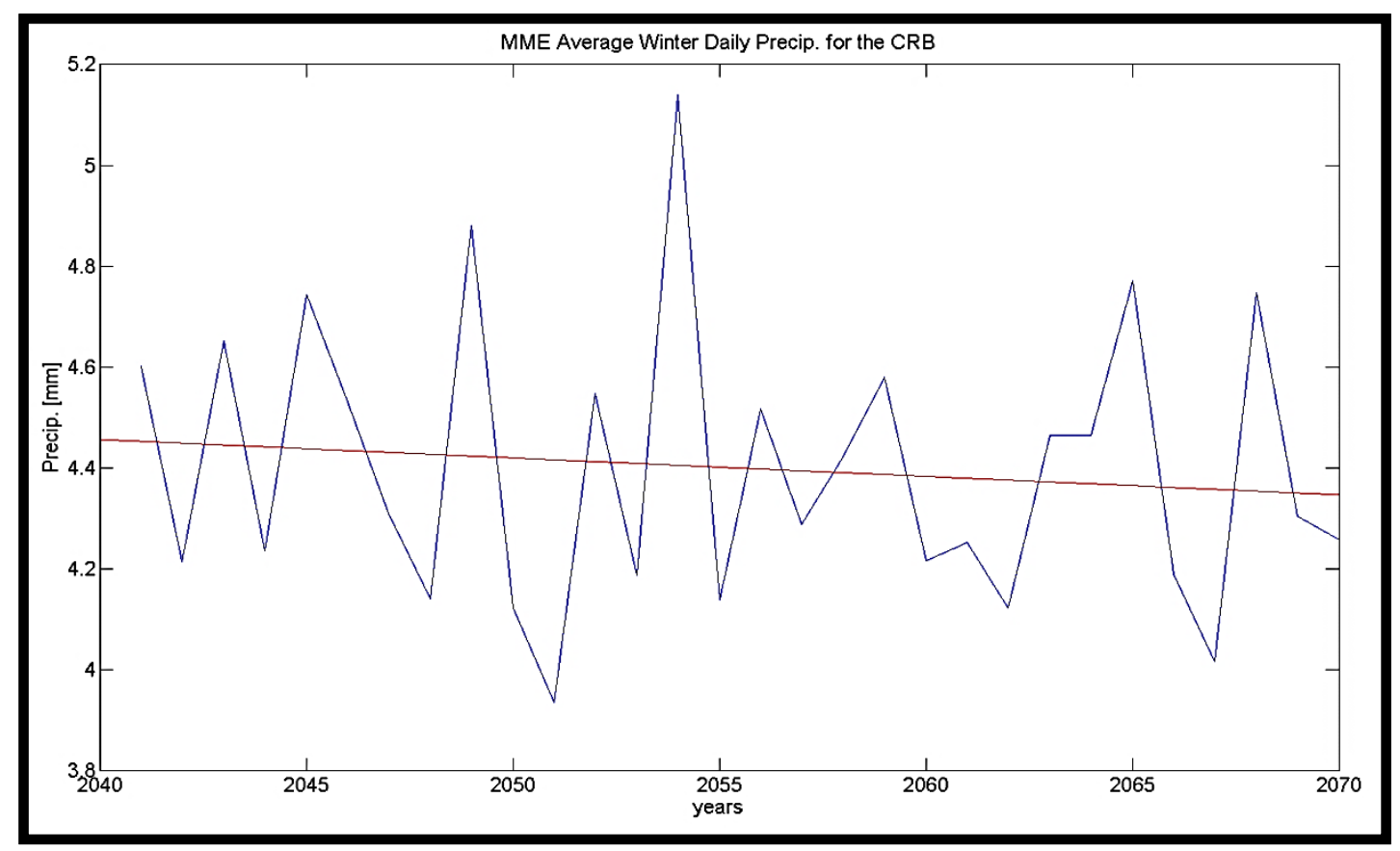

Figure 42: Multi-model ensemble average precipitation $(\mathrm{mm})$ in Winter (DJF) for the future period (2041-2070) over the CRB.

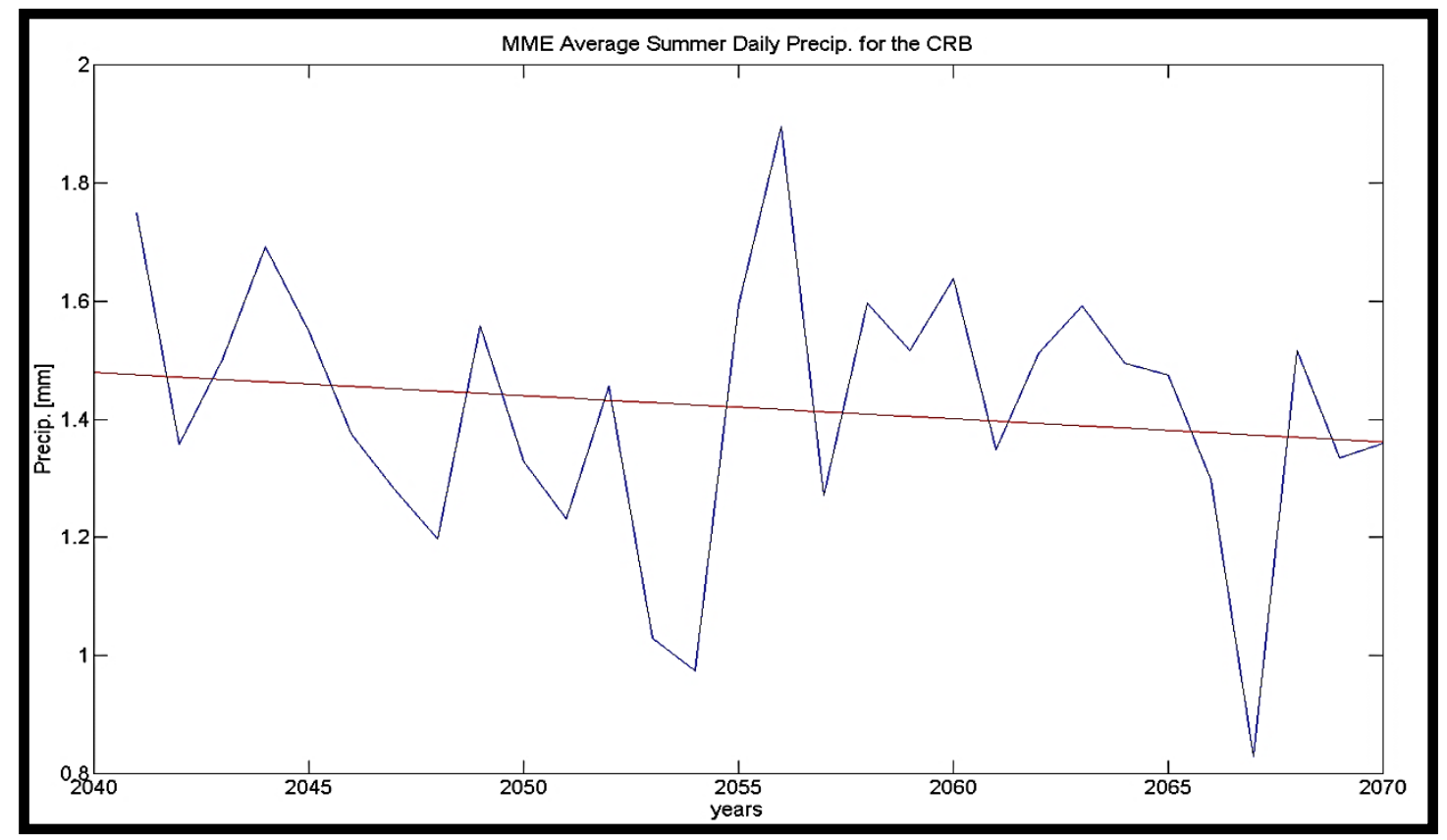

Figure 43: Multi-model ensemble average precipitation (mm) in Summer (JJA) for the future period (2041-2070) over the CRB. 


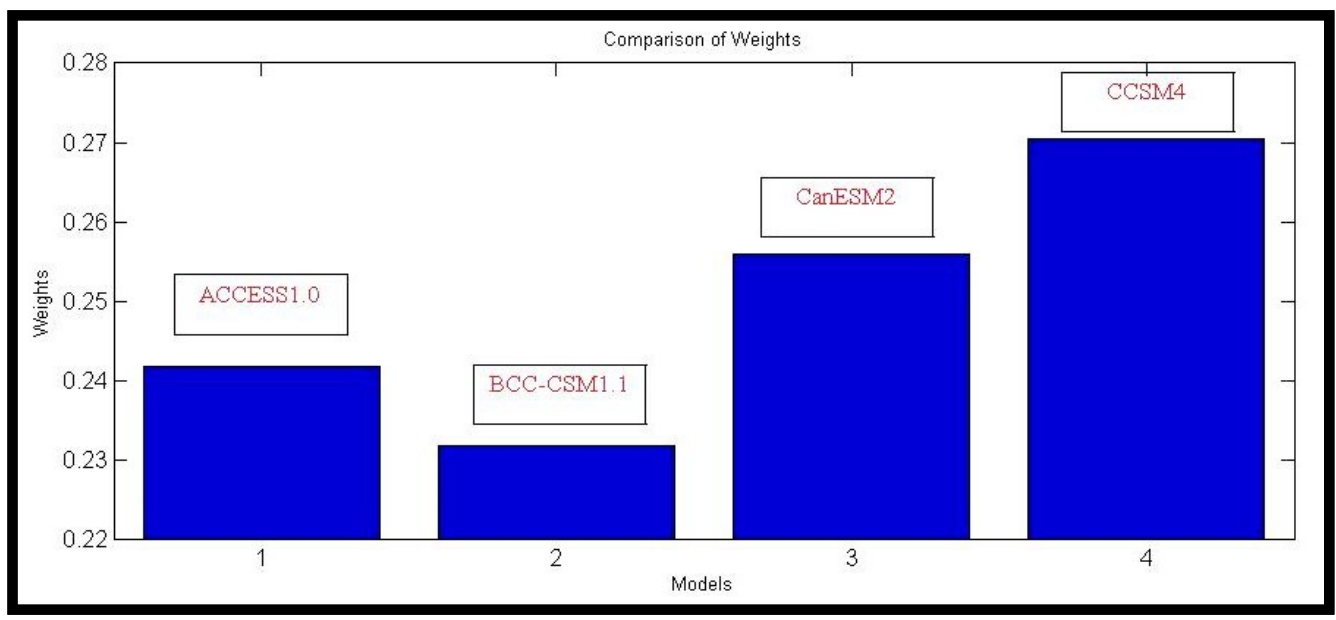

Figure 44: Multi-model ensemble average weights for each model.

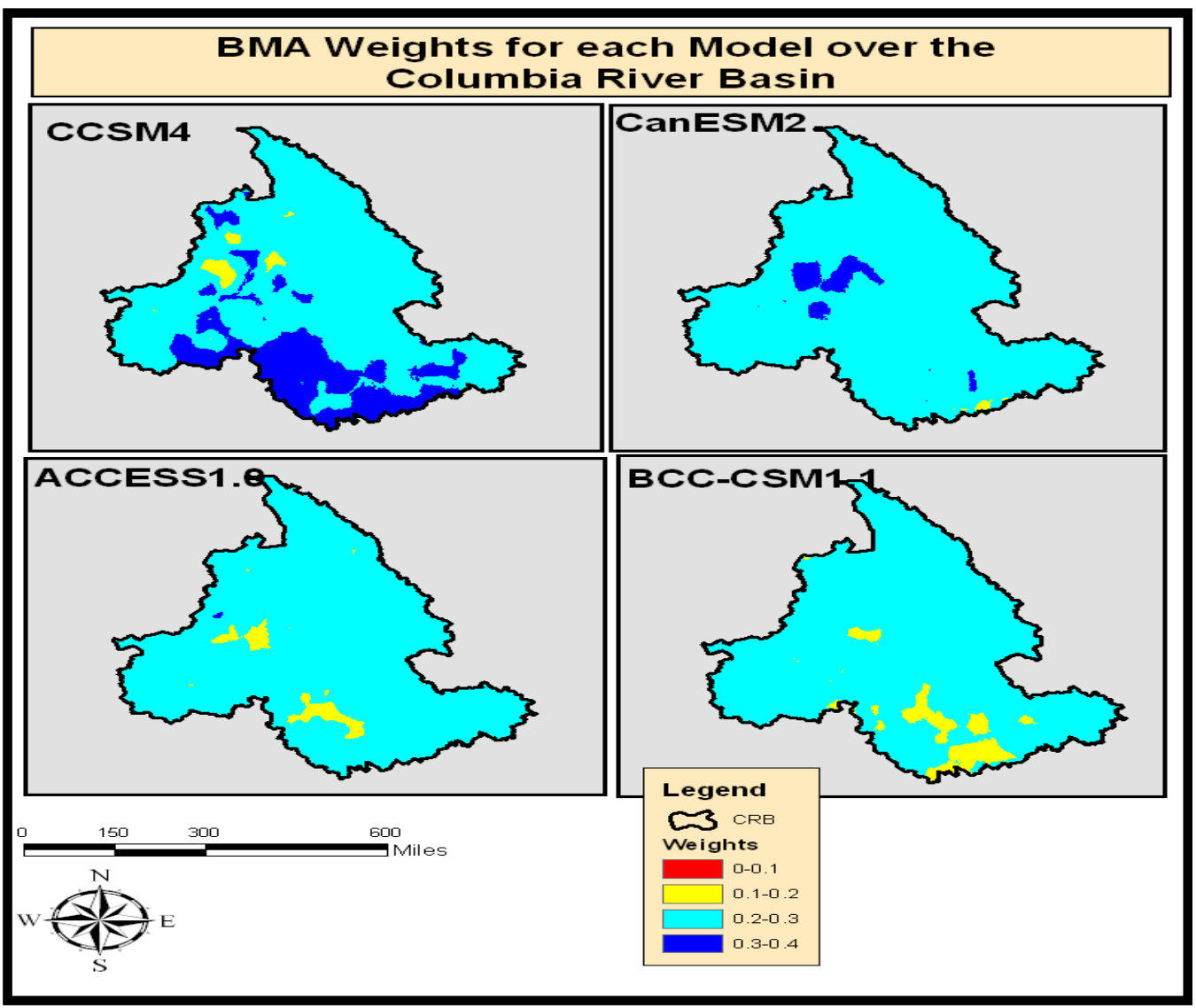

Figure 45: Multi-model ensemble average weights for each model. 


\section{Summary, Conclusion and Outlook}

This study evaluated the extreme and average precipitation events for winter and summer season over the Columbia River Basin (CRB) by simulating four CMIP5 models for the historical period (1970-1999) and future period (2041-2070). The CMIP5 simulations data was collected from the Climate Model Intercomparison Project Phase 5 archive (CMIP5). The RCP85 scenario has been adopted for the future GHG emission scenario. The CMIP5 contains a great number of model output to boost the research and understand the climate processes and their effects. These data will provide a basis of Intergovernmental Panel on Climate Change (IPCC) Fifth Assessment Report (AR5). In spite of some improvements in spatial resolution and other advances in climate models, considerable bias existed in all four climate models, therefore downscaling was performed to remove the bias and downscale the models. In this research, the future changes in the extreme precipitation events for both seasons were evaluated by the tyears return levels.

We estimated the intensity of extreme precipitation for both winter and summer seasons by using the GEV distribution and multi-model ensemble average over the domain of the Columbia River Basin. The results of both methods are described in the results and discussion section. It was noticed that multi-model ensemble mean outperformed compared to the individual performance of climate models. The four CMIP5 models performed very well at simulating precipitation extremes in the winter season which was as expected. In terms of simulating mean winter precipitation, two models BCC-CSM1.1 and CCSM4 performed really well and showed a decrease, 
whereas the ACCESS1.0 and CanESM2 showed an increase and that may not be consistent with other studies which shows that the mean precipitation is projected to be decreasing (Cohen et al., 2000; Dominguez et al., 2012; Karl et al., 2009; Kharin et al., 2007; Solomon et al., 2007).

The four CMIP5 models analyzed in this study showed heterogeneous spatial pattern of summer extreme precipitation over the CRB for the future period as discussed in the results section. Comparing the general performance of the climate models in simulating summer extreme precipitation, the CCSM4 and BCC-CSM1.1 models performed really well. However, in terms of simulating mean summer precipitation, two models CanESM2 and CCSM4 performed well and showed the decrease, whereas the ACCESS1.0 and BCC-CSM1.1 showed increase that may not be consistent with other studies which shows that the mean precipitation is projected to be decreasing (Cohen et al., 2000; Dominguez et al., 2012; Karl et al., 2009; Kharin et al., 2007; Solomon et al., 2007). Looking at these results of the four CMIP5 models, the CCSM4 model performs really well at simulating both extreme precipitation and mean precipitation. Moreover, in terms of multi-model ensemble average, the weights calculated by the BMA (weights are displayed in the figure 44) describe that CCSM4 performs better than all three models; and after the CCSM4 model, the CanESM2 model has more weight of 0.2559 , then the ACCESS1.0 model has weight 0.2418 , and in the last, the BCC-CSM1.1 model performs poor with weight of 0.2319 .

The MME average return levels show a consistent and significant increase in the extreme precipitation with the increase of the return periods in both seasons in the entire 
basin. The MME average shows a generalized trend of increase in extreme precipitation throughout the domain of the $\mathrm{CRB}$, but enormous precipitation is found over the Cascade Range, Coastal Range of Oregon and Washington State, Rocky Mountains Range and the Canadian portion of the CRB, as simulated by other studies (Cohen et al., 2000; Dominguez et al., 2012; Karl et al., 2009; Kharin et al., 2007; Solomon et al., 2007).

\subsection{Lessons Learned}

* The bias correction using quantile mapping method has shown some discrepancy in its behavior mainly due to its blind matching approach explained in (Madadgar et al., 2012), where they showed that using a multivariate method based on copula functions can post process and bias correct the model simulation more effectively. Therefore, future studies are encouraged to incorporate such more advanced and effective bias correction methods.

* The multi-model ensemble average outperformed, so it is recommended that more models should be added in such type of studies. In addition, these types of studies should be compared with the CMIP3 and NARCCAP (North American Regional Climate Change Assessment Program) ensembles to have a broader analysis regarding performance of the models and get reliable future predictions about climate change.

The Columbia River is dominated by the glacial snowmelt, so the increase in the intensity of winter extreme precipitation and decrease in the mean precipitation in the future period (2041-2070), as simulated by four CMIP5 models, is expected to 
contribute to the flooding in the low lying areas especially in the west of the Cascades Range. Therefore, the population living in the west of the Cascades Range is under serious threat of the extreme weather events.

* In addition, the climate change shift could have serious implications on transboundary water issues in between the United States and Canada. The vulnerability of the Columbia River Basin totally depends upon the adaptation policies to effectively cope the adverse effects of the extreme events due climate change. Rise in the extreme precipitation and decrease in the mean precipitation could affect the seasonal availability of the water, and results in increasing water demand among different sectors such as agricultural, industrial, municipal and ecological. 


\section{Acknowledgement:}

“We acknowledge the World Climate Research Program's Working Group on Coupled Modeling, which is responsible for CMIP, and we thank the climate modeling groups (listed in table 01) for producing and making available their model output. For CMIP the U.S. Department of Energy's Program for Climate Model Diagnosis and Intercomparison provides coordinating support and led development of software infrastructure in partnership with the Global Organization for Earth System Science Portals.” 


\section{References}

Ajami, N.K., Duan, Q. and Sorooshian, S., 2007. An integrated hydrologic Bayesian multimodel combination framework: Confronting input, parameter, and model structural uncertainty in hydrologic prediction. Water Resources Research, 43(1): W01403, doi:10.1029/2005WR004745.

Arnell, N.W., 1999. Climate change and global water resources. Global environmental change, 9: S31-S49.

Bates, J.M. and Granger, C.W.J., 1969. The combination of forecasts. Operation Res Quart: 451-468.

Bi, D., M. Dix, S. Marsland, T. Hirst, S. O'Farrell and coauthors, 2012. ACCESS: The Australian Coupled Climate Model for IPCC AR5 and CMIP5. AMOS conference, 2012, sydney, Australia (available online at https://wiki.csiro.au/display/ACCESS/ACCESS+Publications). 43(1).

Cayan, D.R., Kammerdiener, S.A., Dettinger, M.D., Caprio, J.M. and Peterson, D.H., 2001. Changes in the onset of spring in the western United States. BULLETINAMERICAN METEOROLOGICAL SOCIETY, 82(3): 399-416.

Chylek, P., J. Li, M. K. Dubey, M. Wang, and G. Lesins,, 2011. Observed and model simulated 20th Century Arctic temperature variability: Canadian Earth System Model CanESM2. 11(8): 22907-22893.

Clarke, L. et al., 2007. Scenarios of greenhouse gas emissions and atmospheric concentrations, Sub-report 2.1A of Synthesis and Assessment Product 2.1 by the U.S. Climate Change Science Program and the Subcommittee on Global Change Research. Department of Energy, Office of Biological \& Environmental Research, Washington, DC, $154 \mathrm{pp}$.

Cohen, S.J., Miller, K.A., Hamlet, A.F. and Avis, W., 2000. Climate change and resource management in the Columbia River Basin. Water international, 25(2): 253-272.

Coles, S., 2001. An introduction to statistical modeling of extreme values. Springer, New York, $208 \mathrm{pp}$.

Cooley, D., 2009. Extreme value analysis and the study of climate change. Climatic change, 97(1-2): 77-83.

Davidson, H.C. and Paisley, R.K., 2009. The Columbia River Basin: Issues and Driving Forces within the Columbia River Basin. (Available at http://www.ccrf.ca/assets/docs/pdf/issues-driving-forces-ccrf-final-march2009.pdf (accessed on April 13, 2013).): 50 pp.

Del Genfo, A.D., Lacis, A.A. and Ruedy, R.A., 1991. Simulations of the effect of a warmer climate on atmospheric humidity. Nature, 351(6325): 382-385.

Dickinson, J.P., 1973. Some statistical results in the combination of forecasts. Journal of the Operational Research Society, 24(2): 253-260.

Dominguez, F., Rivera, E., Lettenmaier, D.P. and Castro, C.L., 2012. Changes in winter precipitation extremes for the western United States under a warmer climate as simulated by regional climate models. Geophysical Research Letters, 39(5): L05803, DOI: 10.1029/2011GL050762. 
Duan, Q., Ajami, N.K., Gao, X. and Sorooshian, S., 2007. Multi-model ensemble hydrologic prediction using Bayesian model averaging. Advances in Water Resources, 30(5): 1371-1386.

Easterling, D.R. et al., 2000. Climate extremes: observations, modeling, and impacts. Science, 289(5487): 2068-2074.

Ekstrom, M., Fowler, H.J., Kilsby, C.G. and Jones, P.D., 2005. New estimates of future changes in extreme rainfall across the UK using regional climate model integrations. 2. Future estimates and use in impact studies. Journal of Hydrology, 300(1): 234-251.

El Adlouni, S., Ouarda, T., Zhang, X., Roy, R. and Bobee, B., 2007. Generalized maximum likelihood estimators for the nonstationary generalized extreme value model. Water Resources Research, 43(3): W03410, doi:10.1029/2005WR004545.

Emori, S. and Brown, S.J., 2005. Dynamic and thermodynamic changes in mean and extreme precipitation under changed climate. Geophysical Research Letters, 32(17): L17706, DOI: 10.1029/2005GL023272.

Fernandez, C., Ley, E. and Steel, M.F.J., 2001. Benchmark priors for Bayesian model averaging. Journal of Econometrics, 100(2): 381-427.

Fisher, R.A. and Tippett, L.H.C., 1928. Limiting forms of the frequency distribution of the largest or smallest member of a sample, Mathematical Proceedings of the Cambridge Philosophical Society. Cambridge Univ Press, pp. 180-190.

Fowler, H.J., Blenkinsop, S. and Tebaldi, C., 2007. Linking climate change modelling to impacts studies: recent advances in downscaling techniques for hydrological modelling. International Journal of Climatology, 27(12): 1547-1578.

Fowler, H.J., Ekstrom, M., Kilsby, C.G. and Jones, P.D., 2005. New estimates of future changes in extreme rainfall across the UK using regional climate model integrations. 1. Assessment of control climate. Journal of Hydrology, 300(1): 212233.

Fujino, J., Nair, R., Kainuma, M., Masui, T. and Matsuoka, Y., 2006. Multi-gas mitigation analysis on stabilization scenarios using AIM global model. The Energy Journal(Special Issue\# 3): 343-354.

Gent, P.R., and Coauthors, 2011. The Community Climate System Model Version 4. J. Climate, 11(8)(24): 4973-4991.

Gnedenko, B., 1943. Sur la distribution limite du terme maximum d'une serie aleatoire. The Annals of Mathematics, 44(3): 423-453.

Groisman, P.Y., Knight, R.W. and Karl, T.R., 2001. Heavy precipitation and high streamflow in the contiguous United States: Trends in the twentieth century. Bulletin of the American Meteorological Society, 82(2): 219-246.

Gumbel, E.J., 1958. Statistics of extremes. Columbia University Press, 375 pp

Halmstad, A., Najafi, M.R. and Moradkhani, H., 2012. Analysis of precipitation extremes with the assessment of regional climate models over the Willamette River Basin, USA. Hydrological Processes: DOI: 10.1002/hyp.9376.

Held, I.M. and Soden, B.J., 2000. Water Vapor Feedback and Global Warming 1. Annual review of energy and the environment, 25(1): 441-475. 
Hibbard, K.A., Meehl, G.A., Cox, P.M. and Friedlingstein, P., 2007. A strategy for climate change stabilization experiments. Eos, Transactions American Geophysical Union, 88(20): 217-221.

Hoeting, J.A., Madigan, D., Raftery, A.E. and Volinsky, C.T., 1999. Bayesian model averaging: A tutorial. Statistical science, 14(4): 382-401.

Hsu, K.1., Moradkhani, H. and Sorooshian, S., 2009. A sequential Bayesian approach for hydrologic model selection and prediction. Water Resources Research, 45(12): W00B12, doi:10.1029/2008WR006824.

Huntington, T.G., 2006. Evidence for intensification of the global water cycle: review and synthesis. Journal of Hydrology, 319(1): 83-95.

Jenkinson, A.F., 1955. The frequency distribution of the annual maximum (or minimum) values of meteorological elements. Quarterly Journal of the Royal Meteorological Society, 81(348): 158-171.

Jung, I.W., Chang, H. and Moradkhani, H., 2011. Quantifying uncertainty in urban flooding analysis considering hydro-climatic projection and urban development effects. Hydrology and Earth System Sciences, 15(2): 617-633.

Karl, T.R., Melillo, J.M. and Peterson, T.C., 2009. Global climate change impacts in the United States. Cambridge University Press.

Katz, R.W., Parlange, M.B. and Naveau, P., 2002. Statistics of extremes in hydrology. Advances in water resources, 25(8): 1287-1304.

Kharin, V.V. and Zwiers, F.W., 2000. Changes in the extremes in an ensemble of transient climate simulations with a coupled atmosphere-ocean GCM. Journal of Climate, 13(21): 3760-3788.

Kharin, V.V. and Zwiers, F.W., 2005. Estimating extremes in transient climate change simulations. Journal of Climate, 18(8): 1156-1173.

Kharin, V.V., Zwiers, F.W., Zhang, X. and Hegerl, G.C., 2007. Changes in temperature and precipitation extremes in the IPCC ensemble of global coupled model simulations. Journal of Climate, 20(8): 1419-1444.

Kotz, S. and Nadarajah, S., 2000. Extreme value distributions: theory and applications, 57. Imperial college press London.

Leggett, J. et al., 1992. Emissions scenarios for the IPCC: an update. Climate change 1992: the supplementary report to the IPCC scientific assessment, Cambridge University Press.

Loaiciga, H.A., Valdes, J.B., Vogel, R., Garvey, J. and Schwarz, H., 1996. Global warming and the hydrologic cycle. Journal of Hydrology, 174(1): 83-127.

Madadgar, S. and Moradkhani, H., 2011. Improving the Ensemble Streamflow Prediction by Adjusting Hydrologic Ensemble Traces, EWRI Congress. ASCE, Palm Spring, CA, pp. 3743-3751.

Madadgar, S., Moradkhani, H. and Garen, D., 2012. Towards improved post processing of hydrologic forecast ensembles. Hydrological Processes: DOI: 10.1002/hyp.9562.

Maurer, E.P., Wood, A.W., Adam, J.C., Lettenmaier, D.P. and Nijssen, B., 2002. A Long-Term Hydrologically Based Dataset of Land Surface Fluxes and States for the Conterminous United States. Journal of Climate, 15(22): 3237-3251. 
Meehl, G.A. et al., 2009. Decadal prediction: can it be skillful? Bulletin of the American Meteorological Society, 90(10): 1467-1485.

Meehl, G.A. and Hibbard, K., 2007. A Strategy for Climate Change Stabilization Experiments with AOGCMs and ESMs. WCRP Informal Rep. 3/2007, ICPO Publ. 112, IGBP Rep. 57, 35 pp.

Moradkhani, H., Baird, R.G. and Wherry, S.A., 2010. Assessment of climate change impact on floodplain and hydrologic ecotones. Journal of Hydrology, 395(3): 264278.

Moradkhani, H. and Meier, M., 2010. Long-lead water supply forecast using large-scale climate predictors and independent component analysis. Journal of Hydrologic Engineering, 15(10): 744-762.

Moradkhani, H. and Sorooshian, S., 2008. General review of rainfall-runoff modeling: model calibration, data assimilation, and uncertainty analysis, Hydrological Modelling and the Water Cycle. Springer, pp. 1-24.

Moss, R.H. et al., 2008. Towards new scenarios for analysis of emissions, climate change, impacts, and response strategies, Pacific Northwest National Laboratory (PNNL), Richland, WA (US), Geneva, pp 132.

Najafi, M.R. and Moradkhani, H., 2013a. A Hierarchical Bayesian Approach for the Analysis of Climate Change Impact on Runoff Extremes. in Review.

Najafi, M.R. and Moradkhani, H., 2013b. Analysis of Runoff Extremes using Spatial Hierarchical Bayesian Modeling. in Review.

Najafi, M.R., Moradkhani, H. and Jung, I.W., 2011a. Assessing the uncertainties of hydrologic model selection in climate change impact studies. Hydrological Processes, 25(18): 2814-2826.

Najafi, M.R., Moradkhani, H. and Wherry, S.A., 2011b. Statistical downscaling of precipitation using machine learning with optimal predictor selection. Journal of Hydrologic Engineering, 16(8): 650-664.

Nakicenovic, N. et al., 2000. IPCC Special report on emissions scenarios, Cambridge Univ. Press, Cambridge, UK.

Parrish, M.A., Moradkhani, H. and DeChant, C.M., 2012. Toward reduction of model uncertainty: Integration of Bayesian model averaging and data assimilation. Water Resources Research, 48(3): W03519, doi:10.1029/2011WR011116.

Payne, J.T., Wood, A.W., Hamlet, A.F., Palmer, R.N. and Lettenmaier, D.P., 2004. Mitigating the effects of climate change on the water resources of the Columbia River basin. Climatic change, 62(1-3): 233-256.

Quintana Segue, P., Ribes, A., Martin, E., Habets, F. and Boe, J., 2010. Comparison of three downscaling methods in simulating the impact of climate change on the hydrology of Mediterranean basins. Journal of Hydrology, 383(1): 111-124.

Raftery, A.E., Gneiting, T., Balabdaoui, F. and Polakowski, M., 2005. Using Bayesian model averaging to calibrate forecast ensembles. Monthly Weather Review, 133(5): 1155-1174.

Raftery, A.E. and Zheng, Y., 2003. Discussion: Performance of Bayesian model averaging. Journal of the American Statistical Association, 98(464): 931-938. 
Riahi, K., Gruebler, A. and Nakicenovic, N., 2007. Scenarios of long-term socioeconomic and environmental development under climate stabilization. Technological Forecasting and Social Change, 74(7): 887-935, doi:10.1016/j.techfore.2006.05.026.

Salathe, E.P., Mote, P.W. and Wiley, M.W., 2007. Review of scenario selection and downscaling methods for the assessment of climate change impacts on hydrology in the United States Pacific Northwest. International Journal of Climatology, 27(12): 1611-1621.

Samadi, S., Wilson, C.A.M.E. and Moradkhani, H., 2013. Uncertainty analysis of statistical downscaling models using Hadley Centre Coupled Model. Theoretical and Applied Climatology: 1-18, doi:10.1007/s00704-013-0844-x.

Shamseldin, A.Y., O'Connor, K.M. and Liang, G.C., 1997. Methods for combining the outputs of different rainfall-runoff models. Journal of Hydrology, 197(1-4): 203229.

Solomon, S. et al., 2007. Climate change 2007: The physical science basis, contribution of working group 1 to the fourth assessment report of the Intergovernmental Panel on Climate Change. Cambridge University Press: Cambridge, UK.

Stedinger, J.R.e.a., 1993. Frequency analysis of extreme events. in Handbook of Hydrology.: edited by D.R. Maidment, pp. 1-66, McGraw-Hill, New York.

Taylor, K.E., Stouffer, R.J. and Meehl, G.A., 2012. An overview of CMIP5 and the experiment design. Bulletin of the American Meteorological Society, 93(4): 485498.

Tryhorn, L. and DeGaetano, A., 2011. A comparison of techniques for downscaling extreme precipitation over the Northeastern United States. International Journal of Climatology, 31(13): 1975-1989.

van Vuuren, D.P. et al., 2007. Stabilizing greenhouse gas concentrations at low levels: an assessment of reduction strategies and costs. Climatic change, 81(2): 119-159.

Van Vuuren, D.P. et al., 2011. The representative concentration pathways: an overview. Climatic change, 109(1-2): 5-31.

Viallefont, V., Raftery, A.E. and Richardson, S., 2001. Variable selection and Bayesian model averaging in caseâ€ $\square$ control studies. Statistics in medicine, 20(21): 32153230 .

Wilby, R.L. and Wigley, T.M.L., 2002. Future changes in the distribution of daily precipitation totals across North America. Geophysical Research Letters, 29(7): DOI: 10.1029/2001GL013048.

Wintle, B.A., McCarthy, M.A., Volinsky, C.T. and Kavanagh, R.P., 2003. The use of Bayesian model averaging to better represent uncertainty in ecological models. Conservation Biology, 17(6): 1579-1590.

Wood, A.W., Leung, L.R., Sridhar, V. and Lettenmaier, D.P., 2004. Hydrologic implications of dynamical and statistical approaches to downscaling climate model outputs. Climatic change, 62(1-3): 189-216.

Xin X., W.T., Zhang J., 2012. Introductions to the CMIP 5 simulations conducted by the BCC climate system model (in Chinese). Advances in Climate Change Research, 11(8)(24): submitted. 